University of Louisville

ThinkIR: The University of Louisville's Institutional Repository

Electronic Theses and Dissertations

$5-2013$

\title{
The autodidact : Constantine Samuel Rafinesque and the limits of the posthumanities.
}

\author{
Elijah Pritchett \\ University of Louisville
}

Follow this and additional works at: https://ir.library.louisville.edu/etd

\section{Recommended Citation}

Pritchett, Elijah, "The autodidact : Constantine Samuel Rafinesque and the limits of the posthumanities." (2013). Electronic Theses and Dissertations. Paper 1157.

https://doi.org/10.18297/etd/1157

This Doctoral Dissertation is brought to you for free and open access by ThinkIR: The University of Louisville's Institutional Repository. It has been accepted for inclusion in Electronic Theses and Dissertations by an authorized administrator of ThinkIR: The University of Louisville's Institutional Repository. This title appears here courtesy of the author, who has retained all other copyrights. For more information, please contact thinkir@louisville.edu. 


\title{
THE AUTODIDACT: CONSTANTINE SAMUEL RAFINESQUE AND THE LIMITS OF THE POSTHUMANITIES
}

\author{
By \\ Elijah Pritchett \\ B.A., University of Louisville, 2002 \\ M.A., University of Louisville, 2005

\begin{abstract}
A Dissertation
Submitted to the Faculty of the

College of Arts and Sciences of the University of Louisville in Partial Fulfillment of the Requirements

for the Degree of
\end{abstract}

Doctor of Philosophy

Department of Humanities

University of Louisville

Louisville, KY

May, 2013 



\title{
THE AUTODIDACT: CONSTANTINE SAMUEL RAFINESQUE AND THE LIMITS OF THE POSTHUMANITIES
}

\author{
By
}

Elijah Pritchett

B.A., University of Louisville, 2002

M.A., University of Louisville, 2005

A Dissertation Approved on

April 12, 2013

By the Following Dissertation Committee:

Dissertation Director: Aaron Jaffe

Annette Allen

John Gibson

Stephen Schneider 


\section{DEDICATION}

This dissertation is dedicated to Eric Rensberger who first showed me the infinity of a life devoted to thought 


\section{ACKNOWLEDGMENTS}

Many hidden hands and minds made this dissertation, contributors, mentors, muses who, though invisible, are nonetheless part of its essence. To them I give deserved (though inadequate) thanks and recognition. Luminous guides showed the way: Eric Rensberger, Tom Hastings, Ron Keith, Karen Gray, Robert Luginbill, Elaine Wise, Charles Breslin, Nancy Potter. Special thanks to Annette Allen, a life-saving beacon and true friend throughout my graduate career. To these great influences I add my chair, Aaron Jaffe, whose guidance forced me to acknowledge obstacles I otherwise never would have even recognized, let alone been able to overcome. I thank John Gibson and Stephen Schneider for their generous time and thoughtful input. Without these many people I'd be just another autodidact wild child, untamed, unclaimed, and lost in the wood of indiscipline. I thank my patient and loving family who have supported and inspired me throughout: my wife Lori, my children, Alexandra, Maxine, Judah and Sadie, and my beloved mom, Staci. Julie Wade gave essential commentary, and along with dear comrades, James Leary and Carol Stewart, helped me work out ideas in the gym of the mind. I especially give thanks to my very good friend, Monica Krupinski, who made space in her life for me and this dissertation: it is no exaggeration to say that without your careful critique (nitpicking) and attentive encouragement (nagging), this document would never have been brought into existence (note litotes, passive construction, and veiled reference to being/becoming and the Heideggerian Nothing). To everyone mentioned, I

hope this document does some justice to the incredible assistance and inspiration I have 
so selfishly taken from all of you. 


\section{ABSTRACT \\ THE AUTODIDACT: CONSTANTINE SAMUEL RAFINESQUE AND THE LIMITS \\ OF THE POSTHUMANITIES}

Elijah Pritchett

April 12, 2002

The autodidact has a curious structural relationship to knowledge, education, and that assumed distillation of institutional learning, the academy. Because of its subjectivity-producing function, knowledge represents a site of tremendous cultural investment, and one that is challenged, if not even undermined, by the renegade ethos and idiosyncratic approach of the autodidact. Nineteenth century self-taught scholar and Renaissance man, Constantine Rafinesque, serves as a vivid exemplar, or even theoretical matrix, for demonstrating certain problems that the autodidact raises for postEnlightenment knowledge as it assumes the various institutional states, metaphysical postures, and ideological closures necessary for its culturally privileged function. As the work of Michel Foucault has demonstrated, in its capacity as a crucial component in the makeup of the modern individual, knowledge is a cultural good of unequaled value; but its horizon is often one of force, regulatory and normative. This dissertation posits the autodidact Rafinesque as a path for illustrating and exploring these various implicit, but nonetheless binding, regulations, limits and boundaries.

Although a prolific contributor to fields such as taxonomy, botany, economics, linguistics, philosophy, and ethnography, Rafinesque continues to stir debate and generate 
perplexity among scholars. This is due, in no small part, to his unusual status as both social and intellectual outsider, one who in more ways than one challenges the coherence of disciplinary knowledge. Eccentric, unorthodox, self-taught, and with few friends, Rafinesque came to symbolize knowledge in its most unregulated state, and to a large degree this status persists. Each chapter of this dissertation departs from an episode in Rafinesque's intellectual career. Using Rafinesque's writings and correspondence with intellectuals of the time, it joins these to a contemporary post-structural theoretical discussion involving the relationship between subjectivity and knowledge, knowledge and cultural value, and the role of the academy in the modern world. By uniting these theoretical and research trajectories this work posits the autodidact as a type of poststructural subjectivity, one whose very existence offers unique possibilities for the critique of contemporary knowledge as both the engine of apparent self-creation, and of the subject's cultural/intellectual domestication. 
TABLE OF CONTENTS

PAGE

DEDICATION iii

ACKNOWLEDGMENTS iv

ABSTRACT vi

BIOGRAPHICAL NOTE 1

INTRODUCTION: MYTHOLOGIES AND ALLEGORIES OF THE AUTODIDACT

PECULIARLY MY OWN: THE AUTODIDACT'S CONDITIONS OF BEING 27

RAFINESQUE'S HERBARIUM: THE INDIVIDUAL AS KNOWLEDGE, KNOWLEDGE AS COLLECTION 55

ARTHROLOGY: TAXONOMY, CATEGORY, VALIDITY AND THE ARCHIVE--77

INSTABILITIES: WALAM OLUM, KNOWLEDGE CREATION AND DISCURSIVE FORMS 113

THE BONES OF RAFINESQUE: VIRTUALITY AND KNOWLEDGE'S DEFERRED PROMISE 144

REFERENCES 171 CURRICULUM VITAE 178 


\section{BIOGRAPHICAL NOTE}

Constantine Samuel Rafinesque, son of a wealthy French merchant and a Greek mother of German descent, was born in a suburb of Constantinople on October 22, 1783. Rafinesque spent the early part of his youth in Marseille, but as a result of the French Revolution the family fled to Leghorn, Italy in 1792. These circumstances had a determinate effect on his upbringing such that from early youth Rafinesque was polyglot, cosmopolitan, and almost wholly self-taught. In addition to his passion for languages and literature, Rafinesque showed early interest in the natural sciences, in particular botany, ichthyology, conchology, and the day's unifying science, taxonomy. He studied these and many other subjects relentlessly and largely in isolation.

In 1793, Rafinesque's father, while on business in Philadelphia, died when an epidemic of Yellow Fever swept the city. Less than a decade later the young Rafinesque made his own trip to Philadelphia where he botanized and established contacts before returning to Italy to follow in his late father's footsteps as a businessman. Having amassed a significant fortune, Rafinesque left behind his money as well as his young wife, Josephine, and their daughter in order to embark on a scientific career in the New World. He would never see his family again.

An extensive collector, Rafinesque was obsessive in his fieldwork, hunting the unexplored forests for plant specimens and undiscovered animal species. Not only did this process lead to thousands of new discoveries, it also drew Rafinesque into a variety of collateral pursuits such as ethnology and linguistic studies, the cataloging of Native 
American earthworks, topography, viticulture, oenology, pharmacology, meteorology and countless others. In 1819 Rafinesque took up residence in Kentucky to continue his discoveries on the frontier of the New World and teach at Lexington's Transylvania University. By 1826 Rafinesque was terminated from his professorship and shortly thereafter returned to Philadelphia where he continued to research and self-publish on diverse topics such as economics, education, linguistics, astronomy, metaphysics, and an array of scientific topics. Money was an increasing concern for the chronically unemployed Rafinesque, and by the time of his death from gastric carcinoma in 1840, he was not only penniless, but deeply in debt. As his biographer Leonard Warren summarizes the final scenario: "his papers, books, and plant collections, many junked, sell for less than the cost of burial" (xii). He was interred without ceremony in a mass grave on Philadelphia's south side. 


\section{INTRODUCTION: INSIDE AND OUTSIDE MYTHOLOGIES OF THE}

\section{AUTODIDACT}

Constantine Rafinesque is in some ways the exemplar of the Enlightenment's rationalist promise, but at the same time he is the unwitting embodiment of what orthodoxy - here in the form of modern institutional knowledge — strives to repress, and, in his case, to a large extent did successfully repress. Two analytic frames relevant to Rafinesque dominate the present study, and they are inextricably bound up in one another. The first concerns the autodidact as a subjectivity peculiar to a cultural structure and historical epoch founded on knowledge as the primary engine for constituting useful, productive subjects (commonly and ideologically termed "individuals") even while touting reason and knowledge as ends in and of themselves. The second is the dynamic that emerges when this enshrined reason/knowledge takes institutional form, defining its systems, its orthodoxies and heresies, and delimiting those boundaries that will mark its inclusions and exclusions. Rafinesque's story is that of the autodidact, and the autodidact's story concerns the inside and outside of institutional knowledge: what is deemed to fall within the realm of acceptable knowing versus what is judged hopelessly beyond the protective grasp of canonical validation. This distinction between the inside and outside of the orthodox is unreflectively conceptualized as the simple difference between knowledge and non-knowledge, and in terms of agents of learning it separates the expert or cognoscente from the crank, crackpot or dilettante. According to this frame of understanding the autodidact cannot appear other than as Reason's chronic outsider. 
Of course, the binary conceptual structure of inside/outside, knowledge/nonknowledge, rational/irrational, and so on, is and has been prey to a host of poststructuralist critiques concerning the cognitive parsing of post-Enlightenment Reason. Inasmuch as Descartes' Cogito is reckoned (accurately or not) as one dominant philosophical birthing ground for such regulative dichotomies, Derrida, via his critique of Foucault's History of Madness, has demonstrated that, "the choice and division between the two ways ... the way of logos and the non-way, the labyrinth, the palintrope in which $\log$ os is lost; the way of meaning and the way of non-meaning," is a "crisis" that Reason contains within itself (Writing 62). Similarly, Giorgio Agamben's analysis of the logic governing systematic inclusion and exclusion has shown the institutional figuration of an inside and outside to be more legally binding than logically consistent (Homo 15-29). This leads Agamben to the juridical paradox that, "the law is outside itself" (15). Here I would like to argue for a similar confusion with respect to what functions as the inside and outside of knowledge-as-orthodoxy, but I would maintain that it is in this case even more self-evident, the two realms existing in a visible relation of intimacy to one another.

As a subjectivity, the autodidact illustrates this relation of intimacy. The autodidact is by definition alienated from the inner sanctum of orthodox knowledge, but at the same time receives her/his mandate from the very principles that ostensibly determine the conditions of that knowledge. Orthodoxy, whatever its form, is by nature conservative. Yet, philosophically, the practice of modern knowledge is founded largely upon the potentially destabilizing twin imperatives of open critique and unregulated inquiry. The autodidact is especially driven by the latter. But as Rafinesque shows, the autodidact's engagement with mainstream scholarship can have critical potential by 
revealing the limits, overt and otherwise, placed upon knowledge and its practitioners in order to secure stability. Post-Enlightenment knowledge, with its pretensions to universal scope, may not readily admit to having an "outside," but orthodoxy must. And the extent to which orthodoxy as a regulatory structure - whether in the form of the academy, inherited cultural practice, or some other received and binding "common sense"-seeks to safeguard itself against unsanctioned critique or limit acceptable modes of inquiry is one way it defines its own renegades and their practices, i.e. its "outside." The autodidact is at once a confirmation of, and a challenge to, the avowed rules of modern knowledge, knowledge being poised as it is somewhere between the exhilaration of discovery and the strictures of convention. In this sense, Rafinesque's adventures as an autodidactic knower speak both of the subjectivity itself and of the inherent potentialities and prohibitions that make such a subjectivity possible-even inevitable, but at the same time largely unviable as a recognized agent and producer of valid knowledge. This dissertation looks at Rafinesque, and the autodidact, from both vantage points.

The effort to quarantine certain inferior or archaic modes of knowing or methods of inquiry to the margin, or even banish them to the outside, has not prevented the incursion of mythology into modern Reason. Like the paradigms and epistemes of earlier cultural belief systems, modern Reason has its share of fables, origin stories and primal scenes. One significant myth of Reason concerns Ur-philosopher and proto-cultural critic Socrates being brought before the Athenian jurors and forced to answer for his transgressions against the polis. The "history" of this episode is uncertain, the only primary written accounts being Plato's Apology, and Xenophon's lesser known, slightly differing version, Socrates'Apology to the Jury. Nonetheless, the episode is substantial 
enough to form the basis of an enduring account of origin, an account that seems to exert widespread appeal across disciplinary lines. Philosopher C.D.C. Reeve has observed of Plato's canonic version: "like the Gospels, it is an interdisciplinary text studied, sometimes in proprietary fashion, by classicists, philosophers, historians, literary scholars, and students of law, politics and religion" (ix). The editors of the recent Northwestern UP anthology, Reexamining Socrates in the Apology, put this in even more dramatic terms: "we would have no tradition of philosophy without Socrates—but we would have no Socrates without the text. Socrates is a singular figure, font of our tradition" (xiii). Philosopher and theorist, Simon Critchley, has commented on this story specifically in its mythogenic capacity, focusing particularly upon the climax of Socrates' death and its continued resonance: "Philosophy loves to tell itself stories ... and there is one story in particular that philosophy likes to tell ... which, it seems, must be retold in order for philosophy to be capable of inheritance" (17). Critchley defines this legacy as the tradition of "radical de-traditionalization," or in other words, the commitment to critique that Socrates seems to embody and that the western impulse to logos will enshrine as it marches ever forward in pursuit of its rationalist promise. In the modern context this critical impulse seems to inform everything from the Kantian Enlightenment injunction to "dare to know," to the German Idealist notion of transformational Bildung, the scientific principles of fallibilism and falsifiability, and even the critical/theoretical practices of late modern interpretation which informs this dissertation ${ }^{1}$.

Perhaps one reason the episode of Socrates' martyrdom has remained (or perhaps more accurately reemerged) evergreen into modernity is the simple fact that prior to the

1Both Kant's Enlightenment essay and the principles of scientific fallibilism are treated in this dissertation. As to the notion of Bildung see Thomas Mann's 1923 lecture on the Weimar Republic, reprinted in part in Walter Horace Bruford's 1975 German Tradition of Self-Cultivation: Bildung from Humboldt to Thomas Mann, Cambridge UP, page vii. 
$19^{\text {th }}$ century, philosophy was still the catch-all conceptual category for nearly any systematic scholarly inquiry, including science. During Rafinesque's day, scientists were still summoned under the moniker "natural philosopher," and the so-called "liberal arts"-humanities in combination with natural sciences—were similarly glossed such that "philosophy" comes to signify them collectively throughout Kant's seminal 1794 critique of the university, Conflict of the Faculties. But the story of Socrates' demise also has internal qualities that give it mythic endurance, that make it succeed, in the words of Roland Barthes, at "ultra-signification, at the amplification of a first system," which is to say, a system capable of giving underlying structure through symbolic coherence to a matrix of cultural values (Mythologies 133). Schelling and Hegel wrote in 1797 that in order to give rational thought life and meaning it must be made "sensual," thus it was necessary to, "make ideas aesthetic, i.e., mythological" (Philosophy of German Idealism 162). It seems that philosophers (and critical thinkers generally) are themselves hungry for this same mythologizing process, for as Critchley observes, the story of Socrates' apologia, "allows philosophers to reanimate, theatrically and sometimes in front of their students, the passion that founds their profession," transforming what otherwise might seem a dry, drama-free exercise of thought into the climactic result of monumental struggle and sacrifice (17). In this way, logos receives the benefit of pathos, in its dual senses of deep feeling and suffering unto death, and the critical imperative that founds so much rationalist inquiry is given a mythic paradigm for knowledge to be conceptualized as a stance of heroic resistance. Seen from this angle, the contours of the story are familiar enough: Socrates is brought before the tradition-bound Athenian jurors on trumped up charges of corrupting the youth, denying the gods, making the lesser 
argument seem the greater, and so on; ever-defiant, he is found guilty and sentenced to death; stoically content with his fate, Socrates drinks the poison potion and assumes his status as rationalism's first and most significant martyr.

Against this canonical version of Socrates' demise, I would like to suggest a different reading, if not even a parallel alternate myth. In contrast to the picture of the one wise man pitted against ignorant superstition, we could understand the parable as being a myth of origin about the inside and outside of knowledge: knowledge as orthodoxy, and following this line of reason, Socrates as the archetype of the autodidact, the one who by definition must personify unorthodox knowing. By this reckoning, the tale is about the collision of two differing approaches to knowledge, and the Athenian jurors are not merely benighted hoards in thrall to blind tradition, but custodians of an established archive, acting as its gatekeepers and appointed assessors. Through their authoritarian roles these knowers function in the manner described by Francois Lyotard in The Postmodern Condition, by deciding "what knowledge is" and "what needs to be decided," and by their evaluation Socratic knowledge does not fare well (9).

Under this scheme of interpretation one of the central charges leveled against Socrates' takes on a different mytho-theoretical aspect. Accused of "corrupting the young," the crucial Greek verb, consistent in both the accounts of Plato (24b) and Xenophon (19) (again, the only two significant sources), is diaptheirein, one which escapes precise translation into English on account of its distinctive polysemy. Usually rendered "corrupt," the word doubly signifies "to destroy," and "to seduce." Liddel and Scott's lexicon emphasize that the word has psychological dimensions as well as moral, by observing that in the perfect it can indicate "to be deranged, mad" (168). Through its 
effects, this knowledge pursued without cultural approval bears traces of risk, disruptive desire, even madness; and it is this transgressive knowledge that Socrates is accused of cultivating. It is also in light of this accusation that Socrates begins to look most like the modern autodidact, that agent of knowledge who circumvents—or even defies—orthodox channels in pursuit of knowledge as an object of desire, or even as its own metaphysical end. Socrates argues for a definition of knowledge as intrinsically worthy, and the Socratic passion for knowledge reflects this in being self-propulsive, self-justifying, autodidactic - even autoerotic. Through Plato, his most famous student, Socrates gives a picture of what it looks like to sublimate the carnal to the intellectual and along the way offers recipes for cathectic conceits such as "Platonic love," and "children of the mind." Socrates has been seduced (diaphtheirein) by knowledge to the extent of his own destruction (diaphtheirein). But the risk is not confined to Socrates' ruin, nor to the ruin of those youths whom he has figuratively seduced. Inasmuch as the archive is synonymous with the orthodox, to the extent that it constitutes the "inside," it too is threatened by this alien knowledge; and it is this risk that it seeks to curb through Socrates' trial and execution in a hygienic act of self-preservation.

By recounting Socrates' story I am making no historical claims. Rather, I am arguing that even as modern Reason must mythologize its own heroic origins and critical mission, the autodidact already haunts the scene as its repressed remainder. The selfsame account that gives Reason mythic shape and purpose by depicting its hero, its enemies, and their struggle, can be alternately read as a parable of knowledge as an uncertain value in an ever-contested ground. Under the twin aspects of diaphtheirein, destruction/seduction, knowledge exerts its risky allure. Allure because knowledge, with 
its own internal economy of desire, entices, even seduces. Risk because though knowledge sometimes does empower, it always changes—or even corrupts, and often in radical and unpredictable ways; it can change both the subjects who give themselves over to it (those impressionable Athenian young, and Socrates himself) and it can change the archive (the humiliated Athenian citizens, the polis, even the Western tradition as founded upon this myth). It is this dynamic, too complex to be characterized simply as heroic, that informs the adventure of the autodidact as s/he clashes with orthodoxy and its many forms of hemlock.

Given his particular time, place and character, Rafinesque is a striking avatar of this alternate Socratic archetype, offering both a vivid model for autodidactic subjectivity as well as an example of the problems such a figure poses for institutional knowledge. During his productive years in the early $19^{\text {th }}$ century, the orthodoxies that characterize post-Enlightenment knowledge were in a formative stage. ${ }^{2}$ The sciences were just beginning to delimit their horizons of inquiry and in this way separate themselves from each other as well as certain studies—-some of which will come to be called the humanities - that had hitherto been included as part of their make up. This process involves the establishment of internal criteria: repeatable discursive conditions encompassing system or procedure-what collectively comes to be called method—in addition to closed intra-disciplinary networks of authority that will vouchsafe a given practitioner's credibility and output. Combined, these reductive and constructive processes of disciplinary self-definition give each branch of inquiry, scientific or otherwise, an identity and a sense of coherent continuity, but also go far in establishing

2For a revealing but concise overview of this process of development see the David Cahan edited volume, From Natural Philosophy to the Sciences: Writing the History of Nineteenth Century Science, University of Chicago Press, 2003. 
exclusions and creating institutional boundaries, thus demarking both the inside and outside of the field. A revealing aspect of Rafinesque's story involves his inability to observe and obey discursive rules that were emerging as the regulative norms within the sciences, his well as an inability to secure crucial endorsements from those who had come to represent the faces of orthodoxy. These failures not only marked him as unorthodox, autodidactic, they represent transgressions against the rules that the sciences were just beginning to posit in order to define themselves.

This essentially regulatory self-definition at the institutional level to some degree clashes with the exhilaration of Enlightenment faith in knowledge as its own metaphysical end, a trait which characterizes Rafinesque's will to know, and to a great extent that of the autodidact, generally. The postures of self-legitimation and protective closure that Rafinesque's work so often encountered—even if for apparently valid reasons-cannot help but reveal some of the willful blind spots and repressions that were helping to shape once heterodox studies into an emerging governing orthodoxy called the sciences. The determinations of these disciplines have consequently informed our inherited conceptual structure for what constitutes knowledge, per se, as well as its means of circulation, production and management. Through Rafinesque's autodidactic adventures we see not merely the foundational gestures of the emerging sciences, but also the outlines-both positive and negative—-that will come to be reckoned as governing attributes of knowledge itself: its reliance upon various types of system as well as credentialing and corroboration. In this way, the authority structures that are an inescapable corollary to institutional orthodoxy, those social dynamics that always attend validation and certification, the particular discursive and rhetorical forms meant to ensure 
coherence and communicability, are not merely mythologized, but even naturalized as knowledge's essential elements.

The dissonance between the power structures endemic to institutional knowledge, and the promise of the Enlightenment, vis-à-vis, learning and education, are a key issue in The Ignorant Schoolmaster, Jacques Ranciere's study of Rafinesque contemporary, Joseph Jacotot. "Universal teaching," Jacotot's autodidactic pedagogy, is a radical selfconscious reorientation of educational theory around the individual, a figure strictly conceived according to principles of the Enlightenment will to knowledge (52-4). In this respect, Jacotot's theory of "intellectual emancipation" wears its ideological presuppositions like a badge of honor, but does so for the purpose of preserving the integrity of what Kant and other Enlightenment luminaries saw as the fundamental unit of knowledge: the solitary researcher/learner. The academy is also ostensibly organized in service to the same, but Jacotot recognized an inherent conflict between the ideals of Enlightenment inquiry and the drive toward institutionalization and standardization represented by the university and other educational bodies. These collectives only engender intellectual conformity and groupthink, a "stultification" that mirrors the capricious authority wrought of general social imbalance. Using Jacotot's Enlightenment diction, Ranciere sums up: "it is obvious that from the moment men form a society for the purpose of protecting themselves against each other, this reciprocal need announces an alienation of reason that promises no reasonable result ... thus the social world is not simply the world of non-reason it is that of irrationality" $(81,82)$. Following Jacotot, who in turn was pursuing what he perceived to be the inescapable logic of modernity, Ranciere inverts the norm such that the isolated learner, the autodidact, is rendered the 
ideal, and the institution (in whatever form) becomes an egregious anomaly. However, neither his rigorous theorizing nor his educational successes were enough to prevent Jacotot—like his historical fellow Rafinesque—from ultimately lapsing into intellectual obscurity, successfully repressed by the machinations of intellectual authority he opposed and denounced.

Jacotot's hostility to capriciously regulated knowledge is reflected within orthodoxy itself as anxiety concerning authenticity. Jacotot recognized that one of the key pressure points of institutional modern knowledge was its reliance upon specific rhetorical forms and discursive strategies. Ultimately inescapable, since these parameters give knowledge its concrete, communicable shape, orthodoxy additionally relies upon standardized forms and ritualized gestures to function as legible guarantors of authority. One fundamental exercise of Jacotot's universal teaching involved students delivering spontaneous, structured lectures on topics completely unknown to them (Ranciere 42). This lesson, which empowers the learner by urging spontaneous sustained intellectual action and immediate direct engagement with rhetorical process, becomes an almost parodic critique of an institutional knowledge system wherein apparent credentials or seemingly authoritative verbal packaging may traffic in place of actual content. Knowledge's reliance upon authority—or its semblance— invites exploitation and this takes urgent shape in modernity as the hoax. Rafinesque was implicated in such hoaxing. In a notable example, while Rafinesque was a guest of John Audubon during an early sojourn into the Western frontier of Kentucky, the host convinced him that a huge log floating on the surface of the Ohio was an uncataloged species, the "Devil-Jack Diamond-Fish," armored with bulletproof scales capable of emitting enough spark to start 
a bonfire. Upon the authority of his guide, sight unseen, Rafinesque gave the creature a scientific name, Litholepsis adamantinus, and published on it, only to be later mercilessly ridiculed for the mistake (Warren 74). But Audubon's antic says less as evidence of Rafinesque's credulity than as a demonstration of the binding force of testimony-those networks of authoritative witness and corroboration — that necessarily attends evolving intellectual inquiry of drive and sweep. Quite simply, complex systems of knowledge demand a more complex division of intellectual labor, and thus a high degree of reliance upon facts, but also upon representations of facts. This not only allows for the hijack of said representation - the essence of the hoax, but also raises serious questions about the stability of representation, not least of all the challenge of fitting new and exploratory knowledge into well-worn discursive and rhetorical forms. Uncertain speculation disguised by misleadingly authoritative delivery is just the most obvious example of the potential tensions between supposedly unbounded inquiry and rigorously standardized form. One of the most infamous episodes of Rafinesque's career, his "translation" and publication of the spurious Native American epic, Walam Olum, straddles this hazy territory wherein the deceptive merges into that which is merely discursively indefinite. Whatever its "actual" status, the Walam Olum, even more than modernity's other many literary hoaxes, underscores the profound interdependence between authority and representation that goes into constituting what we understand as "facts."

In theory, knowledge does not tolerate a status quo (what Kant, in his Enlightenment essay, called our "self-imposed tutelage") to the extent that it seems to welcome, even demand, critical input—voices from the outside, as it were. In practice, however, knowledge is expressed in paradigms that are both normatively binding and 
reluctant to change, as Thomas Kuhn argued in his well known analysis of the sciences (52). In this respect, knowledge as it is instantiated by governing processes and standardizing forms - the way that most of us access it—is always to some extent absent from itself, its promise seeming to lie somewhat less in the rules than in what will bring their eventual disruption; we endure strict forms and prescriptive structures, regarding them not as the source of knowledge, but only as its necessary police force, and always with the expectation that they will be eventually emended or rewritten according to the dictates of new knowledge. Perhaps this fundamentally conflicted nature is what accounts for the ubiquity of the intellectual outsider, Ranciere's Jacotot being yet another modern figure potentially understood as an embodiment of the Socratic/autodidactic protagonist. "Eccentric" - literally "out of the center" - is the word that seems most often to be invoked in descriptions of Rafinesque. This association is inaugurated by John Audubon, who penned the essay "The Eccentric Naturalist," years after putting up, and putting up with, the wanderer on one of his earliest research sojourns into Western Kentucky. But in spite of this persistent characterization, even minimal research into Rafinesque reveals him to be a ghostly presence in countless areas of intellectual endeavor. Though largely ostracized, he was nonetheless productive in such fields as botany, ichthyology, taxonomy, ethnology, linguistics, to name but a few. In these fields he contributed vast amounts of vocabulary and his work often anticipated or coincided with major scientific breakthroughs of others, including an early primitive theory of evolution, an anticipation of Georges Cuvier's work on classification, a novel approach to comparative linguistic analysis, and significant pioneering ethnological research on Native American tribes. ${ }^{3}$ Rafinesque was even among the first to identify and define an

3For a concise overview of Rafinesque's many accomplishments—and shortcomings—see Charles Boewe's introduction to Profiles of Rafinesque, University of Tennessee Press, 2003. 
emergent scientific discipline of his day, though his proposed name, "somiology," arrived a few years later than Jean-Baptiste Lamarck's now familiar "biology," and was forgotten. In addition, Rafinesque was acquainted with an astounding number of significant historical and scientific figures, a fact all the more striking given his overall isolation from any particular community.

Apart from the footnotes, the scientific names, the copious correspondence and the equally vast catalog of public criticism he endured, Rafinesque persists in more sublimated ways. It is impossible to theorize the autodidact without also theorizing knowledge and to some extent that common metonymic signifier of knowledge, and its rigorous institutional embodiment, the academy. Rafinesque had a momentary affiliation with the academy, teaching for a short time at Kentucky's Transylvania University, perhaps even mentoring the young Jefferson Davis in botany (Warren 81). But this brief appointment cannot account for the spectral connections that Rafinesque has to the academy and to institutional knowledge in general. For example, one of his fiercest and most vocal champions was David Starr Jordan (1851-1931), crusading president for both Indiana and Stanford Universities and the man whom Gerald Graff credits as instrumental in finding the modern American academy's metaphysical center with the creation of the first department of English (67). Jordan, an ichthyologist, early proponent of evolution, and eugenicist, wrote extensively and passionately on Rafinesque, helping to rehabilitate him from the scornful public dismissal that followed the autodidact's death. More circuitously, in a recent work on taxonomy, Rafinesque's primary scientific field, Carol Yoon ties the impulse toward classification to the notion of Umwelt (15-17). This theoretical term, first posited by German biologist, Jakob von Uexkull, and meaning 
“environmental perspective/worldview," fascinated Heidegger (Fundamental Concepts of Metaphysics 261-67), and more recently Giorgio Agamben (Open: Man and Animal, chapter 10), and was one of the chief elements of Thomas Sebeok's biosemiotics. Sebeok had developed the field while professor at Indiana University where he had come to assist celebrated anthropologist Carl Vogelin, chief translator and overseer of Eli Lily's "scholarly" edition of the Walam Olum (subject of chapter 4 of this dissertation). These connections are anecdotal, tangential, even rather nebulous, but in being so they are appropriate to Rafinesque, the autodidact, and the university. Since Kant, theorists of the academy have struggled to identify its stable ground, articulate its logical center. Naturally, this uncertainty carries over to the figure that—on account of being its outsider —is differentially defined by the academy: the autodidact. Ultimately it is my contention that the autodidact and the modern academy interpenetrate one another, both being products of the post-Enlightenment episteme and its specific definition of, and orientation to, knowledge; and yet upon analysis both are—like knowledge itself—curiously protean, even somewhat nebulous, except in their negative or exclusionary attributes. Through the contrast of this solitary learner with this reverend institution, knowledge may be no easier to define, and yet it appears to assume a definite inside and outside. Rafinesque is a fitting tour guide to connect both of these regions.

This study argues that within the landscape of possible post-Enlightenment subjectivities there exists a covert hero—or perhaps antihero—in the figure of the autodidact. A subject both transgressive and necessary, the autodidact is at once embedded in the logic of modernity and alienated by it. She/he is the epitome of the selfmade individual, a human identity founded in, and by, knowledge, but to an unacceptable 
degree. One could say that the autodidact is a "post-structural" subject-position, one which by its very terms of existence speaks to the paradoxical character of knowledge as a modern value and pushes at the acceptable boundaries of the ideologically constructed notion of the individual as an autonomous entity largely founded in knowledge. Literalizing certain post-Enlightenment dictates, the autodidact idealizes knowledge as the primary mechanism for creating individuals over and against the institutional structures that have come to govern and even metonymically identify modern learning. This especially applies to the academy, knowledge's terrestrial epitome, and the structure against which the autodidact is always differentially defined. I use this subject-position, and more specifically, the autodidact as embodied by Rafinesque, as a point of focus for joining several research trajectories encompassing the contemporary critique of the Enlightenment conception of knowledge as well as the institution of the academy.

Michel Foucault's Order of Things began an extensive archeology of knowledge and subjectivity centered upon the fundamental insight that a unique characteristic of the late modern period is that, "man appears in his ambiguous position as an object of knowledge and as a subject that knows" (312). Foucault later sharpened his focus to the actual production of subjectivity through the operation of what he calls power-knowledge, the index of discursive possibilities and prohibitions that determine the defining horizons of individual subjects and which exert themselves locally through what individuals know and how they in turn can be known. From this vantage point knowledge ceases to be an inert amalgam of facts to be gathered, shared out and acted upon, and instead becomes an extensive series of regulatory processes of control and definition (arguably the same thing) essential to structuring reality and the self. In Discipline and Punish, Foucault 
observes the polyvalent nature of these systematized processes of control, so-called knowledge regimes, as they are institutionally exercised: "the individual is no doubt the fictitious atom of an 'ideological' representation of society; but he is also a reality fabricated by this specific technology of power that I have called 'discipline' ... The individual and the knowledge that may be gained of him belong to this production" (194). The Enlightenment dream of knowledge as pure discovery in the aid of unlimited personal agency, summed up by the apocryphal Francis Bacon motto, scientia potentia est ("knowledge is power"), gives way to Foucault's more complex picture wherein knowledge is the discursive boundary circumscribing all human potential, personal or otherwise. This becomes the analytic horizon for mapping the cultural histories of countless institutions, since everything from the penal system to human sexuality to education, per se, is enclosed and governed by such discursive mechanisms.

The cultural institutions which treat knowledge directly also respond to the same analysis, and this is of marked importance with respect to the autodidact, a subjectivity defined by learning and the various forces that structure it. Perhaps not ironically, one important articulation of the Enlightenment euphoria in knowing is also taken as the clarion call for its self-directed critique. Kant's influential essay, "Was Ist Aufklarung" ("What Is Enlightenment") with its imperative sapere aude ("dare to know"), becomes for Foucault not merely a case of, "philosophical thought ... reflect[ing] on its own present," but is also an instance of doing so negatively, which is to say critically (Reader 33-34). Thus begins the meta-critique in which inquiry becomes its own object of analysis, one salient feature susceptible to this operation being the various hierarchical formations which knowledge assumes as it attains its status as premium cultural good. 
The formation of institutional orthodoxy engenders a host of cultural judgments and valuations, sometimes to the detriment of the individual knower/inquirer, the very agent whom Kant saw as the protagonist of Enlightenment strategy—-the darer, so to speak. Barbara Benedict observes in her extensive cultural history of curiosity in modernity that, "the individual, empirical pursuit of information was seen to challenge the social use or organization of knowledge," (4). The narrowing of knowledge into what fits acceptable "social use or organization," i.e. into various disciplinary lenses, resonates beyond the individual in that it also leaves behind a trail of invalidated, marginalized, repressed or ignored knowledges and knowledge-strategies, as Siegfried Zielinski's "variantology," or archeology of orphaned media, has vividly shown. ${ }^{4}$

At the level of pedagogy the repression of knowledge-strategies encompasses the aforementioned Joseph Jacotot, and Ranciere's study of this autodidactic educator, The Ignorant Schoolmaster, is an important antecedent to my dissertation. Not only is Ranciere's text the only contemporary critical-theoretical work to deal directly with autodidaxy, ${ }^{5}$ it also opens a window into some of the Enlightenment presuppositions that structure our contemporary understanding of how knowledge functions both culturally and individually. While Ranciere gives concentrated attention to general social forces and their (largely negative) effect on learning, relatively little is said about the academy specifically. Rafinesque had a much more complex relationship to the university than Jacotot; and in the time since both men were active the academy has come to dominate our understanding of what knowledge is and how it functions, a situation which has ramifications for our continued evolving understanding of autodidaxy. Thus another

4Of particular relevance to this dissertation is Zielinski's treatment of Rafinesque contemporary, Johann Wilhelm Ritter, 159-205.

5Ranciere's own coinage based on Greek roots, 126. 
crucial facet of this dissertation involves the rich critique of the academy itself, a move again inaugurated by Kant with his 1798 analysis, Conflict of the Faculties. Recent critical theory has seen a resurrection of this line of inquiry with Bill Reading's cultural analysis of the "post-historical" academy, University in Ruins, a conversation taken up by Gregg Lambert's Report to the Academy and Jacques Derrida's Eyes of the University. It is perhaps no wonder that the autodidact is a subject position at once untenable and inevitable, for its contrastive term, the academy, has been revealed as equally paradoxical. In many respects this dissertation is an attempt to join into this exchange concerning the institutional status of contemporary knowledge, though it does so through an admittedly—and maybe fittingly—oblique direction.

Rafinesque certainly qualifies as a marginalized agent of knowledge, an irremediable outsider, and continuing uncertainty about the exact nature of his vast—but extremely controversial—input into the emerging modern knowledge carries over into scholarship about the man. The fact that he made significant contributions to both the sciences and the humanities has meant that most treatments of Rafinesque have chosen one disciplinary path into his work over the other, and for a multitude of reasons, many of them relevant to this dissertation, the sciences have generally prevailed. Several brief biographical sketches of Rafinesque have been made, but only recently has a significant biography by Leonard Warren appeared, a text which tries to situate him as a crucial contributor to the emerging scientific understanding of the New World, in spite of Warren's repeated insistence that his autodidactic status marks him as little more than an inspired amateur and a loose cannon at that. The foremost contemporary scholar on the topic is Charles Boewe, a former academic and now retired independent researcher who 
specializes in history and philosophy of science. Boewe has edited a collection of Rafinesque's writing as well as a collection of writings about Rafinesque that spans over a century. In addition, Rafinesque occasionally appears as a topic in scientific journals wherein specialized issues related to ichthyology, botany, or malacology (study of mollusks) are dealt with and his work still has some relevance. Generally, Rafinesque's extremely problematic work in the humanities or sciences has received little attention from the perspective of contemporary humanities theory, though the "scientific" merit of his work in comparative linguistics is still the topic of some debate. ${ }^{6}$

Bypassing the more usual form of biography or linear narrative, this text clusters issues around key themes, images and moments of significance to Rafinesque's story, using these as a way of ordering both the theoretical materials as well as the writings by and on Rafinesque. In this respect, Rafinesque functions less as a protagonist, per se, than as a kind of literary trope giving structure to a series of vignettes each of which offers a critique of knowledge as it assumes the institutional states necessary for its continuing, recognizable status as a value of cultural significance. The first chapter, "Peculiarly My Own: The Autodidact's Conditions of Being," traces a general theory of the autodidact, historicizing this subjectivity, while drawing upon select episodes from Rafinesque's life for illustration. In particular the chapter is concerned with explaining the engine of desire that drives autodidactic learning, and the ways that this desire and its expression fundamentally conflict with modernity's emerging dominant discursive modes for handling knowledge, especially as knowledge is more and more modeled using the sciences as its highest exemplar. To again stress, it is impossible to adequately theorize

6For example, see Vilen V Belyi's, “Rafinesque's Linguistic Activity,” Anthropological Linguistics. Vol 39, No. 1 (Spring 1997), p 60-73. 
the autodidact without looking toward knowledge and how it is ideologically and institutionally constituted and this too is a facet of the chapter. One of the primary points of contention vis-a-vis the autodidact concerns the status of the archive and the extent to which it is a public good, accessible to all and open for unlimited input and withdrawal. This question encompasses the priesthood that is the university and their privileged role in defining and maintaining knowledge orthodoxy. If the autodidact is chiefly defined in contrastive relation to the academy, then how do we define the academy? Here I argue that the autodidact is a subjectivity that emerges as logically from the dictates of Enlightenment values as does the university, but which struggles against the same contradictions that have haunted the modern university since its appearance.

In chapter two, "Rafinesque's Herbarium: The Individual as Knowledge, Knowledge as Collection," I examine the commonsense metaphor of knowledge as a type of personal property. The evolving concept of ownership is essential to the rise of the bourgeois individual, the two joining to form an index of mutual definition. While Enlightenment thinkers such as John Locke used the concept of property to explain inborn rights and labor production, this notion, perhaps naturally, also came to seem applicable to acquired knowledge. But rather than as a type of exchangeable property, or currency, I suggest knowledge should be understood similarly to a collection-even a systematic (scientific) collection—with its more nebulous sense of worth and its contested status as property, existing somewhere between the public and private. To illustrate this conundrum I examine Rafinesque's prized herbarium, a collection that he fetishized, theorized, and even attempted to use as leverage to persuade Thomas Jefferson to grant him an appointment at the University of Virginia. Through Rafinesque's 
herbarium I posit the notion of autodidactic knowledge as a kind of spurned collection on account of its fundamentally uncertain and idiosyncratic value.

Though Rafinesque was known primarily as a botanist, much of his work and thought was devoted to the evolving discipline of taxonomy, and his naming of creatures and species has been one of the most enduring aspects of his legacy (as well as one of the most problematic). Chapter three, “Arthrology: Taxonomy, Category, Validity and the Archive," examines this facet of his career and the ways that it testifies to his intellectual isolation. Just as Wittgenstein questioned the coherence of a radically private language, the autodidact urges us to ask if it is possible to have a private science (in whatever way one wishes to define the notion of science). To what degree is all systematic knowledge fundamentally social or at least dependent upon collective forces for validation? Here I use the example of Rafinesque's correspondence with Cuvier as a model to discuss his standing within, and alienation from, the intellectual culture of his time as well as problems inherent to taxonomy itself. To what extent is taxonomy a linguistic activity, and vice versa? To what extent does it capture nature's own divisions? Although much of science (early taxonomy included) is predicated on capturing the inherent qualities of material and its behaviors, like all human activities, in addition to its overt aims, it cannot help but form an intersection between thought, language and culture. This point of intersection forms a gravitational center that must be obeyed, and that the autodidact (like Rafinesque) defies at his/her peril.

One of the most infamous episodes of Rafinesque's career is his "translation" of the forged Native American epic poem, Walam Olum. This text became the centerpiece of a great deal of ethnological and linguistic research. Perhaps even more 
problematically, the faux epic was unwittingly embraced as part of the Delaware Indian identity reclamation movement during the latter part of the $20^{\text {th }}$ century, and in the manner of creating an artificial "continuity with the past" described by Eric Hobsbawm in The Invention of Tradition, has stubbornly persisted as such even long after its debunking (Invention 1). Nearly the entire body of scholarly work since David Oestreicher's initial demonstration of the text's dubious nature has been preoccupied with arguing the degree of Rafinesque's culpability, and determining the reasons for the socalled hoax. In "Instabilities: Walam Olum, Knowledge Creation and Discursive Forms," I argue that this bizarre text sheds light on the formal necessities inherent to knowledge in the modern age. Though the label "hoax" may apply, examination of the way the Walam Olum has functioned through time invites its comparison to "legitimate" knowledge-texts as they assumes the various provisional forms necessary for circulation. In addition I compare the Walam Olum to other spurious identity-texts, such as the Ossian poems, and the Yasusada notebooks, to demonstrate the problems inherent in gauging the authenticity of certain types of texts. In this respect the hoax-text reveals the degree to which all discursive forms (including those overtly devoted to knowledge) are to some extent subject to the capricious interplay of authority, authenticity and expediency.

The final chapter, "The Bones of Rafinesque: Virtuality and Knowledge's Deferred Promise," represents—as the title hints—something of a departure from the historical Rafinesque and even the autodidact, in order to look more directly at the character of knowledge, generally. Here I use the controversy surrounding Rafinesque's remains as a starting point to discuss his theories of knowledge as well as his vision for a utopian culture based on a metaphysics of knowledge, which is to say, knowledge 
conceived as both arche and telos, the ultimate end in and of itself. These narrative elements serve to illustrate the developing thesis that knowledge is always to some extent in deferral, a promise never realized and essentially unrealizable. This is not to say that knowledge is ineffectual or illusory, but rather that it functions as much in the realm of the virtual as that of the actual, its sense of perpetual absence forming a vital part of its character. Though any study of knowledge in the post-Foucault age cannot risk lapsing into the purely idealistic, the final chapter attempts to preserve some of the benefits of idealism with respect to knowledge, its function and its meaning, while not sacrificing analytic honesty. This aspiration seems true to the spirit of Rafinesque, such that in spite of the broader sweep of the chapter, the dissertation's protagonist-like the section title suggests-persists as its ghostly remnant.

David Starr Jordan, in one of his many pathos-driven accounts of the autodidact, approvingly cites ornithologist Elliot Coues that on analogy with words like "grotesque" and "picturesque," our language is in need of the adjective "rafinesque" (Science Sketches 156 footnote). The always slightly disapproving Warren picks up this idea and even offers his own gloss:

The word rafinesque would be distinct from the harsh and derogatory raffish which according to Webster's Dictionary ( $2^{\text {nd }}$ edition) means (1) disreputable; disgraceful, and (2) tawdry; flash; cheap. These words do not really apply to Rafinesque, who was an honorable, idealistic victim of his imagination, enthusiastic, grandiose in his visions, part charlatan, and forever bringing calamity down upon himself. (230 footnote)

In the obscure lexicon of the autodidact, this word describing one's combined seduction and destruction by knowledge will be found after diaphtheirein. 


\section{PECULIARLY MY OWN: THE AUTODIDACT'S CONDITIONS OF BEING}

The autodidact arouses suspicion. With no recognizable qualifications, no testimonial of academic affiliations, with no obvious motivation apart from the lure of knowledge-for-its-own-sake (itself a somewhat suspicious thing), this singular subject of solitary learning occupies a decidedly uncertain place in modernity's reckoning. In 1819, the roving naturalist and autodidact Constantine Samuel Rafinesque seemingly overcame these suspicions by being appointed professor of botany, natural history and modern languages, at Transylvania University in Lexington, Kentucky.

The bare outline of this event suggests a familiar narrative of restoration, reconciliation, a return to the whole: the renegade is at last brought into the fold; the loose end is recuperated back into the otherwise tightly woven fabric from which it has frayed. This prodigal son motif in which fractious difference is resolved and inevitable order restored speaks to both the autodidact's status and the institution against which s/he is defined. The autodidact arouses suspicion. To make this statement blithely passes over the underlying question central to said suspicion: exactly what $i s$ an autodidact? In response to the question, the most obvious contemporary autodidactic tool yields this terse answer courtesy of merriam-webster.com: "a self-taught person." Apart from the thin meta-joke that whoever happens upon this particular webpage should look no further than oneself for an answer, the gloss is only really helpful in unearthing more questions. Self-taught in what? Self-taught how? And self-taught by whose standards of 
measurement? What kind of knowledge, if any, is actually amenable to self-directed learning? What kind is excluded from this approach? If knowledge must be produced by someone before it can be learned by another can it ever accurately be described as selftaught? If all knowledge acquisition is dependent upon a personal will to know and the individual transformation of that will into action isn't all knowledge in some essential ways self-taught? To what extent is knowledge, its production, and its acquisition, a fundamentally interpersonal process and to what extent does it escape (or to put it more ideologically "transcend") cultural and/or political vagaries? Is the notion of private knowledge, or even privately acquired knowledge, even logically coherent?

Perhaps the most interesting aspect of the web dictionary definition is what its brevity implies. Why should the solitary in teaching/learning be the marked monad with respect to normativity, and how can its mere definition as such be sufficient for us to comprehend it? What fundamental assumptions are concealed by this facile definition?

The "problem" is that to a large degree the concept of the autodidact, and to borrow Jacques Ranciere's term for the non-agentive form, autodidaxy, ${ }^{7}$ subconsciously marshals a host of other equally hazy, contingent and ideologically laden ideas for its formation. The purpose of the forgoing is to untangle some of these notions using the autodidact—and specifically Rafinesque's vivid embodiment of this figure — as a primary frame and theoretical trope. One could describe the autodidact as a kind of poststructural subjectivity of modernity, a figure whose impossibility is scarcely mitigated by the very logic that necessitates its appearance. On one hand, the autodidact is the heroic crystallization of the post-Enlightenment credo concerning the liberatory/instrumental value of knowledge placed at the service of the individual. But as Foucault has shown, 7Ignorant Schoolmaster, page 126. 
knowledge — which he explicitly posits in identity with discursive power-is never so simple as to be purely salvific. ${ }^{8}$ Thus in the autodidact we see the cultural collision between metaphysical euphoria and ideological foreclosure. Power-knowledge forms the subject (ideologically termed the "individual") and thereby simultaneously enables and limits her/him within the regulating horizon of cultural legibility: "one of the main moral obligations for any subject is to know oneself ... and to constitute oneself as an object of knowledge both for other people and for oneself" (Foucault 2007, 151). We must be, first and foremost, subjects of learning, and recognizably so. Culturally regarded, we are what we know, and what we know must be open not only to self-reflection, but also to public review. Private knowledge will not—cannot—be tolerated. In this way knowledge always straddles the line between the individual's volition and subjection, the personal and the institutional, the private and the public, as it forms the primary criterion and fundamental mechanism for both the creation of "self" and the cultural validation/invalidation of subjects.

Given the profound importance placed on knowledge for creating subjects and also guaranteeing the legitimacy of those subjects, it is no surprise that one of the centerpieces of our culture would be the vast institutional apparatus overtly devoted to the task of overseeing said legitimacy, with all that this oversight entails; here I refer to primary schools, but especially to the university as the presumed apex of knowledge, its validation, conservation and dissemination. What perhaps is surprising is that anyoneespecially one whose personality is self-consciously and overtly predicated upon knowledge-would choose to pursue this vocation outside of those channels of cultural

8For discussion of the mechanics and scope of discursive power-knowledge, see Archeology of Knowledge, 181-186; for a discussion of its localized effects on the formation of human subjects, see History of Sexuality, Volume One, 92-102. 
legitimacy. What is the value of knowledge when it has not been culturally certified? What kind of economy of desire drives someone to pursue knowledge irrespective of credentials? These issues form the background of the autodidact's identity, and of Rafinesque's story.

In one of his last and most original works, 1838's Genius and Spirit of the Hebrew Bible, Rafinesque says of his project to re/discover (capitalized and emboldened) "Truth": "many eminent men (nicknamed Rationalists) are doing so in Europe; I have seen but few of their works and my researches are therefore peculiarly my own" (14). There is perhaps no more apt summation of Rafinesque as agent of the modern will to know, the pioneer taxonomist, renegade scientist, autodidact. At the time of his appointment, the thirty-six year old had already been prolific as an independent researcher. Whether a true Renaissance man or just a thinker with a profound lack of focus (as some of his detractors maintain), Rafinesque had shown remarkable breadth in his intellectual pursuits and accomplishments. Between time spent in the United States and Europe, he had amassed (lost, and amassed again) an extensive and costly collection of books and a wide variety of natural specimens, these being the day's paraphernalia of the learned. He had spent countless hours in the field observing natural phenomena, and had published a handful of works on biology and taxonomy. Arguably, Rafinesque had made some notable contributions to the emerging body of knowledge within the natural sciences (especially if one trusts some of the claims made amidst the pages of his own publications). And yet, he had also already come to be suspiciously regarded as something of an outsider within key parts of the American scientific community.

The status of social and intellectual outsider-someone between communities 
(and oftentimes uncomfortably so) rather than within them, someone dangerously out of step with the prevailing order-is one that more or less characterized Rafinesque from birth to death. Confusion over how to understand Rafinesque had a determinate influence on his personal and professional life (thus the apparent triumph of his appointment at Transylvania), and —as if it were some kind of lingering curse—-has continued to exercise its effect on his reputation since. The man whom in 1944 Edwin Betts mourned as "America's most versatile and most tragic naturalist" (368) was in the same year damned by the faint praise of his chronicler Huntley Dupre as a "famous botanist, versatile and prolific writer, near-genius, and wholly eccentric" (1). Ironically, for one so singularly driven by the hunger for knowledge, alienation was especially acute for Rafinesque when it came to those communities concerned with cultivating, conserving, and disseminating learning. Perhaps appropriately, Rafinesque's apartness from institutional learning begins with his own education.

"I never was in regular College, nor lost my time on dead languages; but I spent it on learning alone and by mere reading ten times more than is taught in Schools" (Life 89). Born in 1782 in a suburb of Constantinople, his father a French merchant, his mother a Greek of German descent, Rafinesque's youth seems to have been marked by too much instability—some political, some due to the pressures of his father's international business - to afford a long term, permanent home, let alone an extended connection to any terrestrial institution of learning. Apart from a bit of early schooling in his youth, and subsequent private instruction by a handful of tutors, his education appears to have been largely determined by his own drive and interests, which by all accounts were, respectively, indomitable and extensive. Though Rafinesque had little need to exaggerate 
his intellectual aptitude, a familiar hyperbolic grandiosity colors his description: "before twelve years of age, I had read the great Universal history, and 1000 volumes of books on many pleasing or interesting subjects" (8). The exact nature of this "great Universal history" to which he refers is now something of a mystery, remnants of a time when such thinkers as Hegel and Schiller conceived of all human knowledge as one vast process of teleological unfolding. ${ }^{9}$ But whatever the content of those many books he internalized, Rafinesque portrays his as a definite "program" of study, one essentially equivalent to a college curriculum; this is evident in the language as he recalls the single moment at which he was poised to undertake a traditional institutional education, a transition presented merely as the continuation of the learning he had already begun acquiring on his own: "I was to go to Switzerland, into a College to finish my education" (Life 8 emphasis added). Unforeseen circumstance intervened, and as Rafinesque reports he was left the task of finishing what he had already started, “...this project was not fulfilled. I was taken to Genoa by a trusty man, but sent from thence soon after to Marseille by sea. There I remained till 1800 with my grand mother, and completed my education by myself" (Life 8-9). Rafinesque's course of study_taking him at his word-was the entire body of Western learning theretofore amassed. And in terms of his method, one cannot help recall that reviled autodidactic character of Sartre's Nausea, the so-called “Self-Taught Man," whose pedagogy consists of reading every book of the local library in alphabetical order (Sartre 30). As Rafinesque admits, "I read every kind of books, good or bad." Fortunately for him, his process involved more discernment than Sartre's

9For an in-depth analysis and critique of this metaphysical approach to historiography, see Hayden White's Metahistory: The Historical Imagination in Nineteenth-Century Europe. Baltimore: John Hopkins UP: 1973. 
intellectual antagonist, even if his "system" did not, for he adds, "but happily I knew how to distinguish them" (Life 9).

The value of the conventional modern education is naturally not confined to imparting content, nor to training students in coherent methods of inquiry. One of the chief functions of a modern institutional education lies in its testimonial value. "Proper" channels of transmission confer readily visible qualifications upon the educated; within the so-called "marketplace of ideas," the institutionally educated circulate as commodities of legible and interpretable value. As a byproduct, institutional education provides a link between the social and the intellectual by establishing a structure for differential status between members of a realm that often likes to fancy itself a domain of the mind, pure in motive, idealist in orientation, and thus above such pettiness. In other words, it creates prestige among the educated irrespective of what they actually know. Rafinesque was obviously keenly aware of the credentialing function of education, as well as its reputation-boosting effects. His biographer Leonard Warren describes, "as an autodidact without wealth or tangible credentials who had attended no schools, he saw value in collecting memberships in scientific societies and being awarded diplomas and degrees, and each was carefully added to a growing list that was printed on the title page of his books and pamphlets" (96). Warren characterizes Rafinesque's drive for these honorary degrees, memberships, and other tokens of intellectual recognition as a manic hunger, one which prompted him "to nag his peers in other lands" for more of these types of endorsements (46). The attraction to these honors and certificates of institutional validation was likely a canny compensation for what others might have perceived as lacking. Still, Rafinesque was keenly aware of the disjuncture between knowledge and 
accreditation and he writes of these awards with an air of ambivalence in his autobiography, mocking the disparity between conferred status and actual expertise: "I was refused for awhile in Lexington the Diploma of M.A. because I had not studied Greek in a College! altho' I knew more Languages than all the American Colleges united" (Life 71). Though one cannot help but discern traces of exaggeration in his complaint, it contains a kernel of truth and eventually the degree was granted, but an M.D. withheld on account of Rafinesque's admitted aversion to dissecting corpses. Rafinesque's suspicions concerning the potential emptiness of college credentials is an inversion of those often cast upon the autodidact concerning his/her knowledgeand as an autodidact, upon Rafinesque himself. But it also hints at an commensurate anxiety that the autodidact can instill in the academy and among its denizens: the fear that traditional education is at best a kind of cultural domestication, at worst little more than tokens of prestige, empty titles, embossed personalized certificates and alumni clubs. This represents one localized facet of the perceived tension that persistently surrounds knowledge, the tension between truth and falsity, actual content and the mere appearance thereof. Though cunning with respect to the sign-value of degrees and endorsements, Rafinesque was naive in his belief that knowledge simply and justly trumps credentials. This unwavering faith in the unimpeachable authority of knowledge as content (rather than process) is a sometime trait of the autodidact, lending the role an evangelical quality and engendering a generalized hostility. ${ }^{10}$ Nonetheless, Rafinesque was confident in how he stacked up against those ensconced in the ivory tower, and this confidence powered his undying assumption of a place within the university, some position waiting for him

10Consider this casual dismissal in a recent description of Newt Gingrich: "he has the cocksureness, the insularity, and the continuous need of an audience of the born autodidact." David Bromwhich, "The Republican Nightmare," New York Review of Books, Feb 9, 2012, Vol 59, No. 2. 
despite the fact that he had no academic training to speak of. According to Rafinesque's suspect account, long before his appointment at Transylvania, while still living in Sicily, he was in the running for two professorships until those fell through for various reasons (Life 42-3). Once at Transylvania, he renewed a correspondence with Thomas Jefferson in hopes of securing a better position at the soon-to-be University of Virginia.

Rafinesque's confidence is in part predicated upon a modern ideology of selfcreation through learning. Idealized faith in knowledge and its determinate value for shaping the fate and character of the individual-irrespective of any institution or its endorsement—is repeatedly expressed by Rafinesque in Life of Travels, for instance, when he concludes the long list of subjects in his intensive self-education with the optimistic declaration, "I could have thus embraced any profession I chose" (10). Countering this ideological belief is the cultural fear that knowledge, on account of its powers of transformation, requires special handling, that it is a potentially dangerous or unstable element that threatens to corrupt the untrained and unsupervised (putting the academy in a protective regulatory role). This "Pandora's box"-type narrative of destructive curiosity makes for a commonsense critique of the autodidact and is often leveled against Rafinesque, even becoming one of the central bases of Warren's oftentimes mystified biography: "unfortunately, in his formative years there were no restraining, calming, and guiding influences." One of the symptoms of this lack of supervision, according to Warren, is Rafinesque's lifelong inflated sense of possibility with respect to knowing and learning: "by the time he reached adulthood he was a fearsome autodidact who lacked a critical sense of the limits of human capability—he was a loose cannon" (10). But in failing to theorize autodidaxy, Warren fails to account 
satisfactorily for Rafinesque's peculiarity, his desire for learning, his irremediable singularity as a lone agent laboring in a collective economy of knowledge. Toward such a theory I would like to look at the various problems and possibilities of modern knowledge posited as a self-justifying end both individually and institutionally. In order to posit a theory of method for Rafinesque as a thinker and autodidact, I propose looking — somewhat anachronistically—-toward the notion of theory itselftheory in its historical and even etymological relation to knowledge and sense-perception. Aristotle begins his own theoretical excursion into metaphysics and knowledge with a famous observation on epistemology: "all men by nature desire to know. An indication of this is the delight we take in our senses; for even apart from their usefulness they are loved for themselves; and above all others the sense of sight" (980a). According to Aristotle's account, knowing is a pleasurable and organic function of our basic engagement with reality. Primary delight in the senses, in our raw experience of the world, forms the basis and necessary conduit for higher realms of knowledge: “...science and art come to men through experience" (981a). Aristotle assumes a direct line of connection between sensuous pleasure and the loftiest theory, and Metaphysics not only argues but also strives to illustrate this connection. In this way we are being urged toward a kind of proto-phenomenological approach to the circuit between sense and knowledge, one which, in spite of its intuitive commonsense appeal, is actually far too nuanced to adequately account for here. ${ }^{11}$ Nonetheless, there is a telling confidence in the unquestioning assumption that such a circuit is not only possible, but given; knowledge is

11For an account of the connection between Aristotle's thought and phenomenology, see the text of Heidegger's 1927 lecture, "The Basic Problems of Phenomenology," Basic Problems of Phenomenology, Indiana University Press, 1975, pages 1-23. For a more thorough account of Aristotle's approach to knowledge see, Groarke, Louis. An Aristotelian Account of Induction: Creating Something from Nothing. Montreal and Kingston: McGill-Queen's UP, 2009. 
natural and the proof of this begins with an attentive look at how perception joins up to thought, and vice versa.

The strict correlation between knowledge and nature, and the notion of the human appetite to know giving, and in turn being given, access to all that is worth knowing suggests a state of equivalence essential to Aristotelian metaphysics: the equivalence between thinker and knowledge. It is possible that Aristotle's theory of knowledge in some ways better explains the impulse of autodidaxy (even in modernity), and perhaps tellingly, two early literary accounts of the self-taught derive from his philosophy. Ibn alNafis' thirteenth century novel, Theologus Autodidactus, was inspired by the philosophical fiction of ibn Tufayl from a century before, which in turn was derived from the philosophy of one of the middle ages' foremost commentators on Aristotle, Avicenna. Whereas Tufayl's earlier self-taught protagonist was a feral child in communion with nature, al-Nafis' later novelistic autodidact is nature itself: the accidental mixing of organic materials and elements results in the gestation and emergence of a man.

... deep within the earth, there was a great mass of clay that had been in a state of ferment over the course of many years. Hot vapours mixed with cold and moist vapours fused with dry to produce a homogenous balance of forces ... The most perfect balance was in the centre, where the vapours most fully resemble the humours of man ... At that point, the spirit that proceeds from the command of the Lord attached itself and so firmly did it bind, it would have been hard for either sense or reason to separate the two. (al-Nafis 13)

In this account, "sense or reason" functions not to further separate elements, but to unite them. And this product of natural ferment combined with divine imperative is a being that will eventually learn all of the secrets of the universe-up to an including the revelations of the prophet Mohammed - through engaged inquiry into his surroundings (al-Nafis 39-44). Thus, al-Nafis' autodidact is engaged in a natural process that 
precipitates his birth and eventually results in the highest knowledge, a cyclical process in which nature leads to birth, which leads to learning, which leads to knowledge, which leads back again to nature. His learning is as organic as his spontaneous generation, the assumed result of the intersection between inquiring mind and legible world. Like the Platonic/Socratic notion of evil as a species of error, ${ }^{12}$ there is the implicit argument in this text that to remain in ignorance is simply to fall out of step with nature and her goals.

Rafinesque's most important expressions of a theory of learning come not in some unified treatise of Aristotelian rigor, nor in a fantastic allegory about creation, nor even in an epic poem, but rather in his scattered observations about his own autodidactic education; nonetheless, among these passages there is a similar assumed equivalence between natural human development and knowledge —at least with respect to Rafinesque himself. Throughout his autobiography, A Life in Travels, Rafinesque voices an idealizing faith in knowledge and the determinate value knowledge has for shaping the individual and his/her fate. Rafinesque's early exposure to the written word was matched by an insatiable curiosity, for he did—just as Aristotle asserts—by nature desire to know. His autobiography concludes with a powerful expression of the effects of this desire, in a passage that gives voice to Rafinesque's unwavering confidence in knowledge, education, personal ability and self-fashioning, "it is a positive fact that in knowledge I have been a Botanist, Naturalist, Geologist, Geographer, Historian, Poet, Philosopher, Philologist, Economist, Philanthropist ... By profession a Traveller, Merchant, Manufacturer, Collector, Improver, Professor, Teacher, Surveyor, Draftsman, Architect, Engineer,

12An idea expressed in the dialog Protagoras: "for you have admitted that it is from defect of knowledge that men err, when they do err, in their choice of pleasures and pains - that is, in the choice of good and evil" (357d) 
Pulmist $^{13}$, Author, Editor, Book-seller, Librarian, Secretary ... and I hardly know myself what I may not become as yet" (148)

Books do not constitute the only—or even the main—channel for acquiring viable knowledge for Rafinesque. Like al-Nafis' knowledge-driven golem, and Tufayl's feralboy autodidact before that, Rafinesque believed in direct communion with nature. Returning to the very significant title of his autobiography, A Life of Travels, we find that rather than cold archival researches, the domain of experience constitutes for Rafinesque the richest program for learning; throughout the work, he details at length his many experiences traveling and doing fieldwork in the natural sciences, observing and discovering. ${ }^{14}$ In this respect, Life of Travels, unapologetically assumes that the adventure of knowledge is indeed an adventure, and one that implies a journey, the taking in of sensory experience—especially visual, and finally the processing of that experience into knowledge; the effective sequence of these elements amounts to learning, and ideally culminates in a report on what has been learned (Rafinesque was a prolific writer and sharer of his ideas and discoveries). Explaining the choice of title, Rafinesque plainly states the equivalence in his mind between journeying and self-education, when he says that in spite of his ravenous youthful hunger for books of all kinds, "my favorite studies were still travels and natural sciences" (10). At the book's conclusion, Rafinesque even asks that his readers accept, "the fruits of my travels and researches, which I desire to leave as monuments of my life and exertions" (115).

13Someone who cures tuberculosis; a word derived from another of Rafinesque's coinages, Pulmel, which was the name of the botanical treatment Rafinesque developed for the disease.

14For an interesting theoretical account of how the sciences came ultimately to disavow this approach, see the second section of Giorgio Agamben's "Essay on the Destruction of Experience," in Infancy and History. Trans Liz Heron. London: Verso, 2007 Page 19-34. 
Returning to Aristotle by way of Rafinesque, this circuit between senseperception—-particularly sight—and knowledge inheres at the level of common vocabulary and is apparent in such expressions as "I see," when deployed to mean "I understand." In this respect, the correlation perhaps betrays a more ancient IndoEuropean commonsense empiricism. In Greek the verbal root eido equally signifies both "to see" and "to know." It is also the basis of the noun to eidos ("that which is seen"), a word common in Platonic thought and one which is often rendered into that pluralized English term so familiar to philosophy, "the forms." Perhaps then, given the immediacy of this linguistic/epistemological sensorium, it is no wonder that this would become the basis for some degree of Greek self-analysis, analysis which then persists into English in the form of the word "theory." Theory is based on the Greek word for contemplation, theoria, a word related to the verb theaomai: to view, gaze at, behold. Not only does theoria indicate systematic contemplation and reflection, or theorizing, it also encompasses, "a looking at, viewing, beholding, observing"-and as such is etymologically related to the English "theater," as well as the Greek word for the same, theatron. ${ }^{15}$

Theoria's Greek root, theoros, signifies not an abstract verbal notion, but a concrete subject, an intellectual agent embarked on a veritable adventure of knowing enabled through seeing: "a spectator, observer, one who travels to see men and things." Like that mythic knower of nearly divine intellectual prowess, Odysseus, who through his wanderings is said to have "seen the cities of many men and learned their minds" (Homer 1.1), theoros evinces belief in a fundamental interconnectedness between journeying,

15For etymology, see Liddell and Scott's Lexicon: Abridged from Liddel and Scott's Greek-English Lexicon. Oxford: Oxford UP, 1994. 
seeing, experiencing, knowing and reporting. By the logic of the theoros, travel has yet to be reduced to mere personal amusement in its devolution toward the leisure activity of common tourism, and instead retains a sense as viable basis for pedagogy. This function of the journey and its travelogue as the reliable sense data and point of departure for deeper reflection and broader knowledge informs an entire body of classical literature, from the works of Herodotus, to Xenophon, to Pausanias, and others. The same assumption is to some extent mirrored linguistically when theoros is extended into its derivative, theoria, for then this root passes beyond mere reportage of the seen and experienced, and enters into the realm of the reflected-upon, the contemplated, the processed-in a word, the theorized. In serving this function, the theoros also becomes the object of such theorizing, as both Aristotle and Plato devote considerable attention to the role of this subject as an acquirer of knowledge and agent of its further dissemination; in fact, one of philosophy's most well-known exercises in thought, Plato's allegory of the cave, can be read as a meditation on the proper behavior of the theoros as traveler, discoverer, and finally instructor. ${ }^{16}$

In much the same way that the autodidact-as-subject seems curiously Aristotelian, so Rafinesque's fervor for knowledge, as something to desire, to seek out, to acquire, and then to share, is perhaps better served by the model of the theoros than that of the scientist as s/he appears within the contemporary landscape of subjectivity. In her book on the subject, Andrea Wilson Nightingale has observed, "in Plato's conception of theoria,${ }^{17}$ theoretical knowledge is a sort of 'hot cognition' ... in which eros and the effect

16For examples of this reading, in addition to Andrea Wilson Nightingale which I discuss further, see also Robert Burch's essay in, Wurzer, Wilhelm S. Panorama: Philosophies of the Visible. London: Continuum, 2002. Page 76.

17By this she means the knowledge production of the theoros, per se. 
of wonder play a key role in the activity of contemplation" (8). The distance between the spectatorial subject and object may be total, for this is the essence of observation; as philosopher Hans Jonas has noted, the separation between observer and observed is, “... the concept of objectivity, of the thing as it is in itself as distinct from the thing as it effects me, and from this distinction arises the whole idea of theoria and theoretical truth" (2001 147). Still, this objectifying gaze is a notorious vehicle for sublimating or even facilitating that play of eros and wonder which Nightingale identifies as characteristic of the platonic theoria; and while perhaps ensuring a sense of distance between spectator and spectacle, it nonetheless allows for the aestheticization or even fetishization of the object of contemplation.

Aristotle's treatment of the theoros does not involve the direct discussion of erotic sublimation that sometimes marks Plato's discussion of the same, but it does encompass the inescapably aesthetic dimension that attends the work of the theoros. In the section of his Rhetoric devoted to epidictic — which is to say, non-argumentative oratory, or as Aristotle calls it, "the ceremonial oratory of display"- the theoros is central; it is the theoroi who will judge the epidictic spectacle, and who will then in turn report it in like manner. That this type of rhetoric has an aesthetic component, or even is itself a kind of aesthetic exercise, goes without saying, and in fact is the basis of Aristotle's assessment of it. What is perhaps more controversial is its exact function and proper domain. As Perelman and Olbrechts-Tyteca argue in The New Rhetoric, "in spite of a lack of understanding toward it," the epidictic mode, "forms a central part of the art of persuasion" (49). Freed from any overt obligation to competitive argument, epidictic is a capacious category, one that encompasses eulogy, panegyric, propaganda, and even 
displays of "academic eloquence" (47). This rhetoric of spectacle, "which immediately evokes literature," one "more reminiscent of a procession than of a struggle," lends itself to the forceful and seductive expression of apparent fact, and thus is the ideal rhetorical mode of the theoros. To again quote Perelman and Olbrechts-Tyteca, "In epidictic oratory, the speaker turns educator" (51).

Rafinesque was keenly aware of the attractions of rhetoric, being himself prone to epidictic excesses. Throughout his "scholarly" self-publication on astronomy, taxonomy, linguistics, economics, botany, and countless other topics (much of which is already written in a rather theatrical tone), there are diversions into poems, forays into the nature of wit and the purpose of literature. His short-lived journal Western Minerva contains puzzles suggestive of later concrete poetry: blocks of letters with stray words and messages running up one side and down the other, hidden amidst seemingly random sequences. Rafinesque even attempts the creation of new forms, such as the so-called "polygryph," a compound word coined from Greek roots meaning, "interwoven enigma," and indicating a kind of didactic riddle-in-verse, each of which Rafinesque addresses to a different woman (67). While Rafinesque is not always at a total loss to differentiate scientific discourse from more overtly aestheticized sorts—such as in the case of the World or Instability, his well-known exposition of proto-evolutionary natural theory in the form of an epic poem - he does consistently fail to quarantine the discourse of science from forms that by his day were reckoned unwelcome, or even impure, on account of their color and affect.

Historians of science Steven Shapin and Simon Schaffer have analyzed the necessary shift in rhetoric that has attended the rise of modern scientific discourse in their 
work Leviathan and the Air Pump, a shift well underway by the time of Rafinesque, but not yet universal enough to have attained complete dominance over Europe, let alone penetrated into the wild frontiers of the New World where Rafinesque was laboring. ${ }^{18}$ While the mission of this newer discourse remained essentially the same—-transmitting the rarified experience of a mere few to a general audience by way of print-the rhetorical approach was nearly opposite, characterized not by its flourish, but rather by its restraint. One facet of this newer discourse was its vigorous insistence that it presented unalloyed "fact": theory—not to say, theoria—implies human agency in the form of speculation, contemplative intervention, cognitive modeling, all of which implies rhetoric; by this measure rhetoric is the opposite of "fact," which is to say, data gleaned straight from nature. To create the appearance of a discourse of pure fact, that is, some transparent window through which a reader supposedly gets direct access to nature and her laws, the intermediary of that discourse—i.e. the scientist—has to disappear. Thus within this new discourse there was no room for a self-aggrandizing master of ceremonies; the theoros who witnesses the spectacle and then in turn must create one for the educational benefit of the community was not welcome here. As Shapin and Schaffer show, since the writer of this new discourse could not vanish altogether, he instead had to appear consistently "sober and modest," an intellectual "under-builder," who willingly hides within his own text, for his sole role is to provide the merest platform for Nature to speak in her own voice (65-6). To accomplish this, there emerged the now-familiar discursive style of science, "plain, ascetic, unadorned ... functional," and freed from the corrupting influence of its messenger (66). Ironically, the new spectacle was just this

18Presumably, however, the cosmopolitan polyglot Rafinesque would have been well-acquainted with the scientific rhetoric of Europe that was gradually achieving dominance in that day. Warren even goes so far as to assert, "extraordinarily well-read, he must have been aware of virtually everything that was going on at the time in science and natural history" (156). 
apparent vanishing act on the part of the reporting scientist, for as Shapin and Schaffer observe, "the public display of this modesty was an exhibition that concern for individual celebrity did not cloud judgment and distort the integrity of one's reports" (65).

In a recent essay, science writer Jim Endersby has argued that Rafinesque is perhaps better understood as a literary figure rather than as a strictly scientific one (16878). While this idea has a certain appeal, my own argument to some extent seeks to complicate it in a rather roundabout way. By positing Rafinesque as a kind of version of the theoros, I am in no way suggesting that Rafinesque self-consciously modeled himself upon Greek sources, nor that this Greek institution, as such, has somehow persisted into modernity. Rather, what I am arguing is that the theoretical notion of the theoros seems to be the most mindful and self-conscious articulation of a longstanding commonsense pedagogy in which one knowledge-seeking individual's eye-opening experience must be vividly communicable to a broader community not privy to said experience; in this respect, the theoros is an agent, driven by desire and wonder, and laboring in an atmosphere in which the discourses of science and literature are not, and should not, be separate. This notion of the theoros seems closest to Rafinesque, and it is also the discursive mode that the relatively new discourse of science was intent on displacing. The "heroic" agent of knowledge which the theoros and the autodidact seeks to be is dependent upon a charged personal investment in intellectual inquiry. Friedrich Nietzsche, repentant academic and autodidactic philosopher, forcefully lamented the displacement of this engaged stance of learning:

Let us guard against the snares of such contradictory concepts as "pure reason" ... "knowledge in itself": these always demand that we should think of an eye that is completely unthinkable, an eye turned in no particular direction, in which the active and interpreting forces, through which alone seeing becomes seeing 
something, are supposed to be lacking; these always demand of the eye an absurdity and a nonsense. There is only a perspective seeing, only a perspective "knowing" ... But to eliminate the will altogether, to suspend each and every affect supposing we were capable of this- what would that mean but to castrate the intellect? (119)

The problem is that the very move to conceal perspective knowing, to render it invisible, also conceals the complex cultural foundation upon which all knowledge inevitably rests.

As Gregg Lambert has observed, knowledge is not self-organizing (76), from which we can deduce that it is particularly susceptible to symptoms from the various forces, models and metaphors which come to structure it. To speak of the autodidact is to speak of something imprecise, uncertain, something almost bordering on the fictitious. In being so, it is perhaps to some extent a telling reflection of that space which is assumed to differentially define the autodidact: the university. Derrida begins a meditation on the contemporary academy with the question, "how not to speak, today, of the university?" (Eyes 129). This question, posed as it is in the negative, is a commentary on "the strange destiny of the university," an institution whose ubiquity has remained undiminishedperhaps in fact increased-even as its specific reason for being, its ground or goal, has become ever more obscure(Eyes 155). Any simple appeal to a fundamental principle of Reason, or an organic impulse to knowledge, ignores the complex historical conditions of the university, as argued by other contemporary theorists of the institution, such as Bill Readings and Gregg Lambert. It also ignores the complex historical transformation that modernity forces upon knowledge itself, a transformation which changes our understanding of what knowledge is, and one which effectively displaces those prior accounts of learning, rendering them unconvincing, improbable, even fabular. Such is the fate of the theoros. The new understanding of knowledge - arguably yet another handful 
of metaphors and fables-must account for the bourgeois democratization of knowledge, and particularly that common organ of distribution and production with which knowledge is now metonymically identified: the academy.

Walter Benjamin, failed academic—and a thinker with profound autodidactic tendencies, states quite simply one metaphor of modern knowledge: "collecting is a primal phenomenon of study: the student collects knowledge" (Arcades 210). The model of knowledge as a kind of vast archive, that is, a collection, from which each independent scholar assembles a sub-collection, is the engine of what Gregg Lambert calls, "the encyclopedic impulse, which is the condition of the existence of a University" (76). By this he means the modern university, the one which Kant first theorized, the one whose status seems to Derrida and others beyond simple explanation. It is within the logic of the modern university — that place which Rafinesque, rather erroneously, assumed to be his natural home, and that place which has come metonymically to emblematize knowledge in the modern age - that we encounter many of the problematic parameters of contemporary knowledge: the public versus the private, the hidden versus the open, the collective versus the individual. One crisis-producing effect of the Enlightenment model of knowledge has to do with what Lambert calls "the public character of reason" (77). Knowledge must be reckoned as a kind of common property, although as we shall see this conflicts somewhat with the ideal Kantian agent of knowledge. Bill Readings alludes to this tension between public knowledge and private thought when he observes, "the Kantian University of Reason is modeled upon the individual researcher, perhaps despite Kant's wishes" (Readings 55, my emphasis).

Kant's account of the university, Conflict of the Faculties, early though it is, is 
already riddled with anxieties concerning the relationship between knowledge, and the dynamics of the private and public. As Derrida observes in his essay on Kant's text, it is the character of discourse, the "publicness" of the archive (that same "publicness" discussed above by Lambert), that "designates the unavoidable locus of equivocation that Kant would like to reduce" (Derrida, Eyes 98-9). In this respect, we could say that Conflict, that first foray into theorizing the modern university - a place, to reiterate, which represents knowledge generally—is also an announcement of the university's crises, and thus an announcement of a certain crisis of knowledge. In fact, to some extent that is exactly what Kant intended for his text: to showcase what he perceived as an impending threat to knowledge. Kant maintains that "a university must have a faculty of philosophy," a conviction which stems from his discomfort over the powers wielded by the so-called "higher" faculties of law, medicine and theology (Conflict 45). ${ }^{19}$ Kant argues that only philosophy is endowed with the necessary critical skills to govern the other faculties, an arrangement which he is proposing and which he proposes from a state of fear: the fear that those other departments are dangerously close to enjoying control over philosophy, to being able to influence its operation or silence its voice (Conflict 279). Although Kant acknowledges that the higher faculties offer a certain utility, philosophy is solely concerned with the truth, and for this reason it should enjoy privilege as the governing center for the academy (Conflict 45$)$.

Here it is important to remember that Kant also theorizes the solitary Enlightenment subject of knowledge and in this sense Conflict has a companion piece from within his oeuvre. When Conflict is read together with the essay "What is

19The designations "higher" (medicine, law and theology) and "lower" (philosophy) are in reference to the status of these departments with respect to their political standing and are, of course, in no way indicative of Kant's esteem for the disciplines. 
Enlightenment," a text that debuted fourteen years earlier, when Rafinesque was still an infant, we get a fuller picture of the modern adventure of knowledge acquisition, as well as a more vivid sense of the problems that that adventure engenders. In fact, the tension between public and private use of reason is foregrounded in this essay (though Kant's use of the terms are inverted such that public equals private, and vice versa), foregrounded to the degree that they become the central parameters of regulation with respect to the thinking individual—which is to say, the individual as individual, as thinker, as scholar, and not necessarily as a member of the academy. Enlightenment, as Kant defines it, is animated by the intellectual imperative sapere aude, "dare to know/think," and its force should remain intact in all cases of what we would understand as private uses of reason. Whenever one is acting apart from her/his capacity as a functioning element of civil society, whenever one is freed from the duties and demands of the realm, there should be unfettered ability to exercise thought in whatever way one chooses. The ideal conditions envisioned by Kant are summed up in a slogan obviously intended to appease the monarchic powers looking over the philosopher's shoulder, "argue as much as you want, and about whatever you want, but obey!" (Basic 141).

Michel Foucault has observed Kant's distinctive diction in the Enlightenment essay. Specifically, he notes that "the German word used here is rasonieren; this word, which is also used in the Critiques, does not refer to just any use of reason, but to a use of reason in which reason has no other end but itself; rasonieren is to reason for reasoning's sake" (Foucault, Reader 36). The issue of language is a potentially important one with respect to Kant's essay, a text which—not unlike Aristotle's metaphysics—is as much a kind of fable of knowledge as it is a rigorous philosophical tract. Unlike the later 
Conflict, a document which, given its interventionist purpose, given its attempt to influence policy, should be regarded as political, as being about the political, and thus essentially about the public, the Enlightenment essay tells the tale of an imagined protagonist: an agent driven by a will to know and who, in pursuit of this will, shall remain in necessary isolation, apart from those duties that engender social responsibility. Ostensibly, this is for the protection of those duties themselves, for the protection of a fragile social order, one that could easily be disturbed and disrupted by the incursion of sudden radical critique. But when read against its companion text, which is to say against the situation described in Conflict, a situation where the pursuit of knowledge and the exercise of reason is inhibited or even threatened by various corporate bodies and affiliations, indeed, threatened by the educational apparatus itself, this injunction to remain apart from the workings of society takes on another sense. Kant's framing of the public and private in the Enlightenment essay is, on the surface, just right to appease the suspicions of a wary monarch, but there seems also to be a barely repressed anxiety lurking here, and a veiled—if not even unconscious—concomitant warning to the modern adventurer of reason, that ideal agent of the Enlightenment: keep reason free from outside social control or responsibility, and (taking seriously Foucault's observation on Kant's language) keep it free from obvious utility. Thus a kind of schizophrenic no-man's-land emerges between the individual thinker and the institutional body believed necessary to cultivate, conserve, and even represent, knowledge: knowledge and reason must remain public and collective, but its crucial exercise is conducted by the solitary thinker.

Of course, there was a contemporary of Kant (and Rafinesque) who joined in commenting on this very issue, and in a way much more strident and immediately 
relevant to the autodidact, even if perhaps less theoretically rigorous in some ways. Joseph Jacotot (1770-1840), itinerant scholar and developer of "Universal Education"essentially a systematized program for autodidactic learning — was convinced of the fundamentally dangerous effect of the collective public with respect to acquiring learning. Jacques Ranciere, Jacotot's modern-day theorist, has summed up the position of this early modern proselyte of knowledge and its transmission, "intelligence is only in individuals ... not in their union" (Ranciere 76). Jacotot characterizes the public as a kind of gravitational force that pressures its individual members into a state of enforced stultification (Ranciere 76-7). It is this effect that accounts for the continued ignorance of the public at large, as well as that dynamic within the university that was such a concern for Kant, a dynamic which marks the academy as a place obsessed as much with the exercise of power as with that of thought.

Rafinesque was tormented by the uncomfortable intersection of the public and private with respect to knowledge, perhaps even to the point of delusion. His seemingly genuine commitment to the belief that knowledge should be available to the public is consistent with his tendencies toward socialist thought (Rafinesque even at times dabbled with the idea of joining various communal societies of his day such as New Harmony and the Friendly Society of Mutual Interests). This egalitarian approach to knowledge comes across in a couple of journals he attempted to establish, publications whose expressed purpose was summed up in the explanatory introduction of his Atlantic Journal and Friend of Knowledge, “... to improve and instruct, to scatter the seeds of learning, and become eminently useful by rendering all kinds of knowledge and improvements popular ..." that otherwise might be, "beyond the means of those whom they are most likely to 
benefit" (1). The project is introduced from the beginning as one designed to facilitate autonomous learning, a project for the needy but autodidactically inclined. In spite of this generous intent, Rafinesque perceived his journals to be the subjects of conspiracies to repress; in a letter to Thomas Jefferson, Rafinesque apologizes for not forwarding a copy of his forthcoming journal, Western Minerva, because, "it has been condamned [sic] before its appearance ... by a new kind of Western Literary Inquisition and Censorship" (Betts 372). This is not the only claim of its kind amongst Rafinesque's writings, and therefore is quite possibly evidence of a delusive (though telling) paranoia; and yet, whether for reasons good or bad, by 1819 , according to Warren, Rafinesque had indeed been barred from publishing in the primary American scientific journals, thus banishing him from the general scientific community and relegating him to the reduced orbit of self-published scholarship (30).

Amidst the numerous pages of his Atlantic Journal and Western Minerva are pieces (all written by Rafinesque but often under various pseudonyms such as "Mentor," “Captain Forman,” or “Archimedes”) speculating on humanity’s latent or lost knowledge, pleading for free public education, even "reconstructing" the egalitarian governmental and educational theories of the Pythagoreans. In one of these articles, Rafinesque, under the nom de plume "Benj. Franklin Junr.," surveys the pedagogical approach of his elder contemporary, Joseph Jacotot (Atlantic 123-4). Despite the fact that Rafinesque is virtually the ideal embodiment of Jacotot's educational philosophy, the review skewers the "Natural Method of Universal Instruction and Intellectual Emancipation," on a point by point basis according to the system's chief principles. The only principle to secure agreement from Rafinesque is the first: "God has endowed the human mind with the 
power of self-instruction" (123). As to that other cherished principle in Jacotot's struggle for intellectual emancipation against stultifying dogma and the parade of empty credentials, "intelligence is the same in all beings, and therefore the aptitude to learn," Rafinesque facilely dismisses the notion with the two condemning words, "Quite false" (123). This principle, which Jacotot-interpreter Ranciere perceives as the only protection against the stultifying collective (the public), is an "elevation" of the Kantian-style Enlightenment individual through a radical leveling of ability; arguably this move threatens to efface the very notion of the "individual" as it is understood in modernity, given that one of the chief parameters by which the individual is assessed is by his/her specific store of acquired knowledge and "unique" aptitude. But it is precisely this difference of ability—of aptitude and knowledge—that Rafinesque believes to be his trump over the mindless mandarins of the institution and their meaningless credentials. And, of course, in this, Rafinesque is right: ironically, until the entire world is intellectually emancipated and running smoothly according to Jacotot's system of liberating self-instruction the only possible means for validation an autodidact like Rafinesque has is in appearing to possess superior knowledge and ability.

In the case of Rafinesque, even the appeal to a superior knowledge and abilitysomething Rafinesque seems to have believed he possessed, whether rightly or wrongly -was not enough. One way to account for this is by recognizing that the same collective that Rafinesque was trying constantly to best and humble in its knowledge and aptitude was the very public solely licensed to validate or invalidate him as a scholar, thinker, and knower. Shapin and Schaffer, in Leviathan and the Air Pump, describe the necessary and inescapably social aspect that enters into modern science as it moves from a model of 
observation to one of experimental method: "the foundational item of experimental knowledge, and of what counted as properly grounded knowledge generally, was an artifact of communication and whatever social forms were deemed necessary to sustain and enhance communication" (25). To one without community to speak of, one always at odds with his validating public, such foundation would naturally be difficult to come by, if not outright denied. In this respect, Rafinesque's resemblance to the Greek theoros, resemblance born of being a traveling-scholar, Nietzsche-esque perspectival seer, and reporter of experience-as-learning, becomes completely untenable as a model for acquiring valuable, or even viable, knowledge. What seemed so natural and valid to Rafinesque (and the ancient Greeks) as a facet of self-directed study fails in modernity on account of its radical privateness in an order that cannot tolerate the private. As Shapin and Schaffer state, "the problem with eye witnessing as a criterion for assurance was one of discipline. How did one police the reports of witnesses so as to avoid radical individualism? ... In natural philosophy, as in criminal law, the reliability of testimony depended upon its multiplicity ..." (56). And so, in a realm wherein the rules are dictated by the collective social body—a body perhaps given to silencing and overpowering, as argued by Kant, or even stultification, as argued by Jacotot and Ranciere-autodidactic and self-validated knowledge comes to seem more fetish than fact, a radically isolated collection, private, perverse, autistic. 


\section{RAFINESQUE'S HERBARIUM: THE INDIVIDUAL AS KNOWLEDGE, KNOWLEDGE AS COLLECTION}

In 1819, the year of his appointment at Transylvania, Rafinesque wrote a letter to Thomas Jefferson that reads, "some untoward Circumstances in this University, might induce me to prefer a more eligible situation elsewhere," and thus the purpose of the note at hand: to inquire about the possibility of a professorship at the nascent University of Virginia (Betts 371).

At the time of Rafinesque's 1819 letter, he and Jefferson were already mildly acquainted, having met once in person in 1804 during Jefferson's first term as president and Rafinesque's first stay of residence in the United States; coincidentally, Alexander von Humboldt paid a visit to Jefferson the very same summer. In spite of accounts that Rafinesque, with his customary zeal for knowledge and accuracy, repeatedly interrupted the president during this initial meeting—even daring to correct him, Jefferson seems to have been impressed by the young naturalist and the two thereafter shared a very brief correspondence cemented largely in their mutual interests in botany and the discovery and cataloging of the rich and diverse plant and animal organisms of the New World (Warren 17). On November 27, 1804, Rafinesque concluded this first series of letters to Jefferson with a note inquiring leadingly as to whether, "the American Govert have not sent some Botanist there along with Messr. Lewis \& Hunter"20 (Betts 369). Almost

20Rafinesque is referring to the expeditions to explore the Louisiana Purchase, one of which was that of Lewis and Clark, another being the lesser-known Hunter-Dunbar Expedition. By the time of Rafinesque's letter, both expeditions had already departed. 
immediately after posting this inquiry a deflated Rafinesque left the U.S. for Europe on a hiatus lasting over a decade; but many years later he would ruefully reminisce, "I was told that I might be admitted as Botanist in the expedition which Lewis and Clark were then preparing to survey the Missouri and cross the Oregon mountains" (Rafinesque, Life 24). Whatever source Rafinesque was relying on for this claim is never identified in his account. Having seen the respected ornithologist Alexander Wilson passed over, Rafinesque had not even actually applied for the position of botanist to Lewis and Clark, so perhaps such a suggestion had been leaked from behind closed doors, but this memory may also have simply been the product of a sense of entitlement mixed with nostalgic overblown imagination. For in response to Rafinesque's early searching letter concerning the expeditions, Jefferson had given this cursory, garbled, and ambiguously dissuasive, reply: "certainly I should be happy to add your botanical talents to the party but that is not in my power to propose any berth worthy your acceptance expenses only with little other compensation are expected by the members of the party, who are chiefly induced to undertake the journey for the gratification only of their curiosity" (Betts 370). By the time this response arrived, Rafinesque had already departed for Europe and so he likely never saw it.

Now in 1819 , all of these many years later, writing from his new American home at Transylvania University in Lexington Kentucky, Rafinesque was again seeking a position from his acquaintance. And so began a five year long lopsided exchange of letters between the ex-president and the autodidact. Again Rafinesque would ultimately be frustrated.

Within just a few short years of working at Transylvania, Rafinesque's energy for 
teaching had cooled in comparison to his enthusiasm for field work, and his many eccentricities had caused relationships with administrators and colleagues to grow strained. This to some extent may account for the increasingly pleading tone of the letters to the former statesman, whose responses generally avoid dealing with Rafinesque's questions directly, instead blaming unforeseen delays and vague obstacles. From the very first letter of inquiry, a metonymic association is established between Rafinesque and his collections, an equivalence that will endure until the end of the correspondence. This parallel is formed by his attempt to entice (not to say, bribe) Jefferson into giving him the position: should the scholar be hired, along with him will come his collection of books, his "museum," "specimens" of an unspecified sort, monetary donations to help build the university's library, and the treasure so often mentioned throughout the correspondence, a wonder of plant taxa incarnate, Rafinesque's beloved, "extensive and rich herbarium" (Betts 371).

The valuation Rafinesque placed upon this assortment of plant specimens, his herbarium, is well-documented, and exceeds simple scientific interest, so it is perhaps appropriate that the assemblage should be appointed as the material stand-in for the man and his otherwise immeasurable capabilities. Here Rafinesque is participating in a cultural shift. The term economy is often loosely deployed to describe all manner of circulation, including the circulation of knowledge. And this is somewhat appropriate given the simultaneous (and symbiotic) rise of private property with its reliance upon modern systems of exchange, and that of bourgeois individualism with its reliance upon power-knowledge for the formation of viable cultural subjects. One effect of this systemic interdependence is the pressure to make personal knowledge which might 
otherwise be idiosyncratic and nebulously-valued assume not merely literal form, but even fungible form. Like other entities of exchange, our conceptualization of modern knowledge tends toward standardization as well as literal objectification-a quality exemplified by the ubiquitous ceremonial diploma—so that knowledge may circulate, recognizable and amenable to evaluation. Max Horkheimer gives a trenchant critique of this shift in Eclipse of Reason when he discusses the evanescence of knowledge once understood ideally as "stationary contemplation" (disinterested thought for its own sake), against the rise of the "instrumentalization of reason" (31-2). The redefinition of "knowing" under the influence of capitalist logic, materialist scientism and competitive technocracy parallels a reification of modern knowledge as it comes to be understood, like so many things, as a species of private property: knowing is owning, and knowledge is capital.

Problems emerge, however, when analytic pressure is put upon the model of knowledge-as-capital, since knowledge forms a somewhat uncomfortable border between subjective identity and cultural valuation. In the marketplace capital is impersonal. In the "marketplace of ideas" knowledge is oftentimes made out to be also. But as anyone who has spent time in the academy well knows, attachment to knowledge tends to be very personal: people often find it difficult to renounce their ideas even in the face of compelling evidence, and an attack on one's thought can feel much like an attack on one's person (and is oftentimes treated as such). Given this lopsided engagement, knowledge does not have the fluid qualities of exchange characteristic of other forms of capital, and the result is an unwieldy commodity that must function simultaneously as a site of personal investment and cultural assessment. For this reason knowledge is more 
aptly compared to a private collection on display with its complex dynamic of personal and public worth. The collection is a token of individual interest and values, but it must submit to a broader cultural logic if it is to be reckoned valid. In this respect the herbarium of Rafinesque-the-autodidact (that is, the solitary-thinker) is especially appropriate for metaphorizing him into the legible commodity that the modern agent of knowledge must be in order to be viable. Rafinesque seems to have been at least intuitively aware of this dynamic, and yet—just as he so often demonstrated in other cases-that knowledge in and of itself was not sufficient to guarantee a positive outcome.

Jefferson was in some respects more socially imbedded in the scientific culture of the era—particularly the international scientific culture—-than was Rafinesque, and the president was a keen scientist in his own right. Conversant in many of the European intellectual trends of the day, Jefferson was a commentator on Cuvier and a friend and correspondent to Alexander von Humboldt. Near the end of the eighteenth century, Jefferson had had a famous intercontinental feud with Rafinesque's idol Buffon, based upon the latter's so-called theory of "American degeneracy," as articulated in volume V of his Histoire naturelle. Here Buffon rashly proposed that the fauna of the New World was stunted in relation to that of Europe and the other continents on account of malnutrition and poor climate, an idea that quickly took root in European intellectual society. The sting of this affront prompted the patriotic Jefferson to ceremoniously present the French naturalist with the pelt of a wild panther and a full-sized stuffed bull moose, a gesture that quelled the controversy once and for all. ${ }^{21}$

This episode in which global political rivalry is acted out under the cover of "disinterested science" is but one example of the figurative/symbolic reach of the new

21This episode is recounted in detail in, Dugatkin, Lee Alan. Mr. Jefferson and the Giant Moose: Natural History in Early America. University of Chicago Press, 2009. 
mode of inquiry. Arguably, the scientific impulse has never been as pure as we sometimes like to believe and early modern science could often be suprisingly overt in its mixture of agendas. The undeniably regulatory character of taxonomy and classification, especially, suited the colonial urge toward appropriation and control, and it is under this banner that some of science's most stark expressions of imperial impulse appear. "Captain Cook's Kangaroo," killed, collected, and shipped back to England, was the first discovery claimed and labeled by Joseph Banks and James Cook as their British ship Endeavor lay anchored off the coast of Australia in the summer of 1770 (Ritvo 2-3). The platypus, echidna and a whole continent would soon follow. A strikingly bare articulation of the equation between conquering and classifying is the petulant preface to Thomas Pennant's 1784 contribution to biological taxonomy, Arctic Zoology (Class I.

Quadrupeds), in which he laments,

... this work was designed as a sketch of the Zoology of North America. I thought I had a right to the attempt, at a time I had the honor of calling myself a fellow-subject with that respectable part of our former great empire; but when the fatal and humiliating hour arrived, which deprived Britain of power, strength and glory, I felt the mortification which must strike every individual in losing his little share in his boast of ruling over half of the New World (3-4)

Pennant's maudlin politico-scientific dejection is humorous by contemporary standards. But its flip side is the brutal eroticized control of colonial exploration, a force which gets sublimated and intellectualized into a metaphoric realm in the early natural sciences - though even this could sometimes find comically literal expression. For instance, one striking example of the early life science's "appetite" to subjugate the organic world through understanding is the preponderance of descriptions of newly discovered creatures climaxing with the specimen being killed, dissected, eaten, and its flavor analyzed. Ritvo has argued that in these earlier stages neither taxonomy nor 
science more generally was sufficiently distanced from competing systems of classification-those of butchers and farmers for instance (xii). It is therefore perhaps too much to expect that scientists would be entirely free from this partisan influence when evaluating animals. No wonder then that in the most thorough accounts the subject of analysis would have to be "put into the pot" for final assessment (Knight 54). In keeping with this distinctive degree of curiosity, Banks offers the final word on that mystery-being that would come to be called Cook's Kangaroo when, before shipping it to the motherland he pronounces it, "excellent food" (Ritvo 1). This physio-gustatory driveto-know could also extend beyond the realm of specimens strictly defined as organisms. In traveler Zacharias Conrad von Uffenback's catalog of the holdings of Hans Sloane (the collection that would eventually form the basis of the British Museum) one finds the jarring analysis of some showcased birds' nests: "it is said that the material is formed in the sea like succino and used by the birds to build their nests. But, judging from its taste, appearance and feeling, I took it for a gum or resin ..." (Pearce, Voice 112). Even Rafinesque engages in this sensory immersion with certain subjects of his analysis, for in Good Book's section on the newly classified cephalopod, Ocythoe, he wraps up with the casual mention of dispatching and eating the creature and assures his reader that it was "as good as usual with the octopus" (64).

In the case of the herbarium the issue was not one of world-domination, but rather self-expression. Between the beginning of 1832 and the end of 1833, Rafinesque published a serial in eight installments called Atlantic Journal and Friend of Knowledge. The journal's format—ranging in topic from botany, zoology, philology, architecture, agriculture, economics, education, even poetry, to name but a few, and stretched out over 
the course of months-was ideally suited to showcase the breadth of his mercurial mind, especially given that he was the sole contributor of its more than 150 pieces. But it demanded the support of a paying readership, something Rafinesque's contemporaries were unwilling to give. Shortly before the Atlantic lapsed into oblivion like similar projects before it, Rafinesque produced an extra of the sixth number just as he had also done with the third. But the eighty-page extra of the sixth stands out from the rest of the journal, to the point of being an autonomous work. Not only is this supposed addendum paginated separately (unlike that of three), its masthead deemphasizes the mother publication, replacing it with the large print title, Herbarium Rafinesquianum, the moniker by which it is generally referred within modern scholarship.

At the level of its written content, this Herbarium of Rafinesque is a compendium of ranging data, loosely unified under the concept of botany. It promises to be "Prodromus-pars prima": "a forerunner, first part," presumably of a series, a curious designation given that it is already positioned as one degree in the middle of a series (this sequence-within-a-sequence status has a mise-en-abyme quality not unfamiliar to readers of Rafinesque); however this work stands apart, bearing as little, if not less, relation to Rafinesque's later publications as it does to its parent text.

As a testament to Rafinesque in his capacity as historical scientist, the text becomes much more. Most obviously, it contains excerpts from a letter from Rafinesque to pioneering American botanist John Torrey, followed by a list of "Some Principles of Natural Classification" (11-12, 13-15). Both of these passages involve the mutability of species, which is to say, the conjecture that all living entities are potentially in a slow process of natural change into other types of entities, a theory eventually refined by 
Charles Darwin and unified under the blanket term "evolution." Though already briefly alluded to in prior work, the idea that, "Species and perhaps Genera also, are forming into organized beings by gradual deviations of shapes ... taking place in the lapse of time," was becoming a more central preoccupation for Rafinesque (11, emphasis and capitalization in original). And it was growing in importance to him such that the letter to Torrey closes with the injunction that should Rafinesque die before the theory can be fully articulated, "give me credit for it, and do it yourself upon the plan that I trace" (12).

The significance of Rafinesque's theory as it is limned in this letter and then later works has been the subject of much debate within the sciences. Does it constitute an early articulation of the theory of evolution, or is it merely another general observation concerning the protean nature of life and its forms such as those that stretch back to Aristotle? Darwin himself, in the essay, "An Historical Sketch of the Progress of Opinion on the Origin of Species" (an essay added as a preface to later editions of Origin following the hostility of its initial reception), cites Rafinesque as a precursor (13). However, Rafinesque's own current biographer and most studied champion, Charles Boewe, disagrees, pointing out that in his desperation to situate evolution within a recognizable intellectual continuum Darwin cites other thinkers in the same essay whom no modern scholar would hold up as true antecedents to his thought. Instead, Boewe believes Rafinesque to be ensconced in a growing and (true to form) evolving strand of thought that was well-anticipated by Erasmus Darwin (and others) but which would not reach maturity until Charles (Profiles 118). And yet, most of the positive recognition afforded Rafinesque in the modern day rests upon his supposed anticipation of that Copernican revolution in our understanding of species. 
Whether or not Rafinesque consciously deployed the herbarium as a metaphorical conceit with theoretical implications, Herbarium Rafinesquianum is just that. For under this central image the text becomes a vehicle to catalog his collection (especially its many "rare" holdings) complete with prices, to detail the aforementioned theory of species mutability, chronicle what he sees as critical developments in the science of classification, list his own "Principle Botanical Works and Discoveries" (including, in recursive-loop style, the very text at hand), reprint letters to other scientists, list the many people and places that are represented by his specimens, and advertise his other works, already written or soon to be so. Herbarium Rafinesquianum also establishes a significant equivalence when Rafinesque announces that in accepting new plant specimens, the contributions, "will be duly valued, and the equivalent paid in plants asked, or books, or money" (10). This is a literal marketplace of knowledge, an economy in which articles and artifacts, the production and paraphernalia of learning (specimens, books), circulate and function undifferentiated from capital-proper such that they are essentially interchangeable.

The Herbarium Rafinesquianum could be seen as the textual complement to the concrete collection that is Rafinesque's herbarium, and both contribute to a figurative composite of Rafinesque the person—or more accurately the subject. In the case of the text this includes a window into Rafinesque's most pressing thoughts in the form of his evolutionary theory and his urgent pleas to Torrey to bring these to maturity. The many mentions of contributors and correspondents gives some sense of the social/professional milieu to which the autodidact felt, accurately or not, he belonged (the longest continuous list appearing on pages 4-5). The pamphlet also gestures toward the system of values that 
Rafinesque held, about which more will be said in later chapters, one wherein knowledge is not merely conceptualized as capital, but may even function as a form thereof, thereby equalizing the influence of economy-proper and knowledge-economy in the continued life of the subject. On the first page, just below the title and above the Herbarium's publishing information, Rafinesque announces, "THE LABOR OF A WHOLE LIFE!” and this could serve as a declaration of the broad existential implications of both the textual and the concrete herbarium.

Some of this significance may have dawned on Jefferson when the two had exchanged letters those many years before. Both Rafinesque and Jefferson were enthusiastic collectors. Jefferson had a fervent passion for books, at one time possessing the largest private library in the U.S. (what would eventually become the basis for the restored Library of Congress after the original collection was burned by the British in the War of 1812), and Rafinesque many times throughout the years of their correspondence sent Jefferson clippings and seeds to increase the president's botanical collection. The drive to curate was a common one between these men (indeed, it was a common one to the day's educated generally), as was the obsessive valuation placed upon systematic aggregations of objects, particular those deemed of scientific worth. And the monetary value of such collections was often significant. It is certainly no surprise that libraries could fetch vast sums (Congress had paid Jefferson nearly $\$ 25,000$ for his collection of 6,487 books in 1815), but even herbaria, such as the one Rafinesque was dangling as enticement, could command high prices. In 1816 the American Philosophical Society paid \$504 for just a portion of Henry Muhlenberg's herbarium (Mears 156). Muhlenberg was a sometime contributor of plants to Rafinesque - as well as a critic of his botanical 
taxonomy. An 1842 auction at Sotheby's featured portions of the celebrated herbarium of Aylmer Bourke Lambert broken into smaller lots, a collection that contained a number of prized American plants that had been gathered on the Lewis and Clark expedition; though the individual lots went for seemingly little (5-25 British pounds apiece), one of the purchasers, Edward Tuckerman of Massachusetts, later claimed to have made the purchase as "a venture," implying that he expected significant future returns on his investment (Teece 17).

The monetary value of herbaria obviously varies based on issues such as condition and/or rarity of specimens, but this is only one facet of its assessment. Like other entities wherein knowledge-value and commodity-value overlap or even intersect, the herbarium occupies a strange status as bearer of economic worth because to a great extent its worth is judged otherwise. Although there is a history of herbaria being bought and sold on the open market, there is also a tradition of botanists and collectors bequeathing them to others still at work in the field or donating them to institutions such as schools or museums to be the basis of ongoing public collections. This has been the case with many notable herbaria, such as the one that pioneering American botanist (as well as bitter critic—and even personal enemy—of Rafinesque) Asa Gray inherited then donated to become the nucleus of Harvard's collection. Like with nearly any collection that is intended to edify or participate in an ongoing archive or field of study, as many herbaria were, there is always some inherent illogic in terms of ownership: though the specimens themselves can perhaps be understood as personal possessions of a sort, and possessions with a monetary worth, as articles of actionable knowledge they are everaccountable to the relevant scholarly community who will be implicitly charged with 
assessing their ongoing value as knowledge. A 1952 Science article on institutional herbaria admits, “... when an herbarium ceases to be a private one and when it becomes 'public' or 'institutional' is not always easily decided" (Gordon 218). Though this refers to historical determination, the article already (well in advance of any guiding principle of postmodern undecidability) hints at the conceptual ambiguity between the two senses. For the purpose of sorting and studying the complex floral taxa an herbarium functions not unlike a library, and for any particular herbarium to be botanically valuable in this capacity it must be attested so by a community qualified to judge, thus its status as a strictly private collection is always to some degree mitigated. Furthermore, in terms of worth, there has been at least some debate about the value and validity of the institution of herbaria to the field of botany when viewed from a wider perspective. Humboldt, in keeping with the broad aims of Naturphilosphie, was the pioneer of a much more holistic approach for apprehending flora, urging that plants ideally be studied in their native contexts and alongside their natural neighbors, "in contrast to the artificial isolates on which herbarium practice was based" (Cunningham 181). In this respect, even the logical basis for the private herbarium belongs to an ongoing public discussion: as a coherent and valuable collection it is a cultural — as much as an individual—product, appearances to the contrary notwithstanding.

When Benjamin calls collecting the "primal phenomenon of study," he is not merely being figurative, but rather is identifying a historical correlation that was firmly established by Rafinesque's day (Arcades 210). As John Elsner and Roger Cardinal observe in the introduction to Cultures of Collecting, the physical collection becomes a focal point toward which the taxonomic impulses of science and language are extended 
into space: "if classification is the mirror of collective humanity's thoughts and perceptions, then collecting is its material embodiment. Collecting is thus the narrative of how human beings have striven to accommodate, to appropriate and to extend the taxonomies and systems of knowledge they have inherited" (2). Every taxonomic ordering posits a theory of perception concerning the experiential realm and its structure, and every collection is a physical demonstration of just such a theory. Thus collection is theory made matter, the universal expressed in the individual and its aggregates. And just as science is ideology, and ideology is both super-structural as well as personal, the collection marks one point at which the theoretical edifice and the individual merge.

Foucault, throughout his writings, has stressed the importance of the various analogies, metaphors and other discursive mechanisms that determine the ways, "in which the individual appears and acts as subject of learning" (Reader 335). Inasmuch as knowledge is a collection, and the individual understood as such—which is to say, the individual as a modern subject comprised of various particular ideological investmentsis a kind of collector, determined largely by/in his or her store of knowledge, there is already a profound conceptual link between the mind and the cabinet. This link is also a concrete one, as knowledge more and more comes to be equated with the acquisitive impulses of the ideal individual as imagined by the emerging bourgeois culture. As Carol Yoon, in her recent book on taxonomy, Naming Nature, asserts of the culture that grew up around early modern science, "natural history collections eventually became so commonplace that any respectable family home could be expected to boast its own display of nature's wonders" (34-5). Susan Pearce, professor of museum studies and theorist of collecting, observes of that moment midway between the births of Kant, 
Jacotot, and Rafinesque, "by the middle of the [eighteenth] century, it is tempting to think that almost every self-respecting nobleman or woman, doctor, merchant, or indeed anyone with a sufficient urge to better themselves and the wherewithal to do so, had equipped their home with some sort of gallery or cabinet of curiosities" (Voice 110).

The telling language used here—Yoon's “respectable family," and Pearce: "anyone with a sufficient urge to better themselves"-hints at a function of the collection that exceeds the mere demonstration of scientific principles and instead points toward its role as a newly emerging strategy of bourgeois self-fashioning. The kinship between the "extended self which collections represent," and the mind which Locke already long before the day of Rafinesque had called the "storehouse of our ideas," bears traces of a new metaphysics of knowledge, one in which classifying and knowing render the logic of nature in an orderly, accessible, and demonstrable fashion (Pearce Museums 63; Locke 86). Collecting localizes, or even personalizes this demonstration. Whether it is the gallery of the wealthy connoisseur of fine artworks, the hipster's record collection, or the undifferentiated masses that crowd the hoarder's hovel, these collections seem to speak in the voice of the collector, and what is more, "on closer scrutiny he [the collector] proves to be speaking only about himself" (Benjamin Illuminations 59). In modernity, the collection, "has been seen as at the heart of the private person, helping to create a unique persona and existing in a privileged position in relation to other activities ..." (Pearce Practice 52).

However, like with the broader process of acquiring knowledge, the collectionas a metaphor for legitimate knowledge, and also as a metonymic signifier of the knower — can be neither too private, nor too unique without lapsing into the perversely 
idiosyncratic or even the fetishistic. This especially holds true, of course, for the systematic collection, which, like scientific knowledge in general, is validated in large part by securing the acceptance of the community. In Rafinesque's time, as the above quotations from Yoon and Pearce attest, the personal and systematic collections were not always so clearly distinct from one another. And any such distinction that may historically be said to exist disappears when one considers that Rafinesque first and foremost considered himself a man of science, his personality predicated upon being its full time agent and representative. Pearce asserts that, "systematic collecting ... has in all its different manifestations in the various disciplines been accorded an intellectual primacy, which seems to derive from its apparent capacity to demonstrate understanding rather than feeling, and so to extend our control of the world" (Museums 84). This "apparent capacity" casts an illusory sheen over the operation of systematic collecting, concealing the fact that understanding and feeling, the intellectual and the affective, are often intermixed. And, perhaps ironically, in an intellectual age founded on the awakening hope for "control of the world" through classification, as well as for the powers of the individual-as-collector, the systematic collection can come to be a token of an intellectual world beyond any one individual's control.

Shapin has observed that, "Science, like finance, is a credit-economy: there are activities in which, if you subtract credibility, there is just no product left—neither a currency nor a body of scientific knowledge" (Never Pure 19). On broad reflection, this is true of knowledge and its valuation in general when it is applied to subjectivity (the locus of the credibility to which Shapin refers). Knowledge demands endorsement for validation. Rafinesque had faith—perhaps deep faith—in the intrinsic worth of his 
herbarium. But the requirement of securing credibility — which is to say, the necessity for creating assent (or at least its appearance) within a recognized community-was not lost on Rafinesque. Throughout their later correspondence, Rafinesque bombards Jefferson with documents, heralding his extensive qualifications, lists of honors he has received, societies to which he belongs, all sent in hopes that Jefferson might circulate them among the university trustees. He details "Testimonials in favor of Prof C. S. Rafinesque," and in a move that almost seems to anticipate the internet-age exhibitionism of social networking, the desperate scientist appends to his letters to Jefferson long litanies of notable to semi-notable figures whom "C. S. Rafinesque reckons in the Number of his friends and Correspondents" (Betts 374). Among these are British naturalist William Swainson, Swiss Botanist Augustin DeCandolle, American botanist John Torrey, and, heading the list, Cuvier himself (John James Audubon, who was not only a sometime host to Rafinesque, but had even written on him in a now-famous journal entry entitled, "The Eccentric Naturalist," had yet to make a name for himself, so perhaps for this reason he is omitted from the list).

To impress Jefferson and the University of Virginia trustees, Rafinesque also repeatedly emphasizes what the university stands to gain with his professorship:

Sketch of Prof. Rafinesque's Collections. His Library consists in about 1000 Select Volumes. on Phisics, Chemistry, Natural history, Botany, Mineralogy Philosophy, Travels \& Miscellaneous Works, in Latin, English, french, Italian \&c ... His Natural Collection consist in about 2000 Specimens of Shells, fossil remains, Minerals, Insects, Polyps \& other zoological Subjects, mostly American. (Betts 375)

Rafinesque stresses the size of the collections but also their qualitative character, and in this they are reflective of the character and mind of their owner: the books are polyglot, demonstrating a breadth of focus, even cosmopolitan, while the material pieces reflect 
intensive fieldwork conducted in the American frontier. In this respect the collections could be regarded as two halves of a dichotomous whole, the books forming the conceptual side, the natural collection representing the concrete, or practical. Midway between these there is the collection that most vividly represents Rafinesque's specific professional and intellectual efforts: "His Herbarium Contains already about 12000 Specimens, belonging to about 2000 American species \& 1000 European or exotic Species, and is increasing every year" (Betts 375). Like the collector, the herbarium is both a significant entity in its own right, a product of years of effort, and also a work in progress, under constant construction to accommodate the advances in the field.

In response Jefferson promises to, "take care to lay your letter before the board in due time," but there is no evidence that Rafinesque was ever brought to the attention of the university's trustees (Betts 372, and footnote). Despite Jefferson's further assurance that, "no doubt it [the letter] will command all the consideration which your well known qualifications entitle it to," Rafinesque's biographer, Warren, has speculated that quite to the contrary, “... most probably, confidential criticism—some serious, and some meanspirited and malicious—-had reached Jefferson's ears." Warren concludes that to Jefferson's reckoning, "however learned and brilliant Rafinesque was, he was still too much of a risk, an unpredictable burden" (66).

When Rafinesque reluctantly comes to the bitter conclusion that his "liberal offer was not accepted" (Betts 376) by either Jefferson or the trustees, he resorts to the tactic of implied ultimatum. Nearing the last of their exchange, Rafinesque suggestively urges Jefferson by hinting, "I am rather anxious to hear something precise concerning the University of Virginia, and my prospects relating thereto, since I have some expectation 
to be offered the Presidency of the Cumberland College of Nashville and the Western College of Kentucky seated at Hopkinsville"22 (Betts 375). Along with the collector, the herbarium and other collections are on the brink of slipping away from Jefferson and his trustees, and in his next letter Rafinesque warns that, "meantime I am on the point of endowing Transylvania University with all my past Collections amounting to about 30000 specimens of plants, animals \& minerals, as soon as the Trustees will be able to enter into some needful arrangements in the Subject, in which case I shall not be able to renew my offer to the Univy of Virg[inia] when it might be convenient to accept it" (Betts 376-7).

To reiterate, one of the reasons that the collection is a better model than capital for describing personal knowledge is that the subject's investment in it far exceeds that of the public, the latter acting largely in the role of arbiter and assessor. Like the collection, knowledge is prey to fetishization, and in such cases it is the public that will pronounce judgment on both the value of the assemblage and its valuation by the collector. Shortly before he died Rafinesque wrote in a letter to John Torrey that he planned to settle in Illinois where he and an associate had been planning to establishing a university; Rafinesque stakes his migration on what seems an unlikely swap, "I shall again botanize in the West \& mean to settle there between $1845 \& 1850$ giving all my Collections and Books to [the new university], receiving Land for it" (Boewe Profiles 97). Obsession over his collections, and particularly the botanical collection that was his herbarium, sometimes seems to amount to a fetishizing attachment; and much like Rafinesque's

22The viability of these scenarios seems highly unlikely, however it is possible that Rafinesque-in a moment of self-delusion-sincerely believed them possible. The day before he penned this letter Rafinesque sent another to Charles Wilkin Short, a trustee of Western College, mentioning that a Mr. James Campbell had suggested Rafinesque should be appointed head of the school. Apparently Dr. Short was unimpressed with this suggestion, for it went nowhere (Boewe 2003, 59, footnote). 
endless hunger for new knowledge, herbaria seemed to trigger a strange acquisitive desire in him. In 1831, long after his attempts to win favor with Jefferson and just before the publication of Herbarium Rafinesquianum, Rafinesque's generous patron, Zaccheus Collins, died. Curiously, upon his passing, Rafinesque produced a (seemingly trumped up) bill demanding $\$ 340$ in recompense for "Natural Objects" allegedly provided to Collins (Boewe 32-3). In order to silence the pestering Rafinesque, the executors of Collins' estate reluctantly offered Rafinesque the deceased's herbarium, an object whose value was estimated at $\$ 150$ based upon offers made by various parties, including wellknown botanist and pharmacist, Elias Durand, whose own herbarium was eventually estimated at around 10,000 specimens. Rafinesque gleefully accepted the offer and absorbed Collins' plant collection into his own.

Jefferson, on the other hand, could not be bought off so easily. And in spite of his many attempts to persuade, his many promises of collected wonders, and his eventual threats to dispose of the collections elsewhere, Rafinesque never was offered a position at the University of Virginia. The tone of the letters shows a wearied Jefferson retreating steadily into silence. Eventually, whatever discussion can be said to have existed between the two men comes to an abrupt end when Jefferson brusquely announces to Rafinesque that in his old age he has no more desire or ability to keep up correspondence.

The realm of modern collecting knows no shortage of idiosyncratic acquisitions, obsessive desires made manifest in the form of collections. Pearce has commented of the fetishistic assemblage that,

... these collections are detached from any context, they are removed from the sphere of actual social relationships with all the tensions, efforts of understanding and acts of persuasion which these imply. This detachment is, indeed, a very substantial part of the attraction for their collectors, who use them to create a 
private universe, but its sterility gives to the material that peculiarly lifeless quality which all curators recognize with a sinking heart. (82)

Radical idiosyncrasy and detachment are anathema to the systematic collection, which in spite of its pretensions to intrinsic value or context-free worth (that is, scientific "truth," generally), must also circulate in "a sphere of actual social relationships with all the tensions, efforts of understanding and acts of persuasion which these imply."

After Rafinesque's death, the prized herbarium — which the collector at one time had boasted contained over 50,000 specimens and was worth $\$ 1,800$ — was purchased by Elias Durand for a mere $\$ 45$, and supposedly then only to get at the specimens previously belonging to Collins. Given the metonymic equation between collector and collection, if there is some type of theory to be posited concerning the idiosyncratic autodidactic collection and its perceived worth, it is inaugurated by Durand in a letter explaining his acquisition of the herbarium, which by that time had fallen into disrepair, ill-cared-for, decrepit, and rat-eaten:

Rafinesque's own specimens were trash, incomplete, good for nothing; He was the worst collector I ever knew ... There I saw the wonders he boasted of - the series of what he called his very rare specimens at 25 cents apiece, and a very small piece too; a disfigured flower and a few leaves, not spreading but more or less reflexed and rumpled ... his new genera and species from the ApalachMountains (a locality he loved above all) which were simply exotic plants well known, but disfigured and with addition of parts that did not belong to them ... But enough about that poor insane-Requiescat in pace! (Boewe 180-1)

Given the well-known value Jefferson put upon education, as a force for producing viable subjects within a new democracy, and thus as an essentially public and political force, it is small wonder that Rafinesque was left to languish. The quixotic autodidact and Renaissance man, was-like the herbarium and other collections and 
specimens he had tried unsuccessfully to wield as currency in exchange for a position-a thing of unknown value. In spite of Rafinesque's passion for knowledge and learning, a passion which drove him to barter his most prized possessions, Jefferson was unwilling to gamble on these mysterious stakes. Perhaps Rafinesque sensed this wariness born of uncertainty, for in a letter of 1821, amidst his desperate appeals for a position, he pleadingly tells Jefferson, "I hope you will excuse whatever may be too personal, and bold in this letter. I write under some sharp feelings; and wish you could know me thoroughly" (Betts 373). 


\section{ARTHROLOGY: TAXONOMY, CATEGORY, VALIDITY AND THE ARCHIVE}

In his 1964 work, Elements of Semiology, Roland Barthes dramatically announces the necessity for a new "science":

It follows that the future task of semiology is far less to establish lexicons of objects than to rediscover the articulations which men impose on reality; looking into the distant and perhaps ideal future, we might say that semiology and taxonomy, although they are not yet born, are perhaps meant to be merged into a new science, arthrology, namely the science of apportionment. (57)

The precise dimensions and prerogatives of this new field remain unexplained, and the brief mention serves primarily to give hints of the post-structuralist bent that haunts Barthes' immediate future. In spite of this text's apparent pretentions to science (evident chiefly in its use of terminology), the line between what we would consider the scientific and the rhetorical/semiotic is blurred at significant moments throughout. Here the excess of the signifier is already taking shape as Barthes elsewhere in the book muses over a series of metalanguages, each sequentially swallowing the next (including one to subsume the metalanguage which his own text is positing) in an imagined analytic gesture of potentially endless deferral (93).

One can argue that the two notions—a semiological taxonomy and the limitless constructions of new metalanguages of analysis-are intimately connected in certain important respects, and the mention of the two within the same project is revealing. Language, whether "natural" or artificial, imposes a taxonomic order, and while this 
order is necessary and thus inherently binding and limiting — even to the degree of structuring thought—nonetheless, the idea of constructed categories (for instance, those that comprise the basis of an artificial language of analysis) implies a certain degree of fluidity, suggesting perhaps a point of intervention suited for aesthetic gesture-even experiment.

During Rafinesque's time there was a remarkable amount of change within scientific taxonomy, though whether this flux is better characterized as play or progress likely depends upon a combination of definition and perspective. ${ }^{23}$ Arguably, Barthes' conjecture assumes a unity to the practice of early taxonomy that misleadingly marks it as monolithic in approach and philosophy to the extent that his "new science" is nothing but one more formalization, another reformulation and renaming of the forces and tensions already present during the nativity of modern systematics, and which haunt the field to this day. ${ }^{24}$ Rafinesque participated in this nativity, and contributed to its tensions. But the nature and legacy of his involvement is complicated: too contentious to simply be regarded as a "founding father" of the science, his contribution continues to confound even within the rather limited perspective of the historical development of the discipline. Rafinesque is alienated enough from the mainstream of the science that a history of taxonomy may easily overlook him, and yet his name permeates the early record of systematics, not least of all in the technical appellations of New World species. In this respect he could perhaps be theorized as the source of an essential parasitic noise as

23For an entertaining and accessible account of this period of flux, see Ritvo, Harriet. The Platypus and the Mermaid: And Other Figments of the Classifying Imagination. Cambridge: Harvard UP, 1998. For a look into some of the philosophical complexities, see, Dupre, John. Humans and Other Animals. Oxford: Oxford UP, 2002.

24For an excellent overview of some of the contemporary debates that still surround taxonomic issues, see, Wilson, Robert A. ed. Species: New Interdisciplinary Papers. Cambridge: MIT Press, 1999. 
explained by Michel Serres: a productive participant in a process that—on account of the integrity of its own self-definition—must deny his contribution. ${ }^{25}$ He thus becomes the inescapable interference that all would prefer to ignore. As a case study, Rafinesque in his role as taxonomist illustrates not merely the ways that Jacotot's "stultification" functions (that is to say, the process whereby knowledge becomes organized as an orthodoxy reflecting a power structure involving consensus and enforcement), ${ }^{26}$ but also the tacit concern that the archive itself is vulnerable to corruption from the renegade researcher. Implicit in the story of the fall of Jacotot's Universal Education, and in the cultural attitude to autodidaxy in general, is a worry not for but rather about the autodidact, a concern that this egregious subject of flawed learning may in turn corrupt the fund of knowledge with his/her unregulated meddling. This fear betrays the unspoken assumption that knowledge is public to the extent of its own risk, and that rather than being a static or stable value, is in constant process of creation and revision, a trait dependent upon the influence and input of its agents. But while the overt mythology of modern knowledge as it applies to the individual learner promises an open domain of free exercise and unrestrained engagement, Rafinesque's forays into taxonomy reveal a far more guarded structure, an archive that is malleable but only according to increasingly complicated rules of engagement.

Warren says that, "the era between the publication of Linnaeus' Systema Naturae [1735] and Darwin's Origin of Species [1859], two of the greatest landmarks in the history of biology, was one of identifying and classifying organisms, and the greatest of

25"It was only a noise, but it was also a message, a bit of information producing panic: an interruption, a corruption, a rupture of information. Was the noise really a message? Wasn't it, rather, static, a parasite? A parasite who has the last word, who produces disorder and who generates a different order." (3).

26Ranciere 76-7. 
all identifiers of species at that time was Constantine Samuel Rafinesque” (156). Perhaps to account for the lack of recognition both in his own time and in the present regarding this accomplishment, Warren then goes on to characteristically dismiss his subject on alltoo familiar grounds: "... usually, scientists had some background based upon formal education and training, but this Rafinesque lacked, as he did scholarly caution, and so he might be considered a talented, full-time amateur, learning as he went along.

Extraordinarily well-read, he must have been aware of virtually everything that was going on at the time in science and natural history" (156). Rafinesque's awareness of the scientific trends of his day was indeed legendary (though by no means total, as we shall see), and one facet of this was his knowledge that, although perhaps "the greatest of all identifiers of species" as Warren asserts, he was not the era's greatest naturalist-classifier. The strong contender for this honor was Georges Cuvier, ${ }^{27}$ the man who, among other accomplishments, augmented the Linnaean system with the necessary additional degree of "phylum." Rafinesque seems to have deferred to this elder scientist's authority as a matter of course, though his secondary status in systematics did not prevent him from vigorously theorizing the field. In fact, in terms of his taxonomic contributions, Rafinesque was especially concerned to maintain a positive working relationship with Cuvier; one could perhaps even venture from appearances that he wished to secure the French scientist's professional blessing, and toward this end he expended much effort. Since the two men never met face to face, the professional bond between them was secured, like so many of the day, by long-distance correspondence. Rafinesque eagerly

27For a general sketch of Cuvier, see: Outram, Dorinda. Georges Cuvier: Vocation, Science and Authority in Post-Revolutionary France. Manchester: Manchester UP, 1984. More relevant to this study is Foucault's extensive discussion of Cuvier in his Order of Things, wherein we find this appraisal of the scientist's episteme-forming importance: "from Cuvier onward, it is life in its non-perceptible, purely functional aspect that provides the basis for the exterior possibility of classification ... before, the living being was a locality of natural classification; now, the fact of being classifiable is a property of the living being" (268). 
courted communication with Cuvier, even sharing his specimens with the French luminary, shipping samples of various Sicilian fishes collected while the junior scientist was conducting his own researches in Italy (Warren 78).

The notion of correspondence is an apt one in this context. When regarded broadly, taking into account its varied definitions, the term seems to be an index of many of the relevant historical and circumstantial conditions surrounding Rafinesque's engagement with systematics. On the one hand correspondence straightforwardly designates the written communication between Rafinesque and Cuvier, an exchange depicting a lopsided admiration and often uncomfortable professional affiliation. But even at this literal level, there are multiple layers. Peter Sloterdijk begins his essay, "Rules for the Human Zoo," by paraphrasing Sartre's comment that "books ... are thick letters to friends" (12). Sloterdijk concludes from this that, "humanism is in the narrowest and widest senses a consequence of literacy." Through this lens Rafinesque's correspondence with Cuvier literalizes Sartre and Sloterdijk's theoretical conceit but also preserves its chief article of conjecture: the creation and confirmation of an intellectual continuum secured through the written word, which is to say, a social/textual network for the transmission of ideas through space and time. Under this rubric of "thick letters to friends," the notion of correspondence has yet another meaning, for Rafinesque in his capacity as pioneering scientist could be said to correspond with his naturalist "peers"; in other words, he parallels those also laboring in the infant field of taxonomy and natural science domestically and abroad, thus participating — with varying degrees of intention and cognizance-in a productive post-Enlightenment zeitgeist devoted to the reordering of knowledge and its subjects. This reordering process (and the zeitgeist that facilitates 
it) is just the kind of socio-textual project Sloterdijk limns in his essay, though adherents and practitioners during its day would surely take issue with it being characterized as essentially literary in nature.

Within the specific horizon of knowledge and its workings, correspondence also hints at the notion of a so-called "correspondence theory of truth," one of the fundamental precepts of traditional natural taxonomy as it strives to discover and articulate the supposed real-world analogies and affiliations that will give its categories their coherence and veracity. ${ }^{28}$ But conversely, the word itself cannot help but evoke a lasting post-Enlightenment counter-tradition of antirationalist (or perhaps more accurately para- or even suprarationalist) thinking, beginning with Swedenborg and continuing through Fourier, Baudelaire, Proust, Benjamin and Jack Spicer (to name but a few) ${ }^{29}$ Through this lens correspondence is a logic—and thus arguably a kind of taxonomy—of its own, a system of intuiting the synaesthetic filiations between entities oftentimes seemingly unrelated according to the more positivist literalism of domesticated reason. This parallel tradition of discovering analogies—whether exercised as mysticism or modernism—not only acknowledges but even welcomes the otherwise problematic possibility of aesthetic and linguistic resemblances and resonances, types of likeness that either escape scientific rationality as irrelevant or even vex it as erroneous and misleading. Finally, the term implies the unspoken assumption of mutual

28See David Knight's discussion of the stakes of natural versus artificial classification in, Ordering Nature, 21-3. For a more general discussion of the correspondence theory of truth, see, Kirkham, Richard L. Theories of Truth: A Critical Introduction. Boston: MIT Press, 1995. 119-140.

29This strain of thought is significant as one expression of earlier taxonomic thinking-see Foucault's chapter, "Representing," Order of Things, 46-77-and one with a significant half-life in modern literature on account of its profound implications for language. For an account of one strand of this legacy, see, Wilkinson, Lynn R. The Dream of an Absolute Language: Emanuel Swedenborg and French Literary Culture. Albany: State University of New York Press, 1992. 
correspondence between the knower and the archive — that is, between the one who knows and that which is to be known. Just as knowledge produces individuals (subjects), so too must knowledge itself be produced and organized, and this assumes a more or less stable degree of reflection and equivalence (what is commonly termed "accuracy") between the content of the archive and the knowledge of the individual. In this respect, archive and knower are codependent, and just as each is presumed a reflection of the other, each is also to some degree vulnerable to the other.

This full range of meanings-from the literal sense of written interpersonal communication to the more nebulous conceptual or relational equivalence between entities-applies when one asks what the term "to correspond" means with respect to Rafinesque. In one of his letters to Jefferson, Rafinesque seems to tip his hand in terms of how he feels about one sense of the word (communication with his taxonomic mentor), for topping the list of his "friends and Correspondents" is none other than Cuvier himself (Betts 375). The reality is that even as Cuvier was entertaining Rafinesque's letters and accepting his specimens he was criticizing the naturalist for his discovery and classification of "purely imaginary" fish. This accusation, which is quoted by Rafinesque's (and Cuvier's) contemporary William Swainson as excessive and misguided, and which is in turn cited in Ellsworth Call's reverent 1895 biography of the autodidact-scientist, is telling by virtue of its endurance and chain of transmission as a point of contention: Rafinesque's status among (that is, his correspondence to) early $19^{\text {th }}$ century taxonomists is and was troubled, uncertain, and no amount of argumentative wrangling can change this fact any more than stamping an impersonal professional correspondent with the label of "friend" can make him so, regardless of how many thick 
letters one has addressed to him (Call 76). ${ }^{30}$

Rafinesque begins his 1824 work, Ancient History or Annals of Kentucky, with a dedication to "Alexander de Humboldt" (or in the more common Germanic form von Humboldt), naturalist, explorer, botanist, Romantic philosopher, and—along with his brother, Wilhelm - one of the chief architects of the modern university. This work is an attempt by Rafinesque to situate Kentucky within the "universal history" of humanity, and as such it belongs to that loose but generally recognizable strain of early modern historical scholarship_-one notable less for its rigor than for its broadness of vision (like many of its genre, Annals unreflectively tries to square its account with the biblical timeline). It is certainly appropriate that Rafinesque would want to recognize Humboldt, pioneer of modern botany, a fellow scholar-traveler (a brother theoros, so to speak) and another European with a fascination for indigenous American cultures, a student of their ways and languages, as well as a keen observer of their natural environments of habitation. It is also fitting that Rafinesque would be appreciative of Humboldt's varied interests and achievements, recognizing in him a like-minded renaissance man with a similarly voracious appetite for knowledge and broadness of vision for how it might be applied.

To the modern reader, however, the dedication can also perhaps be regarded somewhat ironically on account of the two men's striking differences, differences which in many respects speak to Rafinesque's alienation as a thinker and agent of the time's scientific learning. Alexander von Humboldt's pivotal role in refashioning the modern

30Cuvier's criticism of Rafinesque's fieldwork seems to contrast markedly with what he was telling the young taxonomist directly. Edwin Betts reprints a letter from Rafinesque to Jefferson in which the former quotes a note he received from Cuvier: "I have been much pleased to find in your works many new animals, and some which I thought new, although you had detected them before me. I have also found that you have noticed before me many generic and subgeneric differences" (Betts 375). This admission from Cuvier is significant, presuming that Rafinesque has reported it honestly and accurately. 
university—an intellectual environment Rafinesque seemed singularly unable to work within, when not outright hostile to-is now all the more apparent given that the major European institution he helped imagine into existence has since been renamed in his and his brother Wilhelm's honor. Against Rafinesque's standing as a man of science, and in particular as a botanist, the dedicatory gesture rings with a certain timbre of pathos. Rafinesque did not correspond to or with Humboldt, in either letter or kind, though Humboldt was to become the exemplar against which Rafinesque (or any other theorist/scientist of the time) would be judged. Humboldt was in some respects the antithesis of Rafinesque, though he was arguably exactly what Rafinesque would have liked to have been, and often tried to pass himself off as: famous, well-respected, intimately connected to many of the philosophical, scientific, and artistic luminaries of his day. ${ }^{31}$

The irony of the dedication seems all the more sharp when the apparent differences are regarded against the many spiritual affinities that could and perhaps ideally should have obtained between the two men (at least as recognizable public figures, given that the two were not personally acquainted). Humboldt was part of a distinctive intellectual milieu—many of the day's premier writers and exchangers of those "thick letters"-whose concerns seem directly relevant to Rafinesque's vocation as a scientist and standing as a thinker; the absence of any association perhaps again speaks to Rafinesque's isolation from certain significant intellectual communities of his time. Along with the emerging sciences and Naturphilosophie, one of Humboldt's preoccupations was finding adequate channels for individual and institutional expression

31His legacy is also in some respects an inversion of Rafinesque's: whereas the latter remains mysterious and largely "unclaimed," Humboldt's celebrated status invites constant "appropriation." For a look at this, see, Rupke, Nicolaas A. Alexander von Humboldt: A Metabiography. Chicago: University of Chicago Press, 2008. 
of the new orientation toward knowledge, a goal he pursued in intimate company with other early $19^{\text {th }}$ century visionaries and philosophers such as Schelling, Fichte, Steffens, Schleiermacher, Wolf, Coleridge, Davy, and others. The range of these thinkers' interests was quite literally encyclopedic and forms an interesting merger between the broad and nowadays often separated realms of the aesthetic, the scientific, and-with their emphasis on knowledge in the form of educational policy—even the political. This intellectual climate was immensely productive, generating not only many significant theories of education, philosophies of knowledge, and visions for what the modern university should look like, but also at least one concrete institution of learning — though professor and theorist of literature and science, Elinor Shaffer, maintains that there was a direct influence from these thinkers on the 1820's founders of the progressive London College (40). Thus this number might deservedly be doubled.

In many respects the accomplishments of the Humboldts and of their intellectual correspondents represent the culmination of Enlightenment hope in the power of knowledge as seen through the prism of Romantic idealism. Shaffer comments of this intellectual continuum and its attempts at reforming education specifically, "most essential of all was Kant's Streit der Fakultaten (Conflict of the Faculties)" and through this text, "the strong continuity between the Enlightenment and Romanticism can be seen in the contribution of Kant to the reform programme of (Wilhelm) Humboldt" (39). Outside of Germany, Kant's thoughts on the topic were having a similarly inspiring effect. Coleridge, who J.A.V. Chapple, in his survey of Romanticism and science, claims, "walked with physical scientists as an equal in understanding, if not in authority," regarded the radically changing status of knowledge and its agents and pledged his 
commitment to a necessary secular cultural intelligentsia, christening them the "clerisy" (11). ${ }^{32}$ Eventually, these Romantic (and-at least in derivation-Kantian) ideas on knowledge, education and the individual found eloquent expression domestically, in Emerson's celebrated 1837 lecture on education, "The American Scholar," and later in his lecture, "Education," with its numerous variations. For an overview of how this vision of education might look, one need only glance toward the nearest institution of higher learning, since the elaborated Kantian program of the university has essentially endured as the structure familiarly recognized as the contemporary university. Bill Readings stresses this point in his positioning of the current conversation on university reform with respect to the "founding documents" of the Kantian/Humboldtian academy: "most projects for the University of the twenty-first century bear a striking resemblance to the University projects of the nineteenth century. The reason it is necessary to reread Humboldt, Schiller, Schleiermacher, Fichte, and Kant is that the vast majority of contemporary 'solutions' to the crisis on the University are, in fact, no more than restatements of Humboldt or Newman" (62). Not only were these thinkers instrumental in determining the shape of the modern academy, they were just as prescient in defining its endemic problems.

The Kantian continuum did not just establish the terms of discussion for the structure of the new academy but also extended into the internal composition of the fields that would comprise it. With respect to modernity's intellectual correspondence (and correspondents), there are arguably no thicker letters to friends than Kant's critiques. For the burgeoning natural philosophy (what we would come to call science), Critique of

32This term/concept was a coinage based upon Kant's notion of the Klerisei, which Shaffer explains as, "a band of secular individuals who within the church of reason would be analogous to the clergy in established churches," Cunningham, Andrew and Nicholas Jardine, eds. Romanticism and the Sciences. Cambridge: Cambridge UP, 1990. Page 40. 
Judgment cast an inescapable shadow over the validity of the entire project, since its questioning of the "purposiveness of nature" (the presence of some overarching scheme of organization that is discernible to human intellection) threatened the validity of the entire enterprise. In the introduction Kant asserts as a basic condition that, "general laws of nature have their foundation in our intellect which prescribes them to nature" (5:180). As James L. Larson summarizes in his study, Interpreting Nature: The Science of Living Form from Linnaeus to Kant, according to Kant's critique, "the idea of a system of nature did not follow from experience but constituted a presupposition that naturalists applied to experience and, in a sense, rediscovered there" (173). Consequently, the doubt that such laws or system actually exist in nature becomes a burden for the scientific mind seeking to discover and articulate valid principles of organization, and this is acute in the science of systematics, given that the avowed mission of any taxonomy is the ordering of entities into meaningful and logical (and ideally natural) categories of interrelation.

If Rafinesque-the-theoretical-taxonomist has a European Romantic parallel it is perhaps Lorenz Oken, ${ }^{33}$ philosopher, classifier, all-around Naturphilosophie Wunderkind, and friend to Goethe as well as the many other Jena intellectuals of the time (in 1807 he assumed a professorship there, though still only in his twenties). Oken, was a mere four years older than Rafinesque, and in professional output and even drive—if not sensibility, the two share many parallels, though it seems that they were both strangers to each other's work, and true to his seniority many of Oken's projects predate those of Rafinesque, though barely. Within five years of each other both had produced a unique theory of systematics, and, based on a common commitment to shared learning as well as

33To date, there is no full-length study/biography of this curious intellectual. For a general overview of Oken's life and career-including brief mention of the Rafinesquian debacle wherein Hegel accused the scientist of "plagiarizing" one of his chief theoretical insights from Goethe-see his entry in, Murray, Christopher John. Encyclopedia of the Romantic Era, 1760-1850: L-Z. London: Routledge, 2003. 
an expansive notion of knowledge, both were enthusiastic editors of journals, in Oken's case, the celebrated long-lived Isis (1817), and for Rafinesque the neglected Western Minerva (1819) and later the equally ignored Atlantic Journal and Friend of Knowledge (1832). The formal sensibility of Oken's journal may perhaps be explained by his intellectual circle. A few decades before, several of Oken's colleagues to-be, still in the throes of fevered youth, penned a document that seems famously to distill the character and concerns of their historical/cultural moment; 1797's “Earliest System Programme for German Idealism," a brief essay believed to have been conceived by Schelling and Holderlin, but scripted in Hegel's handwriting, demands a kind of fair play between the rational and the imaginative, the scientific and the aesthetic, what the authors of the text dub a "mythology of reason" (Behler 162, emphasis in original). Following this Romantic principle urging the parity and even unity of knowledge in all its forms, Isis featured a mix of discourses: science, scholarship, politics, poetry. A similar commitment (though not born of any apparent communal imperative or support) to the validity of the coexistence of scientific, scholarly, and aesthetic knowledge inspired Rafinesque to structure his own journals in like manner.

In the realm of systematics, Rafinesque distributed his scientific philosophy across two works spanning decades, 1815's Analysis of Nature or Tableau of the Universe and of Organized Bodies, and again in one of his last works, Good Book or Amenities of Nature, published the year of his death, 1840. These relatively obscure works (Good Book was self-published and never reissued whereas Analysis-a work originally written in French and also self published-was only first made available in English in the 1990's) parallel Oken's Elements of Physiophilosophy, a text that originally 
appeared in 1810 and then went through several subsequent editions. If Rafinesque's approach to systematics seemed singular to some of his critics, then it is less on account of any challenge to a canonical form than a confirmation that the genre in which he wrote was lacking in any such standard; for Oken's scientific masterwork takes the shape of 3652 aphorisms, spanning 600 plus pages, which depart from the apparent rift between human perception and the mechanical universe and climax with a posited "fourth science," the "Art of War." Between these two poles was a grand scheme classing creatures by way of the occurrence of various sense-data organs, each being an imperfect stage in a hierarchic developmental chain crowned by the comprehensive human sensory apparatus, a perceptual instrument made for and adequate to the task of perceiving the natural—or in Kant's terms "noumenal"—world. Thus the creaturely class, "Glossozoa, or the Fishes, as being those animals in whom a true tongue makes the first time its appearance" is succeeded by, "Rhinozoa, or the Reptiles, wherein the nose opens for the first time into the mouth and inhales air; Otozoa, or the Birds in which the ear for the first time opens externally" and so on (Oken xi).

Oken's first maxim nods at Kant by bracketing any claims regarding the ultimate legibility of nature: "1. Philosophy, as the science which embraces the principles of the universe or world, is only a logical, which may perhaps conduct us to the real, conception" (1). This announcement signals Oken's awareness that, by Kant's directive, all events here must remain squarely within the arena of perception, and so, "6. The philosophy of Spirit is the representation of the movements of ideas in consciousness. 7. The philosophy of Nature that of the phenomena or manifestations of ideas in consciousness" (1, emphasis added). Oken continues to elaborate a scheme of relation 
between the material and the ideational, one that will allow him to respect Kant's critique while still pursuing his organization of natural phenomena. " 8 . The world consists of two parts: of one apparent, real, or material; and one non-apparent, ideal, spiritual, in which the material is not present, or which is naught in relation to the material ... 13. Now since in Man are manifested self-consciousness or spirit, Physio-philosophy has to show that the laws of spirit are not different from the laws of nature; but that both are transcripts or likenesses of each other" (2). As with any document belonging to a broader intellectual trajectory, the spirits of multiple persons crowd this theory, along with Kant a mix of peers, forerunners and possible adherents. Oken's text is both an answer to a thick letter, and one in its own right, and there is no question to whom it is responding even as it addresses itself to the present as well as the unknown future of taxonomy, natural science, and philosophy.

Given the almost wholly materialist direction in which science has since developed, Oken's devout attention to metaphysical/epistemological concerns seems out of place in this type of tract. And since this philosophical platform was essential to the underlying rationale of his homological taxonomy, it is perhaps no wonder that his theory now appears just an erroneous relic of a confused earlier age. But during his time Oken's theory was very much a part of an ongoing discourse that was shaping scientific inquiry. An 1847 English language version of the text produced for the Ray Society (named for John Ray, one of the luminaries of seventeenth century taxonomy) offers a glimpse at just how enmeshed this work was within its intellectual milieu as well as the enduring context of reception for such a theory. Translator Alfred Tulk speaks of its Rosetta Stone-like properties within the realm of Naturphilosophie calling it, "the most practical application 
upon a systematic scale of the principles advanced by Schelling," and extends its explanatory reach by adding that it will also function as a, "readily available introduction to the writings upon similar subjects of Carus, [Henrik] Steffens, Hegel and others ..." (10/vi). The influence of the text even touches French science and (at least textually) Rafinesque's mentor-correspondent, for Tulk then goes on to say that he will refrain from outlining the philosophy of Oken since this has already been done best, "by M. Saint-Agy in the tome complementaire of Cuvier's Hist. des Sciences Naturelles, 1845" (10/vi footnote).

Obviously Oken and his intellectual brethren were not merely applying Kant's philosophy. They were in the process of structuring a conversation that would reshape the archive and literally rebuild the university. Oken's theory-now considered far more of bygone curiosity than anything Rafinesque produced—was part of the productive discursive continuum of his day, and as such was participating in and enabling a particular type of international exchange and theoretical elaboration within the emergent natural sciences. There was space in the conversation for Oken, just as his theory enabled further conversation.

Meanwhile, Rafinesque was pursuing his taxonomic intuitions in relative isolation. Apart from his dedication to Humboldt, Rafinesque seems to have had no engagement with, and little awareness of, Naturphilosophie or even Kant. Nonetheless, taxonomic theory bookends his professional output, being the topic of his last published work as well as one of his earliest. Analysis of Nature keeps the title's promised focus (though in the most expansive sense possible) while assuming that each categorical facet of the natural world implies its own unique branch of scientific study; 1840's Good Book 
continues this project, further subdividing the cosmos into fields of knowledge, some of these already established and plainly recognizable, others clearly visionary in status. In spite of its promised materialist focus, Analysis begins with a brief rhapsodic statement whose metaphysical pretensions are not dissimilar to Oken's first principles, though less rigorous and carefully structured around the time's philosophical debate. Rafinesque acknowledges the age old mind/matter dualist divide and pays brief lip service to a deistic, "Creator ... eternal Architect ... ineffable Author" (110). To this cosmic parent we owe our nature as "a mixed being capable of the most precious advantages; for there exists in him [the all-inclusive "man"] an intimate union between the two different substances which the Universe contains! To a material and organic body, but the most perfect on this globe, he unites a spiritual and intelligent soul. Man forms then as it were a link between the intellectual world and the material world: on one hand we crawl on the earth with the Animals; but on the other we touch the vaults of heaven by the sublimity of our thoughts."

The vaults of heaven is exactly where Rafinesque begins his Analysis, departing his poetic preamble for the widest possible vista the natural world will allow: "Cosmony or Natural History: The Universe is the totality of all that exists, and Nature is the universality of the admirable laws which rule it" (111). Proceeding from the general to the local Rafinesque begins at astronomy, geonomy (study of the motion of rotating heavenly bodies), uranology and astrography (science of the movements of the skies, a study presumably differing from the former in some unspecified way), then arrives in our own solar system with helionomy (the sun), planetonomy, selenomy (moons), tychonomy ("tychomes," or what are commonly called comets) (111-12). Once on earth, Rafinesque 
begins with the master-category geonomy_ "all that has to do with this globe"-which is subdivided into the categories geognosy and somognosy. These are then further divided into such subcategories as atmology (science of the atmosphere), dimnology (science of lakes), potamology (science of rivers), stromosics (physics of terrestrial beds), and so on. Poised to begin his classification of "terrestrial Bodies," those many entities_simple, composite, living and inanimate — that crowd the globe, Rafinesque pauses for some theoretical explanation. Here he acknowledges the essential "gradations" of analysis: empire, kingdom, class, order (116). It is also in this brief passage that Rafinesque posits a moniker for what he believes to be a hitherto unnamed branch of science, proposing the title "somiology" for the study of living forms (117). But in this Rafinesque had been anticipated by Jean-Baptiste Lamarck by just over a decade. The well-connected Lamarck enjoyed the ceremonial position at the Jardin $d u$ Roi fittingly titled correspondant, an honor that had been bestowed upon him by the illustrious Buffon, one of Rafinesque's idols and-along with Linnaeus — the dedicatee of the book just prior to Analysis (Burkhardt 29). Lamarck had risen in the world of international science by the time he published an 1802 taxonomic work establishing the term "biology" (Burkhardt 6). His ideas on taxonomy, including an early theory of evolution, continued to gather in importance such that after his death none other than Cuvier penned the eulogy to be read to the French Academy of Science. The rival scientist seized the occasion for simultaneously praising the man and publically lambasting his ideas with the dismissal that "a system established on such foundations may amuse the imagination of a poet; a metaphysician may derive from it an entirely new series of systems; but it cannot for a moment bear the examination of anyone who has dissected a hand, a viscus, or even 
a feather" (Cuvier 15).

Though a curious form of “thick letter," Cuvier's elegy acknowledges Lamarck's placement and connectedness within his orbit of thought and work, and testifies to his importance for the time's discursive continuum of scientific inquiry. The elegist had himself passed away before the text was publically presented to the Academy, and though his absentee-judgment was severe, the remembrance at least acknowledged Lamarck's scientific significance and engaged his theories directly.

Contrasting this is the notorious obituary to Rafinesque penned by pioneering American botanist Asa Gray decades after his death. One of the few public recognitions of Rafinesque's passing by the scientific community, this scathing document grants that once upon a time Rafinesque had been a "botanist of real genius," whose early work contained merit. But for the next three and a half pages Gray goes on to characterize Rafinesque's mature writings not just as madness but even as a toxin to be scrupulously avoided lest the field be poisoned: "[they] are simply collections of absurdities which if recognized at all would so cumber our synonymy that it would tend to make of it a hopeless tangle" ("Botanists" 149). The source of corruption is Rafinesque's taxonomic “monomania," particularly his enthusiasm for discovering and naming new entities. "Rafinesque should be held up before the young botanist of today as the type of a species-maker run mad." Gray goes on to ridicule "a paper which he sent to a well known scientific journal, in which he described in regular natural history style twelve new species of thunder and lightning" (149, emphasis in original). In fact, the "well known scientific journal" was the modestly local and decidedly unscientific Lexington monthly Western Review and Miscellaneous Magazine. And the article about doing field 
work in the Ohio Valley merely observed the unexpected paths of lightning seen by Rafinesque during the region's spectacular thunderstorms and described their shapes variously as “spark," "darting," "ball," "sheet” (Rafinesque Anthology 159-161)

Gray's obit makes crystal clear that, in terms of professional affiliation, Rafinesque was no Oken, no Lamarck. Nor was the United States comparable to Europe in having an established domestic scientific culture, a fact which might have served Rafinesque; as Gray points out, "never was there a finer field open to the enterprising botanist than this country presented to Rafinesque when he landed here in 1802" ("Botanists" 151). ${ }^{35}$ But in spite of having little to no solid orthodoxy to contrast him with, Gray is intent on depicting Rafinesque as a chronic interloping outsider, even a pariah, to productive American science, labeling him a "dismal ... failure," diagnosing him as insane, describing him as "eccentric," an "egotist," and in an earlier publication on Rafinesque's writings, detailing how he was inevitably and justly neglected on account of his egregious "peculiarities" ("Notice" 221). In the obit and earlier piece, Gray emphasizes his foreignness, both times incorrectly identifying him as Sicilian (“Botanists" 149, "Notice" 221). He minimizes Rafinesque's importance by reference to his ghettoized status, on the one hand complaining that his writings are hard fully to enumerate on account of being "so scattered throughout transient publications," then gratuitously adding that among these far-flung works, "hundreds of pages must be read to find one which contains anything of value." When the obituary was published, Gray was

34To Rafinesque's credit—and perhaps Gray's posthumous chagrin —-many of his observations square quite neatly with modern meteorologists' working classifications of lightning.

35 Warren devotes a useful chapter of his biography to situating Rafinesque within the generally chaotic fragmented and heterodox environment of $19^{\text {th }}$ century American science, pages 49-56, rife with renegades and untrained explorers. Though strangely, this does little to attenuate his persistent characterization of Rafinesque as irremediable amateur and heretic. 
in a unique position to pronounce Rafinesque's status with respect to mainstream American botanical taxonomy (and to some degree the sciences in general), since he was one of its premier representatives. In this respect, the text fulfills a performative function by not merely describing Rafinesque's alienation from science, but even constituting a powerful injunction for this alienation. This becomes starkly apparent when he asserts that poor Rafinesque, "who boasted of having established over three thousand new genera and species, has his name attached to but a paltry dozen of genera in Gray's Manual, which covers nearly all the ground of his personal explorations" ("Botanists" 149). Of course, Asa would be intimately aware of what was included and excluded from this still-authoritative botanical reference work, since the Gray referred to in the title is none other than himself.

Gray's equally mordant 1841 survey "Notice of the Botanical Writings of the Late C.S. Rafinesque," concludes with a glancing review of Good Book, the autodidact's final publication and thus the perhaps arbitrary culmination of his thoughts on taxonomy. Actually, Good Book was to be an ongoing journal, and its restless associative flow, bordering almost on the hypertextual, suggests a still active mind that fancied itself the instrument of a continuing project. A general section on American botany (37-49) segues into a passage in which Ombelliferous plants receive their "proper" names ("the Linnaean Genera were the perfection of absurdity!"36), nearly all of the hundred-plus to now bear "Rafinesque" as part of their moniker—one of the benefits of the nomenclator (49-61). From there a review of other botanist's work in classification (61-63) quickly gives way to a discussion on cephalopods newly-discovered by Rafinesque, and then their fossilized

36Warren makes the perceptive comment, "Absurd was Rafinesque's favorite word" (143). This is certainly true when it came to assessing the work of others. 
ancestors (63-67), which in turn prompts a look at "new Quadrupeds of North America" (67), a brief list composed primarily of big cats including several species of "couguar" (sic) and "2 Mexican jaguars shot in Kentucky" (67), and climaxing with a fossilized deer (whose dentition deserves special mention), a similarly preserved shrew, and the mysterious, "fabulous fossil animal," "rhinoceroides" (68). This slippage from the modern to the ancient then prompts an excursus on the etymology of the "Origon" (sic) Mountain Range, a sierra that, "had absurdly been called Rocky Mts" (68). Rafinesque’s assertion of the "Lenapi" (sic) origin of the name Origon then opens the gate for a discussion of the philological/ethnographic approach which Rafinesque is cultivating, a comparative/classificatory system of the world's languages that, "will find but few readers, although it might be quite equal to the works of Cuvier and Champollion ..." in their respective fields, and which informs the next chapter of this dissertation (68). By the end of its scant eighty three pages the text has wandered from its initial focus on abstract epistemological/scientific categories to encompass botanical discoveries, new cephalopods, quadrupeds and fossilized creatures, striking New World geological formations, inscriptions from the lost city of Atlantis and other "ancient monuments," early American and Chinese alphabetic systems, comparative linguistic analyses, and even a listing of various useful oils from India.

Perhaps unexpectedly in light of its broad range and loose structure, it is not for any lack of system that Gray finds fault with Good Book's approach to classification. Actually, his ridicule seems to hinge upon the unwarranted exercise of too much rigor, or at least, too many divisions. Taking the opportunity to reiterate his favorite anecdote, this time not merely italicized but sealed with an exclamation ("twelve new species of 
thunder and lightning!"), his primary complaint is the multiplication of ethereal categories, many of these simply reiterations of those introduced in Analysis. Gray harbors amused derision for "Astrosy, Heliosy, Tholosy, Selenosy, Toxosy ... Atmology, the science of atmosphere,” and so on. But somehow, Rafinesque's most original classifications seem to escape Gray's comment, if not his attention: “Stiontosy [science] of stony beings"; "Ablepsoms or invisible—Atmisols or visible"; "Phrenomy the laws and knowledge of the human mind"-which Rafinesque distinguishes from psychology, "of the souls," or pneumology, "of the spirits"; and perhaps the most useful categorically of them all, "Abariology," the catch-all science of the "imponderable" (7).

In his obituary Gray grants that Rafinesque's “writings showed an appreciation of natural affinities and of the advantages of a natural classification, but the boundaries of a species or genus lay in an unknown region" ("Botanists" 150). Though the autodidact's work tends toward the science of the imponderable with its mysterious boundaries and unknown regions, Gray's description invokes a common assumption that somewhere safely within nature's own frontiers one may discover her essential affinities and categories. The notion of "affinities" is one that hung in the air at the turn of the nineteenth century; but its utility for science was perhaps clouded from the beginning by its sense of poetic evocation. Humphry Davy, British chemist, poet and sometime friend to Coleridge and Wordsworth was by some standards the epitome of the Romantic intellectual: a pioneering discoverer in the sciences (among his credits are various common elements as well as the use of laughing gas as anesthetic), inventor (for example, the eponymous Davy lamp which significantly reduced the dangers of coal mining), and a recognized writer of considerable talent. In one of his last works, the 
Rafinesquely titled (and, according to Chapple, Coleridge-inspired) Consolations in Travel, or The Last Days of a Philosopher, ${ }^{37}$ Davy demonstrates the fluid connections he perceived to exist between science, metaphysical philosophy, poetry, and narrative art. This enthusiasm and interdisciplinary interest matches Rafinesque's in sensibility, but Davy's surer positioning within early nineteenth century science is confirmed by his legacy: a crater of the moon bears his name (another is named for Buffon-Humboldt warranted no less than a lunar sea), the Royal Society presents a medal in his memory, and he earned a plaque on the wall of London's Royal Panopticon of Science and Arts, to mention but a few of his many honors. Rafinesque mentions Davy in Life of Travels, alongside Humboldt, while discussing other scientists' corroboration of his own work on volcanoes (35).

Davy's contribution to the continuum of post-Enlightenment thought exceeds utile technology and the strictly scientific realm of speculation. Davy advanced a chemical theory concerning the behaviors of metals and other substances with a notion he evocatively dubbed "elective affinities." Like "event horizon," "strange attractors," or other terms from speculative science that seem possessed of a kind of unintentional poetry, this suggestive phrase was fated to exceed its native context, not only securing itself as scientific terminology but also inspiring a novel from Goethe and later a theoretically groundbreaking essay by Walter Benjamin on that novel. In the section of Good Book explicitly concerned with expanding the discipline of systematics to cover all scientific knowledge, Rafinesque seems obliquely to echo Davy's call. Though much of Good Book's section on taxonomy replicates the earlier Analysis, there is a key passage

37For the record, this work by Davy was published—and titled—posthumously, though the title reflects the contents, and — presumably—-the sensibility of the author and his intellectual milieu. 
concerning Rafinesque's theory of the mandate of classification. The science of "Eutaxy"—another coinage from Greek roots meaning "well ordered" (13)—will govern the universal categorization of all entities, and Rafinesque is emphatic about the importance of this "new science" (12). It must be governed by definite principles of association, and Rafinesque posits one of these principles in his section on the "new science" of "the circle of natural objects"; categorical coherence is secured through, "analogies of corporeal forms," or what he terms "collective affinities" (16). Rafinesque does little to gloss this term as he conceives it, but it rings familiar, and so, between the two domains that it straddles the phrase may rightly be said to belong as much to the realm of poetry as science. It is on this point that science, poetry and philosophy converge.

Exactly how categorical affinities correspond to nature (or even whether they do so at all) has been a persistent concern for modern systematics. David Knight gives a sense of the scope of this conundrum in his history of taxonomies, Ordering Man, when he discusses the many attempts to ground category on strictly natural attributes:

Underlying this procedure is the unproveable metaphysical hope that nature really is ordered into unambiguous families. This hope that there is an intelligible order in nature is like, and indeed is probably a version of, other general metaphysical propositions that make any kind of knowledge worth pursuing: that every event must have a cause, and that nature is uniform. (20)

Thus the ideal of natural categories of order assumes its role as one of the cornerstones of positivist scientism. It is easy to see how Oken and the other proponents of Naturphilosophie are recognizing and responding to this essentially philosophical need for an all-embracing explanation of the natural realm and thus their reach for explanations that could accommodate such conceptual heights; and though less fully 
theorized and carefully articulated, this same awareness also explains Rafinesque's insistent tendencies toward totalizing theory. However, even once the philosophical dimensions are acknowledged, the problem remains for how each category is physically constituted, or how the essences of these natural "unambiguous families" are actually instantiated into legible real-world traits, and thus categories. For Linnaeus, botany was explainable by his momentarily useful, but later much-maligned (even by devout follower Rafinesque) sexual system in which classification was arrived at primarily through the style and number of stamens exhibited by the plant—a system that ultimately had to be deemed fundamentally artificial by its own creator ${ }^{38}$ (though certain early acolytes confused it as otherwise). In the faunal realm, efforts were made to found classification naturally on features of the brain, the genitals, or other arrangements of internal/external organs (Ritvo 35-8).

Linnaeus, whose name has become the metonymic signifier of classification in early modernity, was Rafinesque's inspiration (in fact, Rafinesque named his ill-fated only son Charles Linnaeus-the boy died in infancy). David Knight has observed that it was Linnaeus who, "brought it about that natural history (seen as essentially a descriptive and classificatory science) became the leading science of the eighteenth century, as astronomy had been for the seventeenth" (Ordering 57). This is because of classification's fundamental role in all scientific activity. Knight cautions, "it is wrong to think of the sciences as masses of authenticated facts; the ordering of facts is the important part (and without some ideas of the order of things one could not even collect them)" (Ordering 54). Taxonomy is the collection of like things into groups, and it is

38For a very brief but informative overview of Linnaeus and Buffon, see, Farber, Paul Lawrence. Finding Order in Nature: The Naturalist Tradition from Linnaeus to E.O. Wilson. Baltimore: Johns Hopkins UP, 2000. For Farber's incisive account of the Linnaean system, see especially pages 8-11. 
exactly the basis of these groupings that has been at the heart of ongoing debate during, before, and after Rafinesque, and even into the present day. ${ }^{39}$ In its time Linnaeus' complex and often counter-intuitive system, a ranging collection of taxa and classes based on sometimes less-than-apparent criteria, and penned in musty Latin, faced bitter opposition. One of his most vociferous critics was Comte de Buffon, whose compulsively readable Histoire naturelle presented an alternative to the abstract complexity of Linnaean categorization. Buffon accused Linnaeus of promoting an arcane system of spurious relations between entities that was speculative and dogmatic. In its place, Buffon offered a far-ranging approach based on heightened accessibility:

Buffon proposed a convention alternative to Linnaeus's use of hierarchical divisions. Buffon wished to begin by studying natural forms that interest us because of their relation to us. Necessary or useful forms come first, because we know best what is familiar. Admittedly, the order of familiarity was subject to the objection against all artificial methods: it assembled heterogeneous objects. But method existed for purposes of study and considered things in the order in which they were found ordinarily. In this framework, the best way to advance science was to give a complete description and an exact history of each thing in particular. The study of nature would limit itself at first to these descriptions. (Larson 13)

Utilizing this approach—one perhaps more akin to the bestiaries of old in terms of entertainment value, and which Larson claims was perceived by many of the day's

39For a general overview of some contemporary debates, the reader is again urged to see, Wilson, Robert A. ed. Species: New Interdisciplinary Papers. Cambridge: MIT Press, 1999.

As a striking example of modern taxonomic controversy, consider one claim of the late $20^{\text {th }}$ century "cladist" school of classification, in which types are reckoned according to strict relationships of evolutionary descent. By this measure the cladists announced the utter incoherence of the category "fish," on account of extreme heterogeneity of derivation: whereas two aquatic, gilled creatures of apparent similarity would fail to qualify as related, some legitimate lines of filiation would have to join some varieties of fish with certain reptiles and even mammals. Caroline Yoon deals with this debate at length in Naming Nature, summarizing the matter thusly, "as ridiculous as the idea might appear to be, the death of the fish turns out to be scientifically and logically unassailable" (8). 
naturalists as decidedly antiscientific ${ }^{40}$ _Buffon's sixth volume (out of ten), concerned

with mammals, begins with these "technical" observations,

The cat is a faithless domestic ... They are naturally inclined to theft, and the best education only converts them into servile and flattering robbers ... The form and temperament of the cat's body perfectly correspond with his disposition. He is handsome, light, adroit, cleanly, and voluptuous; he loves ease, and searches out the softest places for rest and repose. The cat is very amorous, and what is uncommon among animals, the female appears more ardent than the male; she seeks for and invites him, and by her loud cries announces the fury of her desires or rather the pressure of her wants. (1-3)

Buffon goes on to describe the visually pleasing "chiaro-obscuro" of the Persian breed, the fine coat of the Spanish feline, and those "cats with long hair and pendant ears, and of which the Chinese ladies are very fond" (12).

Rafinesque seems to have been unaware of the bitter disagreement between the two men and their clashing systems; or perhaps the by-then decades-old rivalry merely struck him as irrelevant, and any conceptual dissonance tolerable in comparison to the inspiration he drew from both, for he brings them together in the dedication to 1814's Principles of Somiology: "To the memory of the great Linnaeus founder of the methodical study of organized bodies and to that of the illustrious Buffon their incomparable depictor ..." (Classification 71). By that time both systems were undeniably out of date. Throughout his writings Rafinesque complains of the limitations of Linnaean taxonomy. Warren asserts that, "by the time of Buffon's death in 1788, French natural historians [upon whom Rafinesque generally modeled himself] had had enough of his grand cosmogonies" (158), a sentiment which Larson confirms, pointing out that professional taxonomists of the late $18^{\text {th }}$ century, as exemplified by German Zoologist Peter Pallas and his contemporaries, demonstrated a strong preference for,

40Larson, page 12. 
"limited problems and accurate, well-coordinated information" (25-26). It would be wrong, however, to assume that by Rafinesque's day classification—either scientific or popular—had stabilized into a unified approach, much less settled its more pressing philosophical concerns. Colonial expansion had introduced an entirely new set of problematic entities to stymie science. And disagreement prevailed as various competing systems of organization clashed: an 1869 Punch cartoon parodies an oft-repeated anecdote in which zoologist and natural philosopher Frank Buckland was informed by a railway porter that he would have to pay extra for the monkey he was transporting because it was a "dog," but since his tortoise was an "insect" it could ride for free (Knight 25, Ritvo xi).

Underlying this humorous episode is a very real problem. For in spite of the many valiant (though sometimes far-fetched) efforts at unifying nature into coherent interlocking units, to this day no convincing large-scale fully natural system of ordering organic entities has ever been elaborated, leaving the hope for order into "unambiguous families" generally frustrated. What then can possibly bind together these posited aggregations? The suspicion is that they are perhaps held together by sheer force of will; the specter looms that what we are actually seeing in the scientific category is little more than ourselves or our cultural values in disguise. In this sense, the taxon, far from emanating from nature, is actually an imposition upon nature, an act of violence that radically forecloses multiplicity and slashes the complex organic picture until sized into an artificially imposed frame. And yet, for the taxonomist committed to finding natural order, unnatural imposition may be a blackmail levied of scientific necessity, for without some underlying logic any ordering is, "but a confused, undisciplined crowd of subjects" 
(through Ritvo 16). To the systematic scientist, the stakes of abandoning defined orders are too high to risk, for as Rafinesque stresses when making his plea for so-called eutaxy, "if we deviate from them we fall into disorder and ambiguity" (Good Book 15).

In his unfinished turn-of-the-19 $9^{\text {th }}$-century novelistic paean to science and learning, The Novices of Sais, which friend and fellow Romantic philosopher Friedrich Schlegel had published posthumously, Novalis muses, "it must have been a long time before men thought of giving a common name to the manifold objects of their senses, and of placing themselves in opposition to them" (19). Here Novalis raises the thorny issue of the interrelation between language, category and experience. The inherently categorizing function of language has been a concern to classifiers since the beginning: Plato's dialogs are dominated by attempts to grapple with language's power to form inclusions and exclusions ${ }^{41}$ and Aristotle's Categories is an intensive, systematic attempt to understand the equivocating power of names. To the pioneering seventeenth century taxonomists John Wilkins and botanist John Ray—-the latter of whose system some felt Linnaeus had merely pilfered and dressed up to make his own—language was the interference to perfect classification, white noise that prevented nature from articulating her own categories in full voice (Ritvo 25). Assisted by Ray, Wilkins attempted to craft an artificial philosophic/scientific language, purified of semantic excess and attuned to the essential divisions of the universe. An Essay towards a Real Character and a Philosophical Language is the subject of a well-known meditation by Borges on the impossibility of such a task as creating a perfect analytic language. But Borges' thoughts open into a kind of poststructuralist critique departing from language to encompass taxonomy, category, culture and more as he muses on an encounter with an antique (and 41For example, Socrates' famous attempt to give a precise definition of "virtue" in Meno, 74b. 
likely apocryphal) Chinese encyclopedia wherein, "animals are divided into (a) those that belong to the Emperor, (b) embalmed ones, (c) those that are trained, (d) suckling pigs, (e) mermaids, (f) fabulous ones, (g) stray dogs, (h) those that are included in this classification, (i) those that tremble as if they were mad, (j) innumerable ones, (k) those drawn with a very fine camel's hair brush, (l) others, (m) those that have just broken a flower vase, (n) those that resemble flies from a distance" (103). Foucault credits this essay with causing in him, "laughter that shattered ... all the familiar landmarks of my thought—our thought" (Order xv). He goes on to clarify with a statement that seems almost the direct echo of Novalis: "the thought ... with which we are accustomed to tame the wild profusion of existing things," and whereby we maintain, "our age-old distinction between the Same and Other." This experience becomes the genesis-point for his seminal Order of Things in which he dissects the emergence of the modern episteme through such figures as Cuvier. In this work Foucault analyzes the seismic shift into postEnlightenment rationality as science and reason displace earlier networks of thought and representation constituted by perceived analogies and correspondences between entities, ultimately rendering these affinities nothing more than magic, superstition, poetry. In his survey of Rafinesque's botanical writings, Gray passed this judgment on Analysis (and Good Book as well), "as early as 1814, indeed, he sketched a general classification of organized beings, to which he continued to attach great importance; but there is nothing new in it except the names" (231). Without a doubt, Rafinesque was not just a prolific "splitter" (as opposed to "lumper"-which is to say, one who tends to preserve intact the received species and genera rather than "create" new ones) but he was also a prolific namer. Warren estimates that he is responsible for naming some 2,700 new 
genera, 320 new subgenera, 6,700 new species and nine hundred new varietals in botany alone (27-8). This Adamic tendency irked contemporaries like Gray and Torrey, but can be seen as a facet of Rafinesque's obsessive fascination with language and its power to organize thought.

It is difficult to assert Rafinesque's exact theory of the relationship between category and word, but hints are scattered throughout his writings. 1815's Analysis contains a brief but suggestive passage that hints at a linguistic/semiotic facet of classification. Positing the master category "somognosy" (a coinage whose Greek roots mean "knowledge of physical bodies," or in other words, everything material) he partitions the study into two kinds of analysis, "description" and "history" (116). The first type of analysis covers "external or Description proper ... internal or Anatomy," while the second type, history, more vaguely indicates "use or Cresic [?-perhaps a coinage based upon the Greek verb chraomai, "to use"]" (116). Rafinesque does little to pursue this distinction or parse its terms, but one could speculate that the selfsame object — even an entity of strictly natural origin—could conceivably submit to both types of analysis, the first based upon its organic constitution, the other based upon its continued but ever-changing cultural significance, which is to say, its history (this latter suggests aspects of Buffon's approach). But Rafinesque also shows deep interest and sensitivity to the fluid status of words themselves and his philological writings seek to engage with immaterial—or as he might say, "non-somognosic"—semiotic history.

One of his last and most striking efforts at historical linguistics, 1838's Genius and Spirit of the Hebrew Bible, has baffled readers and Rafinesque scholars since its debut. The book's project is a complete reinterpretation-through painstaking linguistic 
analysis - of the language and text of the Pentateuch, a move to illuminate its inherent rationalist/scientific philosophical truth and rescue it from misuse by generations of rabbis and Christian commentators. Warren wonders at Rafinesque's mastery of the language but calls the book "rambling" and "obscure" (187); Call less charitably asserts that it is, "without the least possible value from any standpoint," and is clearly the product "of a man who has lost the power of acute perception and correct ratiocination" (202); even Boewe suggests that its sole interest may merely be its novel transliteration of ancient Hebrew (Profiles 84). But the text indirectly articulates a philosophy of language; specifically it indicates a profound faith in the power of words to convey subtle and precise intellectual distinctions. Rafinesque maintains that the ancient Hebrew religion possessed a scientific knowledge of "Astronomy, Geology, Natural History, Physics ... Intellectual Philosophy" (53), as well as "Medicine, Music, Grammar" (47), and its language held a profound capacity for qualitative analysis. He begins by positing the existence of a grand scheme of categories and distinctions, "peculiar to the Jews and Rabbis, THE SCIENCE OF GRADUATION AND CONTRASTS" in qualities or adjective things, objects and facts" (47). Rafinesque enumerates a handful of the OBRI (his improved rendering of the corrupt Hebrew) sciences and their native names: “OEXBE, Science—DOH Knowledge-OIUNIH Theory. BINE, Wisdom or understanding ... DFUAE Medicine. SMIXE, Graduation or Science of contrasts and degrees. MBIOH Natural History. MECAER, Metaphysics. NIYUE, Dialectics. GDR, MINSUG, Definition or Generalization, EGIUN, Logic. DKDUK, Grammar, MLIYE Rhetoric ..." and so on (47-8). Following this is a lengthy and even more speculative list of OBRI verbal roots, glossing their denotative/connotative sense (most of which has 
been lost through generations of mishandling, misinterpretation and mistranslation).

From this we learn that, "IEUA, miscalled Jehu by Jews, implies the unique self existing Being (61); AXI ... most sublime names of the diety (sic) ... AXI derives from AX compression or compressive faculty with I the sign of Power, meaning thus the powerful compression or gravitation! The divine energy of consolidation ... his power to materialize, crush, consolidate and render unradiant (61)." At times the connotations are bizarre on account of their peculiar specificity and obscurity of function: "AILH appears to mean the passing will or act of volition ... ECOER effort of modality or infusion (82); EUL, mistranslated Lucifer! ... One of the most sublime words of Obri Philosophy, derived from EU Potential Life, and LL circular motion, thus luminously expressing the powerful living action of rotation (83)." Sometimes the words seem to strive for a metaphysical poetics, "ORBUH, from OR propensity, BUH active space, meaning the animated volition of space!; MXUN ... the collection of reality (87); BR, ray of light, also of a circle, realization, intellectual Son, powerful emanation or creation! sublime Genus (perhaps genius?), from B paternity, R motion of radiance" (127-8).

The effect of reading Genius and Spirit is not at all unlike that of reading Analysis or Good Book, a vast mosaic exposition of interrelated degrees of quality. And it is easy to see that the kind of linguistic precision Rafinesque claims to rediscover in OBRI is what he hopes to activate, via coinages and verbal differentiation, with the modern taxonomic project as he conceives of it. In a footnote at the end of World; or Instability, we find one of the most telling passages—vis-a-vis classification—of Rafinesque's entire oeuvre, in spite of the mention's brevity: "a genus in organized beings is the collection of all the varieties or species that differ essentially from others. A species is the collection 
of all the individuals acquiring distinct forms and colors, and all the deviations that can breed together. They are abstract terms of our own; Nature only acknowledges individuals and vary (sic) them constantly" (228-9). ${ }^{42}$ If this is true, then the taxonomy (that is, the systematic ordering of species and genera) laboring under its implications will likely be complex and ever in process, for its job is to create and enable differentiations rather than merely discover them.

This nominalist impulse toward linguistic conceptual specificity, the coinage of new terms, differentiations and degrees up to and including visions of new disciplines, is perhaps more at home in the theoretical environment of late twentieth century literary interpretation than early nineteenth century science. Perhaps this is "arthrology" as Barthes envisioned it. In this respect Rafinesque was ahead of his time, but still out of step with his discipline. Even in today's metaphysically sober scientific environment there remains the hope that some standard of natural affinity might obtain. As David Knight rather wistfully opines, our advances in scientific classification, "must give us the hope that we are in some sense finding the order rather than seeing ourselves or our society reflected there and nothing more. A natural system without any misfits or classifications that cut across each other may be a dream, but it need not be a chimera" (35). This is not to say that the scientific environment of Rafinesque's day was not one of wild speculation and (by today's standards) fantastic systems. But what differentiated an Oken or a Lamarck from a solitary autodidact is in part that they were part of a culture and a continuum; they were intelligible voices in an ongoing conversation and as such they were working, to some extent, from inside the canon, whether or not their

42This is not the only time Rafinesque voices a nominalist belief about the project of categorization, a position with profound implications for his avocation as a taxonomist; in Herbarium Rafinesquianum we find this casual—but philosophically crucial—mention: "individuals alone really exist among organized bodies" (13), i.e. unifying categories are no more than abstract human impositions upon nature. 
contributions were to become a permanent part of it. One of the most fascinating traits of Rafinesque's legacy is that to this day he remains a permanent question mark on the archive, straddling margin and center, a lingering memento of stubbornly uncertain value. Whereas Oken and Lamarck are safely defined as definitive missteps toward the Truth of science, Rafinesque's contribution persists as contentious, even rather mysterious.

To return to the question, what does the term "to correspond" mean with respect to Rafinesque? Does it imply a parallel between theory and "truth"? Does it suggest a meaningful equivalence between knowledge and the archive? Does it invoke an approach to language and signs that acknowledges semantic excess, semiotic drift, even aesthetic tendencies in our quest to find meaning in, and relationships between, entities of experience? Only in the most literal and impersonal way can we say that Rafinesque corresponded with his peers in scientific inquiry. For though he wrote them thick letters, he belonged to no community of like minds and shared in no culture to speak of. Not merely nominalist, Rafinesque was nominalism incarnate: without category, tragically singular, speaking in incoherent coinages and neologisms suggestive of Wittgenstein's impossible private language. Perhaps the most poignant emblem of this is the sole remaining original copy of Analysis of Nature, Rafinesque's first foray into taxonomic theory, which he eagerly sent to his idol and sometime correspondent for review and approval. On the front it bears the stamp of its illustrious owner in bold: G. Cuvier. But the pages were never cut and thus the book remained forever unopened by the one man licensed to give it validation. 


\section{INSTABILITIES: WALAM OLUM, KNOWLEDGE CREATION}

\section{AND DISCURSIVE FORMS}

In the editor's preface to The World; or Instability, there is a remarkable moment that—if it has even been noticed—seems completely uncommented upon by Rafinesque scholars. As with most of Rafinesque's publications, the appearance in this text of multiple author-contributors is illusory, and, as is universally agreed, the putative editor of this didactic poem must certainly be Rafinesque himself. Amidst descriptive analysis of the author's poetic style, this prefacer lavishes praise on both poem and poet, comparing him favorably to other didactic versifiers such as Erasmus Darwin and James Thomson, and, with respect to purely instructional value, even Newton (5). He proclaims the poem, "altogether superior to Pope ... in moral tendency, variety of subjects, and sublimity" (5), and in relation to Milton claims that on some counts it measures inferior, others equal, "but superior in some peculiar points" (6). For although Paradise Lost, "justly ranks as the best English epic," in addition to certain "defects of style," it has also "been accused of some plagiarisms" (6).

The offhand, but jarring, accusation is noteworthy, not least of all because of the peculiarity of its presumptive basis. In 1747, William Lauder, a sometime humanities professor at Edinburgh University, published the first of a series of attacks in which he claimed that Milton had extensively plagiarized a number of authors in writing Paradise Lost. Shortly afterward scholarship exonerated Milton when it was discovered that Lauder was basing his case upon forged texts, "evidence" which he himself had 
manufactured. Revealed and shamed, Lauder published a confession-apology (strangely, with a reluctant preface by soon-to-be alienated onetime pal and advocate Samuel Johnson) and then retreated from the public world of British letters, absconding to Barbados and a new life. ${ }^{43}$

This literary-historical oddity—scarcely a footnote in terms of lasting impactseems the only possible basis for Rafinesque's charge. The fact that the matter was almost immediately resolved upon arising, and that the incident occurred nearly a century before the publication of Instability only renders its appearance in that work all the more curious: if Rafinesque was aware of the plagiarism charge (as he seems to have been), surely he also knew that it had been thoroughly debunked and that the accuser had recanted. Obviously, zeal to glorify Instability drove this prefatory "editor" to extravagant claims about the poem's literary merits, but why should he also risk questions of credibility or even justified censure by reviving antique accusations widely known to be baseless?

Whatever purpose the casual questioning of Milton's authorship was to have, it apparently did not entirely invalidate the work in Rafinesque's assessment. Instability's preface implies that in spite of this possible perceived stain, the poem's other combined merits carry the day and it remains the exemplar and model for "the lofty aims, the vivid pictures, the sublime thoughts and the ranges of imagination" that Rafinesque's own poem hopes to match (6). Rafinesque here seeks to become part of a tradition, not just of Milton, but of others whose poetry strives, according to the mottoes of Philip Sidney and

43For a very brief sketch of this peculiar individual, see his entry in Encyclopedia Britannica $11^{\text {th }}$ Edition. New York: Encyclopedia Britannica Co, 1911. Page 279. 
Horace before him, to teach and delight. ${ }^{44}$ To the extent to which it has been perceived as a forerunner to Darwinian evolution, Instability partially achieved its desired success. But the fate of the didactic poem as discursive form was not a happy one, and as aesthetic and informational discourses were quarantined into separate, often opposing realms, Rafinesque's epic account of natural philosophy has become a generally unknown remnant of a largely forgotten genre. The same cannot be said for Rafinesque's other poem of significant length, Walam Olum. This "translation" of a pseudo-Native American epic which Rafinesque passed off as linguistic/ethnographic scholarship has remained one of the most enduring objects of controversy for an already contentious "legacy." While much of the debate surrounding this work has centered on the motives for the text and Rafinesque's subsequent culpability, the Walam Olum is susceptible to the nearly endless uses and "misuses" of interpretation that attend any literary (or in this case, at least quasi-literary) entity so enduring and polarizing. What follows is less an assessment of the text in terms of its authenticity or historical veracity. Instead, I will regard this "myth" and its subsequent reception as a theoretical parable of the inescapably discursive nature of scientific knowledge and its uncertain regulation with regard to other "opposing" forms of knowing. The Walam Olum is an entity in perpetual dispute, both as an object and a text, for it calls into question the ways we legislate various types of knowledge and the subsequent forms into which they are relegated and finally accepted. It is for reasons of its sheer undecidability that the text is so vividly illustrative. Whereas Instability perhaps justly joins the ranks with works by teacher-poets Erasmus Darwin, Ibn al-Nafis, James Thomson, and others, Walam Olum transcends this antique genre by

44Sidney, Philip, “An Apology for Poetry,” Norton Anthology of Theory and Criticism. Vincent Leitch, et al, eds. New York: Norton and Co, 2001, page 331. Horace Ars Poetica, line 333. 
becoming — unwittingly—its most contemporary example. Like Instability, Walam Olum has much to teach, but it does so not in its verses but self-reflexively, by demonstration, by its conditions of existence and terms of endurance, and ultimately this is most appropriate to what it has to say.

In an 1819 letter to a fellow botanist, William Baldwin says of the recent rejection of two of Rafinesque's articles by the Academy of Natural Sciences, "I am truly glad ... that they have sufficient independence to reject the wild effusions of a literary madman" (Boewe, Profiles 159, emphasis in original). This striking epithet has garnered some comment. To the many scientists and historians of science who have been the most common readers and researchers of Rafinesque (Boewe, Stuckey, Warren for example), it constitutes a withering ad hominem attack meant to invalidate the taxonomist's credibility by impugning that his objective purity has been corrupted by imaginative fancy (likely Baldwin's intent). To Jim Endersby it is a prompt to recast Rafinesque as one among several early observer-travelers who treated the banquet of New World flora and fauna as the raw material for inspired taxonomy-informed reveries of imagination (Endersby 174). What neither of these approaches takes into account is that Rafinesque was a literary figure-and not merely metaphorically or secondarily. Apart from the many exercises in poetry that lace his several self-published journals, apart from his various forays into rhetoric and aesthetics, Rafinesque had literally epic pretensions as demonstrated in both Instability and the faux-Native American mytho-historical text, Walum Olum. It is important to note that while both of these works' recognized status as literature is problematic (each for very different reasons), their judgment as expressions of madness is on somewhat surer footing since each radically challenges convention in its own way 
(though, tellingly, Baldwin had no way of knowing this since neither had yet been written at the time of his dismissive comment).

It is by now a more or less safe move to state that, by most current definitions of the term, Rafinesque "wrote" the Walam Olum, and the text's bizarre nature seems to echo inside the casual charge Rafinesque levels at Milton. Both Instability and the Walam Olum appeared in the same year (1836), and in light of the latter's status it is an easy temptation to want to explain the accusation merely as some kind of subtle clue, or from a more punitively pathologizing perspective, a barely repressed will to confession on the part of Rafinesque (although in the latter explanation the exact logic of this psychological urge would likely be exceptionally complex, and even more likely to remain hopelessly hidden). The Walam Olum initially appears as the fifth chapter, beginning page 121, of yet another ill-fated Rafinesque journal, The American Nations (only two volumes saw print). It is presented as an epic "song" containing, "Original Annals and Historical Traditions of the Linapis"-in other words, Rafinesque claims to be merely presenting translations of discovered indigenous texts. Although questions about its authenticity loomed from the beginning, over the next century and a half by degrees it became enshrined as a genuine document written in the language of the Delaware Indians, a mixture of myth, history and cultural symbolism. As such it became the centerpiece of a considerable amount of linguistic, historical and ethnological scholarship. But by the 1990's questions of its origin again arose and evidence was marshaled to definitively denounce the Walam Olum's purported origins, not least of all David Oestreicher's intensive linguistic analysis which demonstrated that the text was originally composed in English and then only clumsily rendered into Delaware with the 
help of Native American glossaries compiled by pioneer-missionaries (Oestreicher 1994).

No one any longer regards Walam Olum as Native American literature; no scholar admits its status as valid history (in its current form), or even myth (though some remaining Delaware aver that authentic oral accounts were in fact used as a loose foundation in the construction of the narrative); as stated, it is now widely agreed to be the work of Rafinesque himself. ${ }^{45}$ And while the text's meta-literary possibilities seem almost endless, the many deep and conflicting cultural and historical investments that are bound up in the work may make it simply too contentious to treat as a mere literary artifact. Since its outing as inauthentic, the question that has naturally preoccupied scholars is, why? How do we account for this egregious breach of scholarship by someone so obsessed with the apprehension of knowledge and its precision use, someone who made a regular practice of publicly decrying the inaccuracy, errors and missteps of others? It is primarily within this frame and through these lines of inquiry that the text has been discussed in the last several decades, and though not the final destination, this will also serve as the necessary point of departure for this analysis.

Probably the most compelling theory for the text's genesis was posited by Oestreicher's initial debunking, and has been again reiterated and expanded in Andrew Newman's article on the Walam Olum in American Literary History. Newman argues that Rafinesque's motives were-according to the ethos of science and other systems of knowledge based on its precepts—(largely) pure and his methodology honest but naïve. Oestreicher had dubbed Rafinesque's approach "pictographic palingenesy," which

45Rafinesque scholar Charles Boewe has publicly maintained a belief that Constantine was merely hoaxed and that he himself believed the text to be real, publishing it in good conscience: see his comments on the matter in the introduction to Profiles of Rafinesque, pages xxxiii-xxxv. But in light of what Oestreicher has discovered about the epic's construction, as well as what the "translator's" notes seem to indicate, Boewe's faith in Rafinesque seems little more than just that. 
Newman observes, "implies a process of restoration rather than invention" (37). This notion is acknowledged by Rafinesque himself in 1838's Ancient Monuments of North and South America wherein he nods toward the conceptual origin of his methods: "my process is similar to that of Cuvier and the modern Paleontologists who restore extinct animals by fragments of their bones" (28).

The "process" to which Rafinesque here refers is one of Cuvier's lasting contributions, the so-called "principle of the correlation of parts" (hereafter PCP), a theory that argues for the inferable ordering of the whole by way of the logic expressed in its mere fraction. As Cuvier had announced in a lecture to the National Institute in 1798, "the number, direction, and shape of the bones that compose each animal's body are always in a necessary relation to all the other parts, in such a way that —up to a pointone can infer the whole from any one of them, and vice versa" (Rudwick 36). In dealing with animals some of which have been extinct for countless millennia, Cuvier's principle exceeds the Sherlock Holmesian ability to determine the brand of cigar via its residual ash, but the premise is exactly the same: when human intellection is rigorously trained up to modernity's standards, knowledge promises the key to seemingly impenetrable mysteries.

The appeal of such a promise to one like Rafinesque is obvious, as is the further application to which this principle could be applied by a resourceful polymath possessed of intellectual confidence and a bent for imaginative pondering. In 1840's Good Book (Rafinesque's last publication, and one with a chapter entitled "The Graphic Systems of The Ancient American and Chinese Nations" that reflexively cites Walam Olum as evidence), he elaborates his vision of "Historical and Ethnographical Palingenesy." The 
roots of this term are the Greek genesis, "origin/birth," and palin, "again," and as Rafinesque defines it, "Palingenesy means restoration to life or existence or knowledge" (69). The promise of this "new branch of science," he tells us, may actually equal Champollion in importance but—undoubtedly based on hard experience gleaned from self-publishing — he posits it will remain largely unread and therefore underappreciated (68). It will also pay tribute to the pioneering spirit of its inspiration and model, Cuvier — "he has been greatly praised. Shall I be?," preserving his principle (the PCP) while applying it to the archeology of human culture (69). Rafinesque explains, "I take scattered words of extinct Nations and Languages, and out of a few or any number, I restore them to our historical knowledge ... I directed at first my attention to the old American Nations; but I have since been led to embrace the whole of mankind ..." (6970, emphasis in original). Here Rafinesque seems not only to avow the process that accounts for the Walam Olum according to Oestreicher and Newman's arguments, but it is tempting to think that his vague reference to work on "old American Nations" may in fact be a nod to that very text.

The PCP theory of the Walam Olum advanced by Oestreicher and Newman, and seemingly acknowledged by Rafinesque in the passage above, presumes that even if the work is inauthentic by modern standards of scholarship, within its composition—or at least somewhere in its back-story-there is a factual kernel. This is in keeping with the logic of Cuvier's principle which holds that even when scientific speculation is at its most sweeping and precarious, some authentic fragment-emblematized as a piece of bone in the original articulation-will act as anchor and point of departure. Just what constitutes the factual remnant - the bone, so to speak—in the case of the Walam Olum? The 
question is difficult given the mystery that surrounds the text and its acquisition. Rafinesque claims to have received the document from one "late Dr. Ward," a man he encountered on one of his botanizing sojourns into Indiana (American Nations 122). Apparently, the doctor had accepted the text in return for medical services rendered to Indians residing along the White River, members of the Delaware Tribe (also known as the Lenni Lenape). The text's unusual form is reflected in its title. Wallam-Olum (as it was first transliterated by Rafinesque) means "painted record," or more evocatively, "red score," the text itself being a collection of cedar sticks each with an ideographic glyph etched and painted red on its surface. Every pictograph distills a discrete narrative element, visually communicating an episode requiring translation into a series of words roughly one sentence in length. Supposedly these information-dense glyphs were for use as a mnemonic tool for the ritual chant of the tribal lore. Based on Dr. Ward's text, the reconstituted narrative begins with the creation of the world and ends with the first appearance in 1626 (according to the calculations of the Indiana Historical Society scholars) of Europeans_-"Whites ... friendly people with great possessions: who are they?"- on the east coast of what will come to be called North America (Rafinesque/IHS 206-7). Somewhere between this 1822 acquisition and its 1836 publication, Rafinesque laid hands on an addendum to the Walam Olum, a fragment delivered to him by an unknown source and already translated by a man the equal to Dr. Ward in mystery, one John Burns. ${ }^{46}$ This latter passage, while brief, begins where the other leaves off and updates the narrative, chronicling the disastrous outcome of Indian relations with the newcomers, and concluding shortly into the $19^{\text {th }}$ century. In spite of the dubious provenance of the two passages that make up the whole of the Walam Olum, and in spite 46Attempts to identify both Ward and Burns have proven futile. 
of the mysterious loss of the inscribed sticks originally acquired from Ward, the text has endured and the "original" ideographs have even persisted as an object of study thanks to Rafinesque's extensive notes, which to the fortune of posterity included detailed pictures and analysis of each character. This effort has allowed the Walam Olum to be repeatedly "retranslated" and thus re-imagined. Perhaps ironically, perhaps fittingly, though Rafinesque's reputation as a source of scholarship had suffered greatly even in his own lifetime, in the end he became the sole custodian and conduit for this complicated text to reach the modern world and find its varied readership.

Oestreicher's label for Rafinesque's project, “pictographic palingenesy,” not only posits a theory for the Walam Olum, but also suggests what might be reckoned as its Cuvierian bone- that factual remnant upon which the whole has been developed. According to this view, Rafinesque based his excursion on some actual ideographic representation associated with the Delaware, building up his work from the level of script. A number of points bear observation with respect to this idea. For example, it was for this very reason that Henry R. Schoolcraft, one of the Walam Olum's earliest skeptics, cried hoax (Warren 150). As an interesting side-note, Schoolcraft's own scholarship has been made to function as the authentic relict core for other fantastical epic "reconstructions": his work on the Ojibwe Tribe became the loose source material for Longfellow's romantic poem, "Song of Hiawatha." Schoolcraft was suspicious of the Walam Olum's pictographs because of their occasional obvious similarity to Chinese characters, a feature that has been consistently pointed out by skeptics since-in addition to the apparent influence of Egyptian hieroglyphics on the script. However, this resemblance could be explained as perfectly reasonable to a certain mindset of the day 
(which Rafinesque shared in), since texts like the Walam Olum were thought to belong to an ever-emerging narrative of universal human history, one in which all peoples had deviated from a single origin and language group and suffered the same primordial catastrophic disasters, such as a great flood. ${ }^{47}$

While this urge toward seeking a common human arche was gradually disavowed in history and science (particularly when found to be bearing traces of biblical influence, which it often did), it could be argued that the unifying impulse simply migrated and disguised itself, surreptitiously reemerging later in certain forms of linguistic/ethnographic comparative analysis. A fascinating example of this is the 1954 Indiana Historical Society's version of the Walam Olum. ${ }^{48}$ This remarkable text was the pet project of Eli Lilly, pharmaceutical magnate and Native American enthusiast. Likely it is this work that bears the lion's share of responsibility for whatever continued aura of authenticity the Walam Olum enjoyed throughout the mid to late $20^{\text {th }}$ century. Beginning in the Great Depression and continuing for twenty years, Lilly—one of the poem's true believers—-funded a team of roughly a dozen scholars to produce the definitive edition of the epic. The result of this impressive labor was an oversized, gilt-paged volume, replete with color maps and graphics, an artifact custom-designed for the bibliophile. In addition to a pictograph concordance and critical apparatus featuring scholarly essays on the text, its history, and its significance, every page of text devoted to the poem itself features a reprint of Rafinesque's original notes containing his version of each ideograph and a

47The Walam Olum contains a flood episode similar to the story of Noah in the Hebrew Bible and the Greek/Roman story of Deucalion. It would not be until 1872 that George Smith would rediscover the very similar Atrahasis episode in the epic Gilgamesh, a find that would only make the narrative motif seem all the more universal to later theorists.

48Cited throughout this chapter as "Rafinesque/IHS" in order to differentiate it from Rafinesque's earlier published version. 
rough literal translation. Below this is the updated (and sometimes "corrected")

translation by Edward Sapir-trained linguist/anthropologist C. F. Voegelin, followed by a visual analysis of that page's pictogram (by Lilly himself) and "ethnological observations," that is, commentary by celebrated anthropologist and Voegelin's thenwife, Erminie, comparing that narrative element with other Native American mythological accounts.

Anthropologist/ethnologist and Rafinesque critic Stephen Williams has attempted to exonerate the involved scholars who labored under Lilly's beneficence by observing that their testimony in favor of the text comes across as exactly "what one feels the donor would want to hear" (Fantastic Archeology 113). In spite of this generous assessment by Williams (who in 1991 doubted the verses of the Walam Olum but believed the migration tale at the heart of the poem to be authentic indigenous lore), the scholarship of the 1954 edition validates the text and situates it within an approach to ethnological research/analysis based upon cultural analogy and resemblance. Erminie Voegelin's commentary focuses on finding correspondences between the poem's narrative elements and mythic/religious and historical themes of Shawnee, Ojibwa, and modern Delaware, among others. During the text's early account of creation, Manitou and mermaids and other motifs abound with archetypal resonance, whereas for the poem's later "historical" verses, discussion on trans-tribal rules of succession and political customs predominate. Though her explanatory approach could be read (as Williams apparently does) as a way of discussing the text while sidestepping overt judgment concerning the authenticity (or even substance) of its content, it also forcefully naturalizes the document with its insistent catalog of parallels and cultural contexts for situating the story within the reader's 
understanding.

Lilly's analysis broadens the range of correspondence by universalizing its imagery. In fact, Lilly's commentary often appeals directly to a universal language of image, such as when he notes the use of wavy parallel lines to designate "river" for the Egyptians, Chinese, Babylonian and Sinai-as well as the familiar zodiac sign of Aquarius (233), or the more unlikely entry on page 228 for the concept "clear": "uplifted arms spread sidewise, as in sign language" (presumably ASL). When not clumsily literal (on page 58, below a stick figure holding an arrow Lilly glosses "an arrow indicates the hunter"), the sometimes vague pictographs can come to represent self-evident (but nonetheless esoteric) motifs: "the curve is, of course, the celestial arch" (16). The deeper conceptual well the imagery draws from is often strikingly familiar as the cultural values of observer and observed seem to collide and commingle in obvious ways (to the modern reader, anyway). For example, inimical figures throughout the text are inevitably associated with the snake, laden as the creature is with Judeo-Christian moral implications; toward this end the symbol signifying the concept "evil" is "a double fanglike mark" (220). Under the pictograph concordance entry for the word "sinister," there is the explanation, "a figure crossed by a series of transverse lines like stripes on prison garb." This intrusion of images and words with culturally specific value into a supposedly objective analysis becomes present at the level of language when Lilly goes on to explain, "the Eskimo also used a zigzag-marked figure to express sinners" (234). In his defense, many of Lilly's projections merely extend the logic of thematic tendencies already at work in the poem or the pictograms; still he pursues its lead with enthusiasm and studious attention. 
A strict assessment may dismiss the above as symptom of an unreflective culturally-embedded myopia typical of an earlier generation's version of "academic" analysis, while a more generous account would perhaps cite merely unfashionable pretensions to some archetypal bond between cultures. Either way, the projected universal resonance of the Walam Olum, whether manifested in the text itself or the analysis thereof (potentially a contentious distinction anyway), lends the issue a lasting complexity. As previously mentioned, some Delaware still consider the basis of the poem to be genuine indigenous myth, a point which Newman's 2010 article confirms (34, and see page 51 , footnote 12 , in which he relates the ambiguous email reply he received about the matter from Tamara Francis of the Cultural Preservation Office). Even more significant is the poem's appeal to many younger Delaware Christians who see the text as confirmation of their place within a Judeo-Christian/Native American continuum. To this view the poem, with its suspiciously biblical themes, is a kind of proto-scripture thatalthough by no means gospel-is at the very least prophetic (Newman 34). The effect of this cuts both ways, creating a sense of belonging for Christian Delaware (and given its pan-Indian pretensions, Christian Native Americans generally), as well as a ready-made place of acceptance and recognition for them to be received by believers of the ethnic majority. Users' reviews from the Amazon.com webpage for David McCutcheon's 1993 new age "translation" of the text bear witness to this: "this book is awesome ... the Wallum Olum (sic) begins with the mythical creation of the world, the entry of evil and strife, and a great flood. Sound familiar?"49; or even more forcefully, “The story of the Lenape sounds like the whole story of mankind, complete with Creation, floods and evil serpents like the account in Genesis and records of their leaders just as Kings and 49http://www.amazon.com/review/R2I48FIINA65B0/ref=cm_cr_pr_viewpnt\#R2I48FIINA65B0 
Chronicles contain in the Holy Bible. I felt a sort of kinship with these people, even though I have never met any Lenape personally and though I am a Christian, I sensed the presence of God in their tale as well." ${ }^{, 50}$

A certain potential Christian significance of the Walam Olum was certainly within Rafinesque's awareness and may have even factored into the correlation of its parts—at least negatively. Here one must again enter the muddy waters that confuse the "why?" with the "what?" of the Walam Olum. Oestreicher is nearly unique among those who speculate about the motives of the incident in his emphasis that Rafinesque's likely main purpose was to secure the prestigious and (sometimes) lucrative French Prix Volney award which in 1835-one year prior to The American Nations was published—was pledged to go to new linguistic scholarship in "Lenni Lenappe, Mohegan et Chippaway." Curiously, Rafinesque first submitted a broad-ranging essay on general linguistic issues, then hastily supplemented the submission with the appended Walam Olum, claiming "new philological and graphic materials" (Boewe, Profiles 239). Although one of only two entrants, Rafinesque still failed to secure the prize. This certainly looks coincidental, if not outright suspicious; though even as explanation for motive its use is limited. The coveted Prix Volney may have formed some part (conscious or otherwise) of the inspiration for the Walam Olum (though given a personality as complex as Rafinesque it would also be a remarkably simple and transparent causal agent—elaborate self-delusions notwithstanding), but at best it perhaps explains some facet of the text's genesis or a clue to the timing of the matter; that is, it speaks to the poem's circumstance while saying little to nothing of import about its content and structure. Against this simpler theory of

50http://www.amazon.com/The-Red-Record-David-McCutchen/productreviews/0895295253/ref=cm_cr_dp_see_all_btm? ie=UTF8\&showViewpoints=1\&sortBy=bySubmissionDateDescending 
motive one could posit another, one involving only slightly less questionable impulses, but which at the same time preserves intact the glimmer of embedded fact, or "truth," which the PCP necessitates, and which Rafinesque so avidly pursued and obsessively cherished. This could provisionally be dubbed the theory of the "apotropaic hoax," or hoaxing against hoax in order to advance what is perceived to be the ultimate truth.

Shortly before Rafinesque's publication of the Walam Olum, Mormon founder Joseph Smith had claimed literally to unearth a text with a similarly questionable origin, similarly bizarre form, and similar historical/etiological pretensions, in the form of a long-buried cache of gold plates inscribed with details of the Native Americans' genealogical descent from the lost tribes of Israel. This "evidence" (which swiftly and mysteriously disappeared) was unique to Smith, but not the theory they supposedly confirmed: as already mentioned, even the developing sciences of Rafinesque's time were struggling to reconcile New World entities with the still-prevailing authority of scripture, and to the non-scientific observer the human inhabitants were especially a conundrum. Rafinesque pulled no punches in publically calling out Smith and fundamentalist biblethumping armchair scholars such as Josiah Priest and Ethan Smith in articles like 1832's, “The American Nations and Tribes Are not Jews," from his Atlantic Journal (98-9). ${ }^{51}$ Though Rafinesque harshly criticizes Joseph Smith as a fraud in this piece (as he did consistently elsewhere), not long after, Smith-appointed church elder Orson Pratt cited Rafinesque's authority on linguistics and even the chart of Native American glyphs that begin this very volume of Atlantic Journal to mount a case for the authenticity of the religion's suspicious founding documents in his, "Divine Authenticity of the Book of

51This article had undoubtedly reached a much broader audience when it previously appeared in Saturday Evening Post, vol. 8, Sept 12, 1929, page 1. 
Mormon" (Pratt 88). It was perhaps this glaring irony that led ichthyologist, pioneering university president, and committed rehabilitator of Rafinesque's scientific reputation, David Starr Jordan, to make the baffling attribution in his bio entry for 1899's Science Sketches that Rafinesque was one of the originators of Mormonism (163). Surely this bizarre assertion by Jordan is another case of Rafinesque functioning as a lightning rod and repository for exaggerated romanticized projections about the perverse capability and eccentric accomplishments of the self-fashioned intellectual.

The truth is that against the notion of Native American Hebraic origins Rafinesque was championing the theory of early Asian migrants crossing the Bering Strait. While much of the "history" depicted in the Walam Olum was at the time uncontroversial (except perhaps in its sharp characterization of white settlers' avarice and dishonesty in dealing with their Indian counterparts), the poem seemed to corroborate Rafinesque's favored account of the then still-disputed origins of native peoples in America. This euhemerist "interpretation" of the Walam Olum and its explanation for the indigenous populations turns out to be essentially true, but the poem's timeline, still basically bound by the influence of Hebrew scripture, does not. According to this reading the skeletal factual remnant of the story is an account of historical migration and settlement dressed up in the mythic garb of a quest tale.

One way of generalizing the contrast between ancient and modern epistemological orders might be to say that the scientific approach to a thing's origin, with its positivist emphasis on causality and reason, reveals mythic explanation as primitive, childish, fantastic and flawed; an opposite reading of the same issue might say that myth openly shows itself as the true guiding impulse in every search for origins. 
There is something rather mythic in the premise of the principle of the correlation of parts, with its attempt to give structural—even narrative—sense to the unknown by connecting it meaningfully to the known, and the Walam Olum literalizes this with its offer of Native American lore. But the structure of the poem (including its many contentious elements) also offers insight into the principle's own self-mythologizing tendencies. Consider the imagery of the principle. The remnant, or core, that founds the excursion of thought is its beginning, giving the appearance of a base, of an origin, and a reliable token of truth. The image itself, bone, or in the Latin word that provides the scientific root for terms dealing with bone, ossa (plural), suggests not only the notion of an organic core, but also firmness and stability. However in the functional position of ossa, Rafinesque places glossa: language, speech, verbal representation (though as a curious side-note on the poetry of happenstance, in that other source-language of scientific learning, Greek, the term ossa can designate "voice, an ominous or warning voice, prophesy, rumor"52). With glossa the expectation of pure hard truth gives way to that of signification, rhetorical gesture, and inevitably to that of uncertainty. Cuvier's ossa is not merely an anatomical fragment, but like every origin (arche) it is the guarantor and anchor, the firm foundation upon which equally solid knowledge should be built. But story begets only more story, and glossa announces itself as discursive, speculative, even literary. Part of Rafinesque's move, vis-à-vis Cuvier's principle of the correlation of parts, is to show the fundamental instability of the principle's operation; the PCP is inescapably discursive, and Rafinesque's Walam Olum highlights this.

52Liddell and Scott's Lexicon: Abridged from Liddel and Scott's Greek-English Lexicon. Oxford: Oxford UP, 1994, page 502 . 
The many webs of possibility that persist for explaining the Walam Olum attest to a text that remains largely undecided. Even decades after its "outing," nothing seems fully settled about this work, neither its motives for being, nor its principles of construction, not even the truth-value of its content. But rather than an aberration, this uncertainty is precisely the modus operandi of informed modern speculation. Returning to the issue of shifting epistemological orders, Baudrillard succinctly limns the shift from a premodern order of fixed meaning (characterized by unreflective certainty) to the modern one of inquiry and signification (characterized by automatic skepticism) when he explains that "counterfeit is born with the Renaissance," (simulations 83). The arbitrariness of the sign, the fluidity of meaning under the conditions of representation freed from identity and analogy that accompanies the shift into modernity, one which Foucault tracked extensively in his archeology of the modern era, The Order of Things, is a well-worn axiom of semiotic analysis. Umberto Eco offers a trenchant statement of this phenomenon in his Theory of Semiotics: "every time there is possibility of lying, there is a sign-function ... the possibility of lying is the proprium of semiosis ..." $(58,59$, emphasis in original).

Vivid though it is, Eco's statement offers a nonetheless limited view of the relationship between knowledge and signification in that it presumes the arguably spurious distinction between content and representation. It is in this respect that the shift toward the modern episteme becomes especially complicated, particularly in terms of the so-called sciences and their varied cultural functions. The privilege modernity affords to any knowledge regime fortunate enough to operate under the moniker of "science" is well documented, and its corollary is science's exercise of tremendous cultural authority, 
authority of oftentimes mysterious purview and obscure limits (even to its own avowed practitioners). As to its operative methods, one of the basic precepts of the scientific model of knowledge is that it is ever-contested, subject to constant change, perpetual revision, a principle that is often conceptualized as refinement based on an everimproving grasp of content (though many theorists of the pursuit, such as Thomas Kuhn or Paul Feyerabend, have strongly disagreed with this teleological model ${ }^{53}$ ). This commitment to "correction" is reflected in the sciences' consistent use of the term "theory" to describe even widely agreed upon de facto axiomatic principles, and gets theorized in the principle of scientific "falsifiability" as espoused by Karl Popper and others. ${ }^{54}$ To put this in stark terms, there is implicit acknowledgment in the sciences that much of what passes for knowledge today will have to be changed-i.e. is fundamentally untrue. Inasmuch as science embodies modernity's ideal form of knowledge and the methods of its apprehension, it also passes judgment on knowledge as unstable and insecure, a value with pretensions to essential claims of being, but whose actual status threatens a constant becoming.

In spite of content in flux, the products of knowledge must allow for functional interface; they must effectively join into network with other established and normalizing structures of meaning. In other words, all knowledge demands a discursive connection to the existing knowledge that precedes its appearance. According to Cuvier's principle, a solitary fossilized bone is no isolated curiosity, no stand-alone fact or knowledge-end in itself, but rather it is a terminal ready-wired to reactivate (and thus metaphorically

53See Kuhn's Structure of Scientific Revolutions. Chicago: University of Chicago UP, 1962; and Feyerabend's Farwell to Reason. London: Verso, 1987.

54For more on this theory, see, Keuth, Herbert. The Philosophy of Karl Popper. Cambridge: Cambridge UP, 2005. 
reanimate) a once-living organism and integrate it into the horizons of understanding appropriate to the newly emerging natural sciences. The principle of correlation, with its obvious reliance upon speculation and narrative structure, raises questions about the selfsufficiency of all scientific data (arguably anything that is to be communicated submits to narrative—or at the very least rhetorical—principles), especially in a cultural environment in which "scientific" knowing occupies such a foundational status and is so often summoned as authority for even non-scientific endeavors.

Mindfulness of the discursive component of scientific knowledge or even awareness of the interdependence and complicity between scientific and non-scientific knowledge-discourses informed theory and practice in Rafinesque's time. The Hegel/Schelling/Holderlin collaboration, "Oldest System Programme of German Idealism," bears traces of this when it calls for the elaboration of a "mythology of Reason," suggesting the need for a meaningful narrative structure. Rafinesque's own use of epic poetry as the vehicle for communicating his philosophy of nature shows a keen concern for the relationship between form and content (an example all the more striking given the importance Rafinesque placed on the articulation of this theory, as seen in his letter beseeching John Torrey to see it through in the event of his death). In his analysis of early media (another famously complex domain with respect to the differentiation between content/representation), Siegfried Zielinski discusses Rafinesque-contemporary, Johann Wilhelm Ritter, pioneer in the study of electricity and member of the German Romantic/scientific scene of Goethe and the Jena crowd. In a lecture entitled "Physics and Art," Ritter posited a knowledge-function to each aesthetic medium. The epistemic contribution of painting is the creation of what Ritter called, "half-space," which 
Zielinski explains, “... partially gives back to humans the necessity of an active role, for the observer is compelled to complete the image space ..." (177-8). This interplay between the partial known and the imagined whole, between data and speculation, sounds remarkably familiar. And though overtly concerned with aesthetic effects rather than knowledge acquisition (again, a debatable dichotomy—especially to Naturphilosophen), Ritter's "half-space" recalls the principle of correlation in acknowledging the role of imaginative projection (one could even say creation) inherent in the process of apprehension. Between Ritter's projected spaces and Cuvier's imagined correlations we see the rough outline of a largely unspoken poetics of science that issues from its own speculative thought and the combined impulses of curiosity and creativity that power that thought. In keeping with this experimental and exploratory ethos, we could merge the ideas of these two scientific contemporaries (and contemporaries of Rafinesque) and say that Ritter acknowledges the kinship between science and aesthetics, while Cuvier's principle of correlation at once validates and illustrates Ritter's theory by absorbing and systematizing it into its operation. Toward fulfilling the promise of this merger between scientific speculation and aesthetic practice there stands Rafinesque's Walam Olum as perhaps its most Baroque and beguiling example.

It is here that Baldwin's label of "literary madman" might be revisited and reconsidered as generally accurate but imprecise, not so much because of its inapplicability to Rafinesque, but on account of its facile assumption of the purity of the sciences and her methods. But assuming that Rafinesque's text at once exemplifies the principle of correlation, while also pushing its logic to the extreme limit, it is probably no surprise that the Walam Olum's closest parallels come from the realm of literature. The 
basic content of the poem is the appropriate and familiar stuff of cultural epic, a genre that already encompasses the discrete but overlapping realms of history, myth, religion, and ethnic identity. It begins with an account of creation; as a beneficent deity creates the earth and begins to populate it with life, a parallel malignant demiurge produces "powerful men and those water monsters ... he created the flies and he created the mosquitoes" (Rafinesque/IHS 22-3). In spite of this rather Manichaean parentage, the entities of the world live for a time in peace until a serpent-god unleashes a great flood, driving the people first to the cold north and then toward the east (apparently across the Bering land bridge into what is now North America). The text then traces how this Urtribe gradually spreads and splinters through struggle and schism, forming the many groups that finally people the continent. As previously mentioned, the pictographs conclude with the arrival of the first Europeans, where John Burns' addendum picks up to advance the narrative into Rafinesque's own day.

In the introduction to the Indiana Historical Society version, Lilly likens the literary contribution of Lekhibit (the presumptive name of the Walam Olum's author based upon a single mention in the Burns fragment) to that of Homer (Rafinesque/IHS xiv). In more than one way the comparison is apt. Homer is certainly the prototype for much Western literature, perhaps least fortunately that of cultural self-definition. The epics attributed to this apocryphal author gave the politically (and to a great extent culturally) fragmented communities of the Ancient Aegean and their many far-flung subsidiary colonies at least linguistic commonality through their narratives. Not long before Rafinesque's birth this socio-unitary literary model and its mandate had been further refined by James Macpherson to serve the emerging needs of identity as 
structured by nationalist/ethnic affiliation. The aftershocks of the fantastically popular (and ferociously controversial) Ossian Scottish epic were still reverberating during Rafinesque's adulthood having enchanted people as diverse as Thomas Jefferson and Napoleon Bonaparte, inspiring operas and paintings among other artistic tributes and providing impetus and model to the nascent Romantic sensibility. The climactic scene of Goethe's career-making novel Sorrows of Young Werther even centers upon the dramatic reading of the poems between its central pair of star-crossed lovers. Nonetheless, even at the time of publication the poems' authenticity was doubted by such notable figures as Samuel Johnson, and this intuition proved correct since eventual scholarship revealed them to be Macpherson's fabrication.

The 1762 release of this newly "discovered" epic story of a mythic king, ${ }^{55}$ the supposed work of an ancient Celtic court bard, Ossian (pronounced "o-shane"), provided a solid and intoxicating literary framework for galvanizing Scottish nationalist sympathies and general interest in the recovery of lost cultural roots, both of which were brewing at the time (Trevor-Roper 2009). It is worth noting the complex aesthetic mechanics at work in the text, a strikingly vivid example of the interplay of presence and absence that animates representation. The reader of the poems imagines (one could even say longs for) an idealized lost culture linguistically crystallized in the form of its lost verses. Macpherson promises to resurrect this forgotten but precious remainder, a task he can only accomplish in the already provisional mode of "translation," a literary form whose combined sense of intimacy and distance always tantalizes as much as it satisfies. Applying Ritter's notion toward literature, it could be said that translation produces a

55Fingal, mangled avatar of the "real" mythic Fionn mac Cumhaill, AKA Finn McCool, who reappears in Joyce's Finnegans Wake and O'Brien's At Swim-Two-Birds among other places. 
notably rich "half-space" by offering an especially porous artifact for the projection of extra-textual inferences and expectations. In the case of Ossian, with its combined aesthetic, ethnographic, archeological and anthropological pretensions, the already heightened sense of wish-fulfillment that attends reading a work only available in translation is multiplied as an imagined poem and its people flicker like an evanescing ghost for the reader just beneath Macpherson's words.

The promise of recapturing a lost people and their ways is precisely what animates Rafinesque's approach to linguistic archeology (actually, any literary payoff is relegated to mere byproduct). It is even tempting to think one hears a trace of Ossianic pathos as he describes his application of the principle of correlation to ancient tongues in Good Book:

Give me but a single genuine word of an ancient or extinct Language, and I can find out its analogies with all others. Give me 2 or 3 or a few, and I can trace its alliances. Give me several, and all its origins, parentage, filiation, claims, affinities, peculiarities \&c can be traced. The larger the Vocabulary collected out of any source the better can we proceed in the investigation — and the whole leads to know the migrations, contests, habits, manners, civilization, religion \&c of the extinct Nation and cluster of human beings of Yore ... (70-1)

At the surface there are but a few surviving words, below this the essence of a people. And though epic poetry is not directly invoked, what the paragraph's final sentence promises might as well be a laundry list of the information we expect from one of these literary instruction manuals of a culture: migration (just as the Trojan survivors flee to people distant Italy under the guidance of Aeneas, or the Delaware cross the Bering Strait); contests (as when Odysseus plays games against his Phaeacian hosts, or Pollux boxes Amycus, Arjuna strings his bow, or any of the many more deadly competitions that 
crowd epic literature); and of course the intimate snapshots of basic cultural/religious practice that permeates every people's poetry. However, lest we mistake this enterprise as merely the "scientization" of Ossian, Rafinesque goes on to add an important element: "[this] knowledge may be confirmed or increased by the study of their Antiquities, Monuments, traditions and annals of extinct Nations." What Ossian would prefer to conceal - the "factual" back story behind its verses, the "true" history to which the poem belongs, its unalloyed semiotic dependencies and imported contexts of meaning Rafinesque wishes to foreground. By his account, the "reconstructed" glossa is overtly intertextual, openly reaching out for connection to the various knowledge structures-no matter how imperfect or partial—upon which it is dependent, and to which it hopes to join up.

Newman begins his account of the Walam Olum by invoking what, theoretically speaking, is perhaps its more appropriate literary analog: the Yasusada journals that variously vexed and delighted the English language poetry community of the mid 1990's. These notebooks full of poems, letters, English assignments, shopping lists and other jottings were reputed to be the work of a Hibakusha, a witness to the Hiroshima bombing. Uniquely attuned to the sensibilities of the Western avant-garde and almost wholly unpublished himself, after his death Yasusada's private writings were discovered by his son whereupon they were turned over to a trio of translators, rendered into English, and gradually began appearing in Western poetry journals. The revelation of Yasusada's nonexistence (along with that of his son, the translators, and nearly everyone involved in the story), as well as the realization that the poems had been written in English, prompted outrage from many of those taken in, with Arthur Vogelsang calling the project, 
"essentially a criminal act" (quoted in Nussbaum 82-84).

However, the theoretical response was a bit more nuanced. Marjorie Perloff argued that the poems be understood as an aesthetic meditation on the impossibility of accurately depicting the "other," a prompt to reexamine texts, authentic or otherwise, that purport to represent impassible cultural differences that by nature defy representation (Yasusada148-166). Perloff cites a wealth of clues strewn throughout the text-Barthes' Empire of Signs, Yasusada's fascination with Jack Spicer, among others—which signal that the collection is not meant to be read as an authentic diary but rather as an elaborate intertextual work from within a realm of critical self-reflexive writing. Mikhail Epstein's response to the "hoax" was a call for a new domain of "transpersonal" authorship: "this writing in the mode of otherness is not just a matter of pseudonym, but rather of hypernym ... hyper-authorship is dispersed among several virtual personalities which cannot be reduced to a single 'real' personality" (Yasusada 134).

What many of the theoretical responses to Yasusada recognized in the poems is the operation of something that could be provisionally described as a "meta-positing." All texts, no matter how seemingly self-contained, naturally rely upon outside structures of meaning to give them sense (one facet of the Derridean absent supplement). But the Yasusada poems overtly gesture beyond their own scripted borders toward an outside ideational realm upon which they are dependent, a textual unconscious that both enables and limits their signification. The journals force the reader to marshal an array of outside "data"—commonly shared knowledge and impressions about history, war, Japanese culture, the effects of the atom bomb, technology and its impact on tradition, the interplay between language and identity—and activate these into the reading process. These pieces 
of data are sometimes incomplete, uncertain, imprecise, even flawed (Perloff points out, oftentimes obviously so), but they are nonetheless actionable - that is, they combine to produce an exceptionally vivid overall picture, so much so that the reader is tempted to suspend her/his awareness of the provisional information upon which this picture depends. Undoubtedly it was this effectiveness that led to the charge of hoax, and which gave it its sting for those "taken in."

Nearly every defense of the Yasusada author ${ }^{56}$ (or Rafinesque) depends in some way upon extricating the project from the staining label of "hoax." Brian Mchale has even elaborated a taxonomy of hoaxing in order to properly situate the journals. He argues for differentiation between "true hoaxes," which are designed to endure in their deception (Ossian qualifies, as does James Frey's A Million Little Pieces), "trap-hoaxes" which are meant to humiliate or shame upon revelation (Sokal or Ern Malley, for instance), and so-called "mock-hoaxes," such as Fernando Pessoa's many constructed literary identities or the Yasusada journals. One of the ironies of this move is that if there is an obvious theoretical explanation for Yasusada it is in its vivid questioning of authorial intention as guarantor of a text, and in order to exonerate the journals one must argue that the authorial intent was not to deceive (which is the basic defining feature of a hoax). But what may in literature amount to a question of intent, can elsewhere be understood as an issue of operational necessity. In the Boston Review, Harvard professor of Asian Studies Stephen Owen wrote of Yasusada, "it is an obvious fact that when reading poetry from another culture, if we are seeking only that which confirms our own prior interests and anticipations, then a hoax will always satisfy us far more perfectly than

56The presumption is that the author is Yasusada enthusiast and editor, community college professor Kent Johnson, but Johnson continues to deny this. 
the real thing" (Summer 1997). That which to Owen makes Yasusada unsavory as poetry — the associations and "meta-positing" that the poems encourage, the appeals they make to our always-imperfect base of knowledge, the agreement they attempt to secure with "our prior interests and anticipations"- - these also could be used to characterize the operations of pictographic palingenesy, the principle of correlation, or countless other "theories" that give rhetorical shape to evolving forms of thought. As has been argued here and elsewhere, between its own explanatory ambitions and the demands placed upon it by cultural expectation, science often assumes an oracular mode that involves the construction of narratives, narratives which connect new knowledge with old, which make sense of once disparate and disconnected "facts," and which open the possibility for new actionable information. Perhaps the best of such narrative explanations is the one that can most convincingly join up existing strands of knowledge into a compelling picture, thus creating the most viable and functional half-space. But there is no guarantee that such an account will remain convincing, nor that one moment's iron-clad explanation will not constitute tomorrow's intellectual embarrassment. For the appetite that seeks total veracity in all knowledge, it is perhaps most judicious to reckon culturally embedded scientific explanation (and arguably that is most if not all of it) as an expansive unstable continuum upon which truth and falsity are to be found telescopically connected to one another in some shifting degree. The Walam Olum is just this kind of explanation.

In trying to seek out the historical nature of the Walam Olum, it would be wrong simply to dismiss the notion of hoaxing as a cultural force during Rafinesque's time. The manufacture of phony authenticity for a variety of purposes was rampant during the early $19^{\text {th }}$ century, as attested by such striking examples as the notorious Kinderhook Plates, 
showman-pioneer Gilbert Imlay's Louisville-set melodrama/land advertisement of stilldebated parentage, The Emigrants, or the rise of roving hucksters like P.T. Barnum. Rafinesque was himself famously hoaxed by host John Audubon while a guest at the latter's home in Western Kentucky. Apparently as retribution for the destruction of a beloved Cremona violin, an instrument Rafinesque had smashed trying to bring down an especially juicy specimen of bat that flitted through the room one night, Audubon, while leading the naturalist on exploratory excursions through the wilds of the region, would spin vivid descriptions of the exotic fauna that usually crowded the area but which at that moment lay hopelessly out of sight. ${ }^{57}$ Enthralled and convinced, Rafinesque even published a few articles based solely on Audubon's testimony, which surely did little to help his overall reputation. But in addition to cases involving the defrauding of others for personal gain, or for the satisfaction of malicious or vengeful impulses, there are also more mysterious examples of the interweaving between truth and its opposite (however that may be reckoned), and Rafinesque was involved in one notable example. The practice of scientifically describing, and even classifying, based on second hand accounts was not only acceptable (though not preferable) in Rafinesque's time, but even oftentimes necessary given the problem of uniting experts with sometimes hard-to-get specimens. Long before Lewis and Clark made their famous journey into the unknown, trapper Charles LeRaye was kidnapped and dragged throughout the west during a four-year (1801-05) captivity by the Sioux. In 1812 his narrative of the ordeal and of his travels in the as-yet-unseen (by white men, that is) wilderness was published, and it gave sufficient detail for Rafinesque to be able to classify and assign scientific name to heimionus, the

57This included the infamous Devil-Jack Diamond fish, a monstrous Ohio River denizen, several feet long and with scales hard enough to be bullet-proof upon which hunters could strike a spark for a campfire. Seen sunning itself on the water's surface by Rafinesque from a great distance, this turned out to be nothing more than a dead branch. 
American mule-deer, by way of LeRaye's description. The name and classification stuck and holds to this day; LeRaye turned out to be an invention and his account merely a fantastic fiction..$^{58}$

Whatever the Walam Olum's “actual status," perhaps some kernel of fact, some bony relic, remains buried within, either within its pages or within its back-story or merely off to the side, part of its status as a meta-narrative about the uncertain nature of knowledge. The phantasmal Homer had first Chapman as translator and then Heinrich Schliemann to unearth the remains of the historical Troy buried under centuries of rubble. Lekhibit may simply prove to be the bard of a truth that is by nature far more unstable.

58Dollar, Clyde D. "The Journal of Charles LeRaye: Authentic or Not?” MA thesis, Univeristy of South Dakota, 1974. 


\section{THE BONES OF RAFINESQUE:}

\section{VIRTUALITY AND KNOWLEDDGE'S DEFERRED PROMISE}

According to legend, at the time of Rafinesque's 1825 firing from Lexington's Transylvania University (familiarly known as "Transy") the terminated professor unleashed magical forces to vex the institution in revenge. This lore is loosely based on his own version of events from Life of Travels: “... thus leaving the college with curses upon it and Holley (then president); who were both reached by them soon after, since he died next year at sea of the yellow fever, caught at New Orleans, having been driven from Lexington by public opinion: and the college has been burnt in 1828 with all its contents" (78). Apparently Transylvania administrators had forgiven this supernatural slight by 1924 (though it continues to this day to be invoked as both explanation and excuse by students and staff) for that year the university sponsored a project to have Rafinesque's remains exhumed from their resting place in a potter's field in Philadelphia and reinterred in a dark chamber on the lower floor of Old Morrison, the school's imposing neoclassical administrative building.

Charles Boewe recalls talking to the last surviving witness to the exhumation, Robert K. Spencer, who just happened to be Boewe's textbook representative when he was still a fledgling professor. Spencer had skipped school that day to watch his father, James, supervise the dig and he recalled to Boewe that among the various bones unearthed by the search there was a, "massive skull," an outsized relic whose distinctive shape, "suggested a man with a bulging forehead" (Boewe, Profiles 374). Boewe relates 
how, at the time, he and Spencer agreed that this feature was consistent with the one surviving image of Rafinesque known to be authentic, the engraving featured on the frontispiece of his 1815 publication, Analyse de la Nature. ${ }^{59}$ They also agreed about this trait's meaning, a conclusion consonant with Audubon's description of Rafinesque upon his first encounter with the "eccentric naturalist": "his forehead was so broad and prominent that any tyro in phrenology would instantly have pronounced it the residence of a mind of strong powers" (Profiles 368).

Rafinesque likened phrenology to astrology, calling it "a vain pursuit," and a "mere hypothetical horoscope of the brain and its propensities" (Celestial Wonders 25). Pseudoscience though it may be, Rafinesque's description acknowledges the metaphorical power of this branch of "study" for giving form to the otherwise intractably disembodied feature that we call mind or intelligence. Like the autodidactic protagonist of Edith Thomas' L'Homme Criminel ${ }^{60}$ who “diagnoses" himself as genetically felonious by his casual reading of a library book on physiognomy-based positivist criminology, Audubon, Spencer and (at the time) Boewe could not help but recognize the intellectual significance of this striking physical characteristic. The shape of Rafinesque's head becomes the legible trace of an otherwise invisible intelligence.

In this way the skull of Rafinesque joins up with a host of metaphorical tokens that have guided modernity's attempt to give concrete form to this highly prized, but largely indefinable and stubbornly amorphous trait. The measurement of IQ, the folds of the brain, the enduring legend that humans only harness ten percent of their gray matter

59The mystery surrounding Rafinesque portraiture and the debates concerning the authenticity and accuracy of the purported surviving likenesses are the subject of a full chapter in Boewe's Profiles of Rafinesque.

60Paris: Gallimard, 1934. 
for everyday living (the exact quantity varies according to the telling), or the Iron Curtain-like divide that separates our logic from creativity in the left and right hemispheres, all of these fables speak to modernity's obsession with the powers of intelligence, our faith in its capabilities, but also the way that this capacity eludes direct conceptualization, even—or perhaps especially —in the language of scientific thinking, rooted as it often is in material causes. Within each of these images there is emphasis on the potential of intelligence, its possibility and promise - un(der)tapped though it may be, as if mental capacity were best cognized as the coil of a spring. Whether in the guise of the (nearly) uninhabited uppermost regions of the intelligence scale, or some as-yet unlit treasure vault of the brain, the imagery suggests a kind of unrealized mental capacity and latent super-knowledge that up to now has been reserved for those future races and alien invaders of cinema.

Intelligence, then, is not unlike its ostensible object, knowledge. For knowledge too oftentimes operates largely by way of its sense of unrealized-and even sometimes unrealizable_-promise. As a site of ideological investment, one of the premises of modern knowledge is that it works to unite the actual with the potential, to make the wonders of the imagination real and available. But as such, knowledge itself often becomes just this kind of ideational wonder, always deferred, never instantiated, a hope rather than a reality. This is not to say that the pursuit of knowledge in modernity has not been extremely fruitful or generated its share of wonders. But the drive for knowledge acquisition often exhibits a kind of paradox in its quest for fulfillment. Like the Lacanian conception of jouissance, ${ }^{61}$ knowledge acts as the erotic goal for much intellectual

61See, Lacan, Jacques. The Seminar of Jacques Lacan, Book VII: The Ethics of Psychoanalysis. Ed. Jacques-Alain Miller. New York: Norton and Co., 1992. Pages 167-218. 
striving, but also as the essentially unattainable promise that governs the eternally unrequited character of that pursuit. No matter what we now know, it is but a partial and pallid reflection of what may one day be known. No matter who we are now, we can learn to be something different, perhaps something more. Knowledge as a postEnlightenment cultural value is always to some extent conceived as, and motivated by, what it not yet is, and Rafinesque, who embodies the modern ideology of learning, in more ways than one illustrates this fictive promissory aspect of knowing.

Actually, true to form, Rafinesque's skull is a fundamentally unstable emblem of intelligence and knowledge — that is, of the mind's potential as understood according to the ideological valuation of modernity — and therefore for the purpose of this analysis it becomes a vivid theoretical image. The bones of Rafinesque turn out to be "inauthentic," or perhaps more appropriate to the argument, merely virtual. Boewe, ever the sleuth, determined for his article "Who's Buried in Rafinesque's Tomb?", that according to the measurements of the dig and the description of the contents thereof, the exhumation was far too shallow to reach the scientist's resting place in his pauper's grave. The bones spirited to Kentucky and now resting in that Transylvanian crypt must belong to one Mary Passimore (382). ${ }^{62}$ So in terms of Boewe's line of inquiry about the remains now resting at Old Morrison, the only just response to the question posed by his title is, not Rafinesque. But arguably, the contents of that crypt could not be more appropriate as a symbol of knowledge, and thus as a symbol of Rafinesque—especially on account of their problematic status, especially by virtue of their uncertainty. For what is buried in Rafinesque's tomb is exactly the same thing that Spencer saw emerge that day from the

62According to Boewe, Transylvania officials refuse to allow analysis of the bones now interred in Old Morrison, in spite of numerous requests by scientists and their promises to treat the remains with the utmost respect and keep their findings within professional circles. 
Philadelphia potter's grave, and what Audubon recognized in the features of his "odd fish" guest: mental capacity as matter. Like the shape of Rafinesque's head, his remains are another case wherein the vapors of the incomprehensibly ideational must assume determinate concrete form, word must be made flesh; and in such an instance factual accuracy is less important than the power of metaphoric illustration.

Forensic phrenology notwithstanding, Rafinesque was a keen purveyor of the promise of knowledge precisely as promise. One of the ways this took shape was in his visions for how knowledge could be harnessed to determine the future shape of society. Harboring longtime socialist leanings, Rafinesque often deployed his intellectual talents toward a kind of speculative politics of welfare. Though aware of many of his utopianminded contemporaries such as Charles Fourier, or domestically, Robert Owen, founder of Indiana's Owenite community at New Harmony (a collective he at one time considered joining), Rafinesque's musings often took him away from the strictly political and instead toward theorizing those embedded institutions that ensure the stability of communities or that shape their character. In addition to his lifelong concern for education, Rafinesque was interested in overhauling the economic structure of society in order to eliminate competition and guarantee parity for deserving citizens. In The Pleasures and Duties of Wealth, perhaps the closest thing to a manifesto ever to issue from his pen, Rafinesque makes the diagnosis, "the besetting national sin of America is cupidity" (27). The principle of "mutualism" that Rafinesque puts forward as remedy is in part dependent upon eliminating the use of wealth for speculations - for this merely facilitates greedand instead basing the monetary system directly on labor performed (10).

This tract, one of the last works published by Rafinesque, is a philosophical 
counterpart to an economic system which the scientist-inventor had devised many years prior. Like the ideal equivalence between labor and its recompense, the so-called Divitial Invention was designed to ensure a more direct correlation between various types of ownership and wealth through a system of exchangeable coupons to stand in for personal assets. The adoption of these divisible chits of value (essentially a type of alternate currency) would allow greater flexibility of resources for those of more modest means and those whose worth was of a type otherwise unable to circulate. Rafinesque coined the term "Divitial" from the Latin word dives, "rich, wealthy," on account of the expectation that after the deposits were converted into currency they would earn interest and a dividend would be regularly paid to the holder. Thus the system would create wealth. Rafinesque patented the Divitial system, and a Philadelphia firm even instituted it successfully for a few years, though by the time of his death in 1840 the inventor seems to have long since been effectively cut off from the enterprise and his economic system to have come to the end of its brief life as anything more than theory (Warren 180).

The intellectual as a recognizable figure and cultural trope, even as it describes Rafinesque, naturally predates him, and arguably has some surprisingly ancient antecedents, as does the conception of that identity's exaggerated abilities and foibles. Thales of Miletus, hailed by tradition as the first philosopher (and therefore an exemplar of intellect's essential character), illustrates a prototypical version of the comically absent minded professor. In Theaetatus Plato has Socrates recount how the Ionian thinker was so lost in contemplating the constellations overhead that he failed to watch his step and fell into a well (174 A). But the fantastic potential of intellect is also part of the legend of philosophy's original practitioner. Aristotle relates that upon being chided over the 
pointlessness of philosophical speculation, Thales used keen observation and analysis about the growing season and its relation to supply and demand to make a killing in the olive oil market, an anecdote that confirms a mental correlation between genius and the ability to outmaneuver others strategically, even in economic contexts (Politics 1259a) ${ }^{63}$ In spite of the Divitial Invention's unrealized potential as a widespread engine of wealth, Rafinesque was apparently a genuinely canny businessman, though the precise relation of his business sense to his broader intellectual pursuits remains uncertain. Hailing from a merchant family, he amassed a fortune while in Europe only to lose it over time between various ventures and the expenses of a wife and daughter he left behind in Italy. ${ }^{64}$ Once in the United States, his intellect and entrepreneurial spirit collaborated toward a number of projects with assumed commercial potential, but few amounted to much more than a supplementary income. ${ }^{65}$

It would surely be an insult to the ambitions of critical intellect if its founding mythology amounted to mere get rich quick-schemes, bald aggrandizement of the individual's material self-interest. So appropriately the legend of Thales does not merely inaugurate the intellectual as the potential master of markets, but also as Philosopher King — or to give it more modern spin and terminology, as realpolitik nation-builder. According to Herodotus, the war between the Medes and Lydians had no end in sight until Thales predicted a full solar eclipse would occur during heated battle. When this came to pass, fear prompted the laying down of arms and immediate peace negotiations (Histories 1.74). In the legend of Thales, the trained-up intellect seems to have unique 63This anecdote is reiterated in Diogenes Laertius, Lives of the Eminent Philosophers, Book I, 1.1.27. 64For an overview of some of Rafinesque's wildly successful early business ventures, see Warren, page 37. 65Rafinesque's botanical cure for tuberculosis, Pulmel, seems to have been one of his most successful domestic ventures, though it did not yield anything remotely close to wealth or riches (Warren 121). 
access to both riches and brute power; as if in anticipation of the Hobbesian demigod Leviathan, the idealized genius of lore is equipped to cultivate and mete out fearful punishments as well as just rewards, necessary ingredients to good government. ${ }^{66}$ Once Rafinesque's Divitial Invention failed to transform the arena of American capitalist economics, he turned toward other possibilities for the exercise of his idealist political vision. In an unsolicited 1825 letter to Joel Poinsett, fellow botanist/scientist-traveler and then-minister to Mexico (as well as the namesake of the Christmas flower), Rafinesque requests that the representative send him vocabularies of indigenous Mexican languages: "the importance of these fragments to history are beyond belief ... [they] will enable me to trace the origins of all the Mexican Nations" (Boewe Profiles 24). Though the concern here initially seems to be for the reconstruction of ancient "nations" (perhaps not dissimilar to the project of the Walam Olum), the letter's second half introduces a vision for the construction of the new-born state still taking shape just to the south. Hoping to use Poinsett as a go-between, Rafinesque offers his Divitial Invention as the basis for the creation of a Mexican bank. But should his egalitarian economic system fail to entice on its own terms, Rafinesque offers to sweeten the deal with an irresistible asset to national security, a mysterious doomsday device:

As a further inducement for the Mexican Government you may acquaint them that I have made a dreadful Discovery in the Art of Defensive War. Or invented a New Kind of Artillery, a single discharge of which will destroy One thousand Men in Arms, one mile off, or sink a large Ship of War. This awful Invention will be communicated Secretly to all such governments who will grant me a patent or Privilege for my Divitial Invention. I hereby authorize you to offer the knowledge and use of it to the Mexican government if they grant me the privileges asked above. (Boewe 24)

66A combination of principles nine and eleven of Hobbes' "Rights of Sovereigns by Institution," Leviathan: or the Matter, Forme, and Power of a Commonwealth Ecclesiasticall and Civil. Cambridge: Cambridge UP, 1904. 125-6. 
In 1840's Pleasures and Duties of Wealth, Rafinesque optimistically quotes David Brewster-scientist, astronomer, university administrator, inventor of the kaleidoscope, and in an odd coincidence, son-in-law of Ossian's James Macpherson-that "the labors of science have no counterpart of evil" (Pleasures 21). Within a hundred years this sentiment would be utterly unthinkable even for Enlightenment Reason's most Pollyanna adherent. And whatever the reality of Rafinesque's promises to Poinsett (no other evidence of his proto A-bomb exists outside of this letter), they uncannily anticipate the character of the twentieth century's particular vision of progress, poised as it was somewhere between dreams of a salvific economics and the threat of manmade mass annihilation.

In Rafinesque's letter to Poinsett we see hints of the genetic connection between the broad and sometimes amoral scope of the so-called myth of progress and the more manifestly metaphysical utopian visions of modernity. Knowledge in the abstract becomes a kind of repository for the projection of hope (and sometimes fear) concerning humanity's someday self-realization. Pleasure and Duties of Wealth describes an envisioned ideal community within the ever-present (and arguably conceptually inescapable) horizon of individuals as laborers and owners. That this becomes a primary schema for the discussion of all matters political is likely the natural byproduct of a nearly universal cultural conception of the individual based on ownership and production. As C.B. Macpherson succinctly summarizes in his landmark study, The Political Theory of Possessive Individualism, "society becomes a lot of free and equal individuals related to each other as proprietors of their own capacities and of what they have acquired by their exercise" (3). Naturally then, every convincing political theory positing a 
community wrought by design will ultimately have to address the issues of work and wealth and their precise relation to one another. Rafinesque's version necessitates the elimination of competition and the "inducements" of "cheaper food and expenses by clubbing for cooking and everything else" (16). As to the issue of labor he offers a "proposal quite peculiar," in which the necessary work will be transformed-essentially aestheticized—into an experience approximating leisure by making it "as easy and pleasant as a festival." Toward this end "ploughing, reaping, manual labor \&c. are to be performed with songs, music and dances, just as if going to a wedding" (16). The glimmers of a Schilleresque "eutopia" based in the play-drive ${ }^{67}$ begins inadvertently to suggest Benjamin's “aestheticization of politics" (fascism—and likely, the more generous moods of Stalinist communism would also qualify) ${ }^{68}$ when Rafinesque explains, "this is certainly something new (unless martial music for soldiers is a pattern)."

The community of Pleasures and Duties is a kind of cooperative in which labor is more evenly distributed, and thereby generally reduced, but some type of system of ownership and exchange is preserved. Rafinesque envisions four hours of work each day per person, leaving the rest of the time for "study, reading, recreation, extra labor, exercise, meals, \&c. besides 8 for sleep" (16). The order of this list of leisure activities is telling in its glimpse of the values that will ideally guide this community of knowledge. For in spite of its future-leaning orientation, the text draws its authority from what Rafinesque sees as universal principles regarding the intellect. When Sir Thomas More coined the term "utopia" he stitched its fictitious nature into the word itself: Greek ou,

67Schiller, Friedrich. On the Aesthetic Education of Man. Trans. Reginald Snell. Mineola: Dover, 2004. The actual term used by Schiller, and rendered by Snell (among others) is “ideal state," Page 28. 68Benjamin, Walter. Illuminations: Essays and Reflections. Ed. Hannah Arendt. Trans. Harry Zohn. New York: Schocken Books, 1968. Page 242. 
"no,"+topos, "place"="no [real] place." Rafinesque perhaps unwittingly pays homage to More's self-conscious acknowledgment of playful make-believe when he proposes names for his fantasied community, among them Eden, Elysium, Arcadia and, in an echo of both Schiller and More, Eutopia (homophonic to More's imagined land, but this time using the Greek prefix $e u$, "good") (15). But apart from the as of yet contrary-to-fact existential status of the community, Rafinesque bases its values on what he understands to be realworld ethical imperatives. In the passage limning those duties of wealth alluded to in the pamphlet's title, he explains that "to foster and protect Genius is one of the highest prerogatives of wealth" (21, emphasis in original). He goes on to give further definition of his terms:

Genius however is not confined to Painters or Machinists, it applies and belongs to all Inventors, whoever seeks, finds and makes known useful or valuable facts or things, to Original Authors, Poets, Dramatists, Philosophers, Historians, Naturalists, Botanists, Astronomers ... as well as Manual Laborers, from the inventor of Sandals or Shoes, to that of Steam Engines and Telescopes. To all these the friendly help or patronage of Wealth is needful at present; in a better state of Society, it would be the duty of the public to reward them (21)

Knowledge — even just as raw potential—is to be enshrined as a kind of communal telos, the primary point of focus toward which the community as a whole should be oriented; it is the expected goal for times of rest, and the purpose of production's surplus, the anchor of both work and leisure.

Rafinesque explicitly explains the centrality of knowledge as a general cultural value, assigning its functional position in the scheme of human relations, in passages laying the philosophical foundation for Pleasures and Duties. Appropriately for a taxonomist, the section of the pamphlet critiquing society as it is currently structured reads as a kind of classification (though admittedly not a very rigorous one), defining the 
relevant terms, the actors, and their relationships. Some people fall either into the wealthy or destitute poor, and to further discriminate into subgroups, these may be divided into "Worthy ... and the Vicious or Unworthy." Fortunately there is a "third and medial class, which balances these two, and often happily preponderates: it is that nameless middle Class of Individuals neither rich nor poor, with a competence of property or emoluments of labor, that possess neither the superfluity of Wealth, nor dread the evils of poverty" (5). This middle is the ideal, "the Nucleus and main strength of society, and to which if all could belong, there would no longer be to fear the evils of exuberant Wealth or destitute Indigence." The key to erasing all poisonous difference in privilege and bringing everyone into the noble fold of one vast, peaceful middle class is the proper recognition, use and management of the three basic human powers. Rafinesque identifies these as wealth, industry and knowledge (6). Toward the necessary changes that will inaugurate a better society, wealth "should furnish the means," and "industry effect them." Standing centrally between the resources (wealth) and the results (industry) there is knowledge, pure possibility, the what can and what may be. In a Rafinesque Eutopia, wealth serves knowledge, industry realizes its conceptions.

Knowledge in Pleasures and Duties is discussed as a force so discrete and recognizable, so concrete and instrumental, one can nearly forget that its appearance in a utopian tract renders its status subjunctive. The rhetorical force of this gesture is appropriate to its context. Elsewhere knowledge appears more nebulous, discussed in terms befitting an abstraction, though admittedly one with a profound and extensive-if not even quasi-theological—investment. Atlantic Journal's first piece (following a short introduction) is a brief paean to "Latent Knowledge" (1), that combined mass of learning 
some of which is "nearly forgotten and lost," some merely "sleeping." Rafinesque includes within this notion the combined knowledges of all world peoples throughout history, as well as that not yet discovered: “...fortunately the latent or dormant may yet be restored and rendered yet available, by care, patient researches and exertions." The project he envisions is part recovery, part discovery, ${ }^{69}$ and presumably its ultimate destination is a state of total awareness that bridges historical difference and transcends the limits of time and place through its object, knowledge. Of course, like in its function as the engine of a Eutopia to be, what chiefly characterizes this latent knowledge is its state of constant irremediable deferral. Perhaps what Rafinesque imagines could be understood as a kind of naïve Hegelian "end of history" culminating in pure selfawareness under the radiating glow of "absolute knowing," but for now, the very pathos and yearning that accompanies musings on this state of pure wisdom mark it as unrealizable as utopia’s "nowhere."

The kind of knowledge envisioned by Rafinesque, and the imagined state wrought by the total apprehension and comprehension of that knowledge, both echoes Hegel (at least in certain elements) and anticipates the fantasies of Progress that have preoccupied much science and fiction during the last century in particular, and not merely in their moments of overtly utopian reverie. The notion of knowledge as a kind of quantifiable value, always in a state of increase or decrease, and capable of bringing salvation or doom in the wake of its discovery or loss is a familiar enough idea to qualify as an article of culturally shared common sense. The potency of this idea permeates a well-worn imagery of enlightenment versus dark ages, times in which whole cultures rise and fall

69The last entry of Atlantic Journal is a blurb for The Book of Knowledge (no other evidence of the text exists), promising, "Discoveries and useful Facts, latent knowledge restored, lost knowledge reestablished ... facts and truths neglected or forgotten" (212). 
according to the threat of invading Vandal barbarians or conversely the accomplishments of liberator-luminaries. Regarding the powerful grip this picture holds on modernity's imagination, Walter Benjamin, in the Arcades Project section "On the Theory of Knowledge" writes that, "overcoming the concept of 'progress' and overcoming the concept of 'period of decline' are two sides of one and the same thing" (Benjamin Arcades 460). In this capacity knowledge becomes reified as a discrete and identifiable though elusive and exceptional entity that has the power to elevate humankind from the base state to which nature impels us. But at the same time knowledge appears as an article of faith, a self-justifying teleological goal, akin to the metaphysical gnosis of ancient thought. Hans Jonas, in his attempt to illustrate certain parallels and differences between Gnostic and modern thought ${ }^{70}$ has observed,

'Knowledge' is by itself a purely formal term and does not specify what is to be known; neither does it specify the psychological manner and subjective significance of possessing knowledge or the ways in which it is acquired. As for what the knowledge is about, the associations of the term most familiar to the classically trained reader point to rational objects, and accordingly to natural reason as the organ for acquiring and possessing knowledge. (34, emphasis in original)

This idealized understanding of knowledge—supposedly drained of any metaphysical pretensions-is perhaps the real mystification; it is certainly the more rarified and alien to modern experience in being purely formal, empty, abstract. The notion of knowledge as separate from any content, detached from any knower and centered squarely upon "rational objects" is as convincing as the notion of "natural reason," which is to say, only at the level of abstraction. Knowledge in action, especially according to modern contexts of usage, is quite the opposite in being nearly always bound up in its subjective

70In particular, existentialism; see Jonas' "Gnosticism, Nihilism and Existentialism," in the Gnostic Religion, pages 320-40. 
significance to knowers, the modes of its acquisition, and issues of its content; and while this content is not categorically irrational, it often is speculative or even fantastic. Jonas continues his analysis of different understandings of knowledge, specifically, knowledge as a metaphysical value: 'in the Gnostic context, however, 'knowledge' has an emphatically religious or supranatural meaning and refers to objects which we nowadays should call those of faith rather than of reason." Ultimately, this is not merely knowledge of the arcane, but also knowledge itself as arcana, as a cosmic end in itself, knowledge as it both circumscribes and escapes the boundaries of the material here and now and continues its rule into the realm of the hereafter, great or otherwise. According to this metaphysical scheme, the human soul and its qualities are to be measured in degrees of knowledge, thereby establishing a fundamental correlation that assumes ever subtler forms at later historical moments especially as the materialist imagery and cause-andeffect logic of scientific reasoning is eventually brought into play. The alchemical faith in a correspondence between matter's behavior and divine awareness assumes this primary identity between mind and spirit, a perceived equivalence that will reach even profounder maturity in Hegel's untranslatable concept of Geist. ${ }^{71}$

The cultural sacralization of knowledge—what we will call "gnosis" whether its use is literally liturgical or merely secular-metaphysical—does not necessarily render it a wholly positive value. The longstanding suspicion concerning the effects of knowledge, the pain of its acquisition and its indeterminacy of worth once acquired, is expressed as gnomic lament in Ecclesiastes 1:18, "he that increaseth knowledge increaseth sorrow." One could say that in its capacity as a metaphysical value, knowledge retains that aspect

71For a quick but incisive overview of Hegel's treatment of Geist, here rendered as "Spirit," see Stern, Robert. Routledge Philosophy Guidebook to Hegel and the Phenomenology of Spirit. New York: Routledge, 2002. Pages 34, 74, 135-82. 
of the mysterium tremendum ("mystery to be shuddered at/terrified of") that Rudolf Otto thought essential to all things numinous and that Derrida resurrected as central to his critique of Christianity and its relationship to Western rationalism (Otto 12, Derrida Gift of Death 7). Inasmuch as knowledge embodies metaphysical value, its relationship to us cannot function as anything but irremediably "Other," such that the quality of this relation falls somewhere between perceived indifference and abject terror. Here the ambiguity of the concept of "comprehension" comes into play, as we intuitively grapple with the complex and unsettling relationships of inclusion and exclusion, power and subjugation, in our roles as both subjects and objects of knowledge. We realize ourselves as entities thrown into a "truth" (knowledge) after which we will always seek, but which will always exceed our full grasp. Imperfect knowers who are in turn wholly known, we are like isolates standing in a circle of light encased by an endless ocean of darkness. Benjamin expresses this conundrum of gnosis in his meditation, "On Language as Such," when he avers, "that which mourns feels itself thoroughly known by the unknowable" (Reflections 330).

The autodidactic Benjamin was poised by reasons of history and personal sensibility to be a bridge between neo-Gnostic pessimism ${ }^{72}$ and a deflationary modern metaphysical epistemology. Drawing influence from Jewish esotericism, Benjamin spoke in the tones of the Hegelian dialectic as inflected through twentieth century Marxian terminology. He died just before the European debate about the Hegelian dialectic could reach its apex in Alexander Kojeve's influential lectures on Phenomenology of Spirit, a debate that perhaps made knowledge seem a more ambiguous

72This is the contention of Kristen J. Grimstad in her work, The Modern Revival of Gnosticism and Thomas Mann's Doktor Faustus. Rochester: Camden House, 2002. Grimstad credits this notion to several articles by Norbert Bolz, 37-8. 
value than ever before. ${ }^{73}$ Are we currently living the so-called "end of History," enjoying the era of "absolute knowledge"-i.e. the age of realized gnosis? Kojeve, in clarifying what the terms "end of History" and its corollary "end of Man" both mean, gives a picture of this metaphysical telos that—at least in its reckoning of aesthetics and playharmonizes with Rafinesque's knowledge-governed utopia:

... Knowledge (Revelation) is indifferently related both to natural Being and to human Being ... the natural World remains what it has been from all eternity ... Man remains alive as animal in harmony with Nature or given Being ... Practically, this means; the disappearance of wars and bloody revolutions. And also the disappearance of Philosophy: for since Man himself no longer changes essentially, there is no longer any reason to change the (true) principles which are at the basis of his understanding of the World and of himself. But all the rest can be preserved indefinitely; art, love, play, etc. etc.; in short, everything that makes man happy. (158-9, footnote)

True change disappears and knowledge becomes purified to the point of no longer needing philosophy, let alone human struggle. But in the end, Kojeve's state of absolute knowledge may bear less in common with the paradise of Pleasures and Duties than with Rafinesque's letter to Poinsett in which the bliss of a Divitial utopia is offset by the need for ingenious devices of mass destruction. The skeptic may be prompted to ask: if this moment we're living is truly the era of absolute Knowledge (as Kojeve argues, and Hegel implies) where is that pacific aesthetically-powered paradise? In response to this, Kojeve's interpreters and acolytes have observed that the all-inclusive post-Hegelian notion of knowledge (gnosis) recognizes and even subsumes "the unreasonable origins of reason" (Descombes 14, emphasis in original), including its violence and terror. In fact, in an effort to differentiate this metaphysical "knowledge" from the word's more

73This famous Hegel seminar, a series of Paris lectures given between 1933-1939 and attended by the likes of Georges Bataille, Jean-Paul Sartre, Maurice Merleau-Ponty, Jacques Lacan, Andre Breton, and others, forms the basis of Kojeve's Introduction to the Reading of Hegel. 
common, humble and strictly functional sense, Kojeve employs the term "Wisdom" (75) to signify knowing writ large - that is, knowledge in full awareness of the workings of apparent "unreason." As Kojeve proselyte Georges Bataille puts it, "we can ignore or forget the fact that the ground we live on is little other than a field of multiple destructions" (23), the implication being that mere forgetting does not make them go away. Returning to the above quotation from Kojeve, the operative term with respect to Knowledge and human being is "indifferently related." Negativity (that is, those acts of violence and upset formerly dismissed collectively as "the irrational") still exists and wreaks havoc but is now liberated from the burden of purpose; and the task of true knowing is simply to recognize and accept this fact. Knowledge/Wisdom/Gnosis by this definition is characterized by its tacit admission of the limitations of its own understanding.

By leaving knowledge somewhere between fully comprehended and totally incomprehensible, post-Hegelian dialectic thought strips gnosis of its utopian positivity while preserving its thaumaturgic function as a mysterious breeding ground for hope and fear-or put more neutrally, as the source for future possibility. Kojeve observed that the received disciplines_-including that so-called "love of wisdom" bequeathed by the ancient Greeks—are not adequate to capture knowledge in its full array: “'Wisdom' (is) opposed to Philo-sophy (and to Theology as well as vulgar Science)” (75). Rafinesque demonstrated similar suspicions about the efficacy of any one disciplinary regime, though it is important to remember that in his day branches of knowledge and their agents had yet to assume the same categorical closure that they would in another century. In fact, during Rafinesque's time the term "science" was still new, but the term "scientist" had 
only just been coined and was not yet fully accepted as the signifier of that vocation ${ }^{74}$ (Chapple 1); likely he was totally unaware of the title. For all of his obsession over classification and category, Rafinesque showed a remarkable openness to the many varied forms by which knowledge might appear, including those that we would regard as decidedly aesthetic. His "Fragment of a Philosophical Poem on Knowledge" in Atlantic Journal gives formal testament to this (as does World: or Instability), and describes a process of searching characterized in terms of darkness versus light with overtly metaphysical presumptions: "yes, God and truth are one, and both, what is,/Has been, will be" (36). When read alongside "Latent Knowledge," the jaundiced eye of contemporary criticism might take this poetic statement to be more melancholy than hopeful: God is Truth, which is knowledge; but the slender knowing of an imperfect present is always bookended by that wisdom lost to a vast dark past and whatever good or ill may yet visit us from the limitless abyss of the future. Here a glimpse of Lacan (another disciple of Kojeve) and his psychology of lack begins to show through, as knowledge becomes the mark of perceived deficit and the ceaseless striving to overcome that deficit-i.e. the site of Jouissance, a profound emptiness whose impossible remedy becomes the ultimate raison de etre: "this place is called Jouissance, and it is Jouissance whose absence would render the universe vain" (Ecrits 694). Given the little that actually is known and the unreliability of its channels of apprehension-that is, those limiting disciplines of study such as Philo-sophy, Theology and/or vulgar Science-the status of knowledge begins to look remarkably nebulous and uncertain.

74Actually, prior to the 1840's the term "philosopher" was often used to designate what we would call a natural scientist. 
This fluid nature, situated somewhere across or between fields of study, always simultaneously present and absent, suggests something more than a simple lack, and perhaps the status of gnosis-knowledge could best be understood in terms of the virtual. ${ }^{75}$ Indeed, the concept of the virtual (in its contemporary usage) is itself somewhat protean.

Precisely what does this word mean, not necessarily in any specialized capacity, but rather as a common and functional item of cultural discourse? Though in many quests for knowledge (not to say gnosis), a Google search yields as much confusion as awareness, in matters related to cultural disposition it can prove to be a remarkable resource, and in response to queries about "the virtual" it reveals a ranging and oftenused term that has people grappling for precise definition. Many definitions appeal to the realm of computer technology and electronic representation as the primary (if not sole) authority on the word's usage, but amidst these accounts there are others that try to capture the more fundamental existential quality of this flexible morpheme as it is pressed into service in contexts other than those created by cyberspace.

Answers.Ask.com features a user post that begins, "virtual is an adjective that describes something which is not tangible or an actual thing," and Webopedia begins its answer to the question, "what is virtual?" all the more simply and forcefully as, "not real." 76 From here the site goes on to explain the term's value for computer technologies, but returns to its fundamentally ontological underpinnings: "it distinguishes something that is merely conceptual from something that has physical reality," and to illustrate it offers up a heuristic dichotomy: the brain (real) versus mind (virtual).

75This is not to imply that Lacan's concept of lack is in any way simple; but it is possible that his notion could also be framed according to the notion of the virtual as well.

76http://answers.ask.com/Reference/Dictionaries/what_does_virtual_mean ; http://www.webopedia.com/TERM/V/virtual.html 
Assuming the validity of these ontological definitions it is safe to say that the notion of the virtual long anticipates the rise of computer representation, though this technology perhaps becomes the term's most vivid and illuminating (and thus largely inescapable) illustration. The birth of the concept may in fact extend all the way to the origin of speech (since what is language if not the first order of a virtual reality?), however the term itself seems initially to appear in Antonin Artaud's seminal work, The Theater and its Double, in that text's essay, “The Alchemical Theater." Here Artaud argues that, "there is a mysterious identity of essence between the principle of the theater and that of alchemy" (Artaud 48). Specifically, both create parallel and-importantlyintersecting worlds of symbols and concepts with respect to the domain of perception and matter, i.e. that which has been canonized and enshrined as "the real." "Where alchemy, through its symbols, is the spiritual Double of an operation which functions only on the level of real matter, the theater must also be considered as the Double, not of this direct, everyday reality of which it is gradually being reduced to a mere inert replica-as empty as it is sugar-coated-but of another archetypal and dangerous reality..." (48). Alchemy alludes to "what might be called philosophical states of matter," but theater to something even more universal, and it is at the point of this revelation of the philosophical/conceptual that "the virtual reality of the theater" and alchemy may be said to be akin to one another (49, emphasis in original).

What is crucial to recognize in Artaud's formulation is the extent to which it complicates any simple definition of what is real versus what is not. It is important to remember that one of the preoccupying themes of Artaud's text is that theater-in spite of its "imaginary" status_constantly threatens the realm of the real. This notion becomes 
especially acute in the text's celebrated manifesto, "Theater of Cruelty," where we are urgently reminded that what defines theatrical spectacle is that at any time it may break out from being merely virtual (i.e. merely spectacle) and degenerate into embodied acts of violence, mayhem or sheer force. Following Artaud's lead and dispensing with the obviously regulatory (and ill-defined) linguistic notion of a real versus unreal, it is perhaps more accurate to say that the virtual is less unreal than simply materially unrealized or even just under-realized, though this does not mute its potency, nor does it negate the many unexpected and unpredictable ways that the virtual intercepts and unsettles the "real," i.e. that which seems given on account of being embodied, instantiated and integrated into the commonplace, ready-to-hand order. One possible definition of the monstrous would be that it is a state exemplifying the imbalance between the conceptual and the material. A monster is an entity that assumes very definite shape, while remaining murky and uncertain in concept. Conversely, the virtual could perhaps be understood as over-realized in concept but under-realized in material form. Whether this qualifies as necessarily monstrous, per se (Artaud would perhaps argue so), it certainly renders the virtual (and with it the notion of gnosis that we have been pursuing) mysteriously phantasmal.

The fantastic virtuality of gnosis that gets so grandly projected as utopian dreams and post-Hegelian apocalyptic nightmares also distills itself at the atomic level of the individual. This is perhaps where the epic myths of progress and decline take on their most acute sense by being personally internalized as fictive images reflecting fears of mental perversity and hopes of exaggerated prowess. About his own future learning, Rafinesque muses, "I hardly know myself what I may not become as yet" (Life 148). 
Nearly everyone engaged in the educational process has some similar vested hope in the transformational power of learning (or at least in the system of qualifications that gives lip-service to that power), and the modern cultural imagination has given us no shortage of fables concerning the fantastically empowering and monstrously corrupting effect of knowledge on individuals. Movies and novels are strewn with the trope of the superheroic genius mind—Sherlock Holmes or Indiana Jones—but also with the image of the fragile intellect pushing learning to dangerous extremes: Doctor Frankenstein, The Invisible Man, Mister (or Colonel) Kurtz, to name but a few. Interestingly, Rafinesque joins these in being the fictionalized subject of James Whaler's 1931 epic, Green River: A Poem for Rafinesque. In spite of failing to become an enduring masterpiece, Hart Crane praised the work in a 1932 review in the journal Poetry on account of Whaler's portrayal of the "intimate aspirations of his subject" (44). Presumably Crane bases this comment on Whaler's own postscript, a biographical sketch shot through with the same speculative romantic pathos as the poem itself: "he became obsessed with dreams of scientific discovery, dreams which ... became a refuge from the hurt of his personal sorrows and the abuse of his contemporaries" (Whaler 150). In Whaler's poesy Rafinesque becomes a once pistol-wielding swashbuckler-scientist who retreats into the world of thought after being betrayed by his Italian wife. Falling into a wondrous cave housing the remains of a once enlightened but isolationist civilization, he is metaphorically reborn, emerging from underground back into the light, and in the process pledging to abandon his misanthropic obsession for knowledge. Throughout Whaler's poem a stark binary is affected by the text's moral conscience pitting desire for learning in opposition to erotic desire: "You spend your thoughts on fishes, worms, and 
weeds/Rather than study what a woman needs" (25/44). But through this apparent contrast the equivalence between the two is cemented, and hunger for learning comes to seem not so much the opposite of carnal yearning, or even its surrogate, but rather a perverse species thereof: "stung by a maggot wild as poetry/Or love,-my inexterminable lust/To know the essences and laws august ... Josephine ... May love defend you from my inward battle ... the daemon that becharms my mind" (40-1).

Fictive fantasies of the autodidact, a relatively small but distinct subset of the trope of the intellectual, seem particularly prone to themes of erotic irregularity. Though Whaler merely alludes to Rafinesque's autodidactic status by suggesting an inborn (perverse) proclivity to need to know- - "therefore something distorted me at birth/to be a seeker up and down the earth",77_elsewhere this trait becomes a marker of transgressive desire, generally. Hardy's Jude the Obscure aspires to become a scholar and attempts to teach himself. His plan is hampered when in a fit of "erotolepsy" he is fooled into marrying the churlish Arabella Donn (Hardy 112). At last resuming his self-study he is persistently haunted by obsessive desire for his cousin, Sue Bridehead, and their eventual marriage and incestuous union turns disastrously tragic through their children in a spectacular episode of murder/suicide. Far less sympathetic, though no less tragic, is Sartre's Self-Taught Man, whose autodidactic studies in the public library double as occasions to seduce young boys. The text climaxes with the symbolic destruction of this ambivalent figure as his desire and intellect are simultaneously thwarted upon being beaten and permanently driven from the library (Sartre 163-9). A recent vivid, and remarkably similar, version of the same theme is Max Cady from Martin Scorsese's 1991 remake, Cape Fear. Though already a brutish thug, Cady uses his prison sentence to 77 Whaler, page 40 . 
embark on an extensive autodidactic education that will facilitate a long-desired act of revenge: the premeditated rape of his former lawyer's adolescent daughter. Long before Lacan theorized desire as lack, Plato articulated the same intuition, as well as pondered the various metaphoric/metonymic sublimations, substitutions and associations that issue from those fantasies about what we want but do not (and by definition, cannot) possess. ${ }^{78}$ In fictional accounts of the autodidact, the general equivalence between the desire to know and erotic desire is further inflected such that yearnings both intellectual and sexual seem not merely unregulated but even irregular and transgressive. Even for the autodidact of fiction a certain consensual normativity pronounces judgment, but this only confirms the existing association between knowledge, desire and fear.

As is so often the case, Rafinesque seems not merely to illustrate but also to epitomize some facet of the workings of knowledge—even down to his skeletal remains. And this is certainly true in the case of metaphysical knowledge, gnosis in its virtual capacity as a dream-deferred, an ideational promise ever-postponed but always in some sense driving the here and now. At the end of his life, more or less shunned by the scientific community and failed within the academic establishment, Rafinesque turned his utopian hopes for learning toward the creation of his own university. "The Eleutherium of Knowledge" was a visionary consortium, really a think-tank of two, though Charles Wetherill seems to have been the benefactor leaving Rafinesque as the primary (if not sole) idea man. The Eleutherium's plan was to purchase a vast tract of land in unsettled Illinois for the establishment of several towns, Industry, Honesty, Benevolence and Tolerance, which together would comprise the city of Agathopolis. Within this imaginary city an imaginary university was to flourish, home to colleges of agriculture and labor,

78See especially the celebrated Diotima episode from Plato's Symposium, 201d. 
arts and sciences, teachers and languages, medicine, and a school for adult education. Obviously such an institution was never realized, but during its brief tenure the Eleutherium had already become the academic press for the "Central University of Illinois," publishing several works including a few of Rafinesque's most imaginative forays. Thus, in a way, Rafinesque, ever the idealist and an indefatigable searcher after gnosis, did succeed within the university, even succeeded at founding one - at least, a university of the mind.

It is possible that given modernity's quasi-religious expectations for knowledge and its capability, what it actually is and does comes as something of a surprise (this is certainly true for many readers of Kojeve). And after the twentieth century's demonstration of the tremendously amoral and even destructive power of knowledge, it is perhaps also possible that we are taken aback by what knowledge was and what it has done. For anyone invested in the acquisition and creation of knowledge (perhaps especially at the professional level) this uncertainty between what is imagined-even promised, and what actually materializes might raise ethical questions. Here I am reminded of Bill Readings' argument concerning the state of the modern university. "We have to recognize that the University is a ruined institution, while thinking what it means to dwell in those ruins without recourse to romantic nostalgia" (169). Like the university in ruins, the disparity between actual and ideal knowledge is with us, and apparent upon reflection. But perhaps Rafinesque (and the autodidact in general) provides a useful case study somewhere between his Eleutherium and his "remains" at Transylvania. Knowledge is never fully instantiated in the here and now, nor is it irretrievably consigned to the realm of the ideal; it exists virtually, somewhere in between, and the 
goal is to invest fully and knowingly in this in-between. Perhaps Rafinesque had some inkling of this, and perhaps that is why he so enthusiastically invested his last days in a virtual university. In a strange move to potentially cast doubts on his culpability in the Walam Olum incident, Boewe claims that Rafinesque had no sense of humor, and in fact claims to know of only one joke in his entire corpus. This simply is not true. Though perhaps not riotous, several passages of Western Minerva feature attempts at humor, including a faux-proposal for a future academic journal called, The Monkeys (68). And if humor, as they say, always contains a grain of truth, one of these articles, jokingly proposed by Rafinesque, seems especially resonant: "an inquiry into the meaning of the words Old and New, the former implying what we never knew and the latter what we never will know. By Dr. Last." 


\section{REFERENCES}

Agamben, Giorgio. Homo Sacer: Sovereign Power and Bare Life. Trans. Daniel HellerRoazen. Stanford: Stanford UP, 1995.

---. Open: Man and Animal. Trans. Kevin Attell. Stanford: Stanford UP, 2004.

Al-Nafis, Ibn. Theologus Autodidactus. Trans. Max Meyerhof and Joseph Schacht. Oxford: Clarendon Press, 1968.

Artaud, Antonin. Theater and Its Double. Trans. Mary Caroline Richards. New York: Grove Press, 1958.

Barthes, Roland. Elements of Semiology. Trans. Annette Lavers and Colin Smith. New York: Hill and Wang, 1977.

---. Mythologies. Trans. Annette Lavers. New York: Hill and Wang, 1972.

Bataille, Georges. Accursed Share: An Essay on General Economy Volume 1: Consumption. Trans. Robert Hurley. New York: Zone Books, 1991.

Behler, Ernst, ed. Philosophy of German Idealism: Fichte, Jacobi and Schelling. New York: Continuum, 2003.

Benedict, Barbara M. Curiosity: A Cultural History of Early Modern Inquiry. Chicago: University of Chicago Press, 2001.

Benjamin, Walter. Arcades Project. Trans. Howard Eiland and Kevin McLaughlin. Cambridge: Belknap Press, 1999.

---. Illuminations. Trans. Harry Zohn. New York: Harcourt, Brace and World, 1968.

---. Reflections: Essays, Aphorisms, Autobiographical Writings. Trans. Edmund Jephcott. New York: Schocken Books, 1978.

Betts, Edwin M. "The Correspondence between Constantine Samuel Rafinesque and Thomas Jefferson." Proceedings of the American Philosophical Society 87.5 (1944): 368-380. 
Boewe, Charles, ed. Profiles of Rafinesque. Knoxville: The University of Tennessee Press, 2003.

Borges, Jorge Louis. Other Inquisitions: 1937-1952. Trans. Ruth L. C. Simms. Austin: University of Texas Press, 1964.

Buffon, Georges-Louis LeClerc. Natural History Containing a Theory of the Earth, a General History of Man, of the Brute Creation, and of Vegetables, Minerals, $\& C$, Volume 6. Trans. anonymous. London: T Gillet, 1807.

Burkhardt, Richard W. The Spirit of System: Lamarck and Evolutionary Biology. Cambridge: Harvard UP, 1995.

Call, Richard Ellsworth. The Life and Writings of Rafinesque: Prepared for the Filson Club. Louisville: John P. Morton and Co, 1895.

Cape Fear. Dir. Martin Scorsese. Perf. Robert De Niro. Amblin, 1991. Film.

Chapple, J.A.V. Science and Literature in the Nineteenth Century. Houndmills: MacMillan, 1986.

Crane, Hart. "From haunts of Proserpine." Poetry. Vol. 40, No. 1 (April 1932): 44-7.

Critchley, Simon. "Black Socrates? Questioning the Philosophical Tradition" Radical Philosophy. 69 (January/February 1995): 17-26.

Cunningham, Andrew and Nicholas Jardine, eds. Romanticism and the Sciences Cambridge: Cambridge UP, 1990.

Cuvier, Georges. "Biographical Memoir of M. de Lamarck." Edinburgh New Philosophical Journal. Vol XX, Jan 1836, pages 1-22.

Derrida, Jacques. Eyes of the University: Right to Philosophy 2. Trans. Jan Plug, et al. Stanford: Stanford UP, 2004.

---. Gift of Death. Trans. David Wills. Chicago: University of Chicago Press, 2007.

---Writing and Difference. Trans. Alan Bass. Chicago: University of Chicago Press, 1978.

Dupre, Huntley. Rafinesque in Lexington: 1819-1826. Lexington: Bur Press, 1945.

Eco, Umberto. Theory of Semiotics. Bloomington: Indiana UP, 1979.

Elsner, John and Roger Cardinal. The Cultures of Collecting. Cambridge: Harvard UP, 1994. 
Endersby, Jim. “The Vagaries of Rafinesque: Imagining and Classifying Nature.” Studies In History and Philosophy of Science Part C 40 (2009): 168-78.

Fagan, Patricia, and John Russon, eds. Reexamining Socrates in the Apology. Evanston: Northwestern UP, 2009.

Foucault, Michel. Discipline and Punish: The Birth of the Prison. Trans. Alan Sheridan. New York: Vintage, 1994.

---. The Foucault Reader. Ed. Paul Rabinow. New York: Pantheon Books, 1984.

---. Order of Things: An Archeology of the Human Sciences. Trans. anonymous. New York: Vintage, 1994.

---. Politics of Truth. Trans. Lysa Hochroth and Catherine Porter. Los Angeles: Semiotext(e), 2007.

Gordon, Robert Benson. "Oldest Natural History Museums and Institutional Herbaria in America.” Science: New Series Volume 115, No. 2982 (Feb. 22, 1952): 217-18.

Graff, Gerald. Professing Literature: An Institutional History. Chicago: University of Chicago Press, 1987.

Gray, Asa. "Notice of the Botanical Writings of the Late C. S. Rafinesque." American Journal of Science Vol. xl, No. 2 (Jan-March 1941): 221-41.

---. "Some North American Botanists: C.S. Rafinesque.” Botanical Gazette Vol. 8, No. 1 (Jan 1883): 149-52.

Hardy, Thomas. Jude the Obscure. New York: Harper and Brothers, 1896.

Heidegger, Martin. Fundamental Concepts of Metaphysics: World, Finitude, Solitude. Trans. William McNeill and Nicholas Walker. Bloomington: Indiana UP, 1995.

Hobsbawm, Eric and Terence Ranger, eds. The Invention of Tradition. Cambridge: Cambridge UP, 1983.

Horkheimer, Max. Eclipse of Reason. London: Continuum, 1974.

Jonas, Hans. The Gnostic Religion: The Message of the Alien God and the Beginnings of Christianity. Boston: Beacon Press, 2001.

---. The Phenomenon of Life: Toward a Philosophical Biology. Evanston: Northwestern UP, 2001.

Jordan, David Starr. Science Sketches. Chicago: A.C. McClurg and Co., 1911. 
Kant, Immanuel. Basic Writings of Kant. Ed. Allen W. Wood. New York: Modern Library, 2001.

---. The Conflict of the Faculties. Trans. Mary J. Gregor. New York: Abaris Books, 1979.

Knight, David. Ordering the World: A History of Classifying Man. London: Burnett Books, 1981.

Kojeve, Alexandre. Introduction to the Reading of Hegel: Lectures on the Phenomenology of Spirit. Trans. James H. Nichols, JR. Ithaca: Cornell UP, 1969.

Kuhn, Thomas. Structure of Scientific Revolutions. Chicago: University of Chicago Press, 1962.

Lacan, Jacques. Ecrits: The First Complete Edition in English. Trans. Bruce Fink. New York: Norton and Co., 2005.

Lambert, Gregg. Report to the Academy: (RE: The NEW Conflict of the Faculties). Aurora: The Davies Group Publishers, 2001.

Larson, James L. Interpreting Nature: The Science of Living Form from Linnaeus to Kant. Baltimore: Johns Hopkins UP, 1994.

Liddell and Scott. Lexicon: Abridged from Liddell and Scott's Greek-English Lexicon. Oxford: Clarendon Press, 1994.

Lyotard, Francois. The Postmodern Condition: A Report on Knowledge. Trans. Geoff Bennington and Brian Massumi. Minneapolis: University of Minnesota Press, 1979.

Locke, John. Essay Concerning Human Understanding. London: T. Tegg and Son. 1836.

Macpherson C.B. The Political Theory of Possessive Individualism, Oxford: Clarendon Press, 1962.

McHale, Brian. "A Poet May Not Exist: Mock-Hoaxes and the Construction of National Identity." The Faces of Anonymity: Anonymous and Pseudonymous Publication from the Sixteenth to the Twentieth Century. Ed. Robert J. Griffin. New York: Palgrave Macmillan, 2003. 233-252.

Mears, James A. "Some Sources of the Herbarium of Henry Muhlenberg." Proceedings of the American Philosophical Society Volume 122, No. 3 (June 9, 1978): 155-74.

Newman, Andrew. "The Walam Olum: An Indigenous Apocrypha and its Readers." American Literary History 22.1 (2010): 26-56. 
Nietzsche, Friedrich. On the Genealogy of Morals and Ecce Homo. Trans. Walter Kaufmann. New York: Vinatage, 1989.

Nightingale, Andrea Wilson. Spectacles of Truth in Greek Philosophy. Cambridge: Cambridge UP, 2009.

Novalis. Novices of Sais. Trans. Ralph Manheim. New York: Archipelago Books, 2005.

Nussbaum, Emily. “Turning Japanese: The Hiroshima Poetry Hoax." Linguafranca: The Review of Academic Life. (November 1996): pp. 82-84.

Oestreicher, David M. "Unmasking the Walam Olum: A 19th Century Hoax", Bulletin of the Archaeological Society of New Jersey 49 (1994):1-44.

Oken, Lorenz. Elements of Physiophilosophy. Trans. Alfred Tulk. London: Ray Society, 1847.

Otto, Rudolf. Idea of the Holy. Trans. John W. Harvey. Oxford: Oxford UP, 1958.

Owen, Stephen. "The Paradox of Values." Boston Review (Summer 1997). Available from http://bostonreview.net/BR22.3/Owen.html

Pearce, Susan M. Collecting in Contemporary Practice. London: Sage Publications, 1998.

---. Museums, Objects, and Collections: A Cultural Study. Washington D.C.: Smithsonian Institution Press, 1992.

Pearce, Susan, and Ken Arnold, eds. The Collector's Voice: Critical Readings in the Practice of Collecting. Vol. 2. Burlington: Ashgate, 2000.

Pennant, Thomas. Arctic Zoology, Volume 1: Class One Quadrupeds. London: Henry Hughs, 1784.

Perelman, Chaim and Lucie Olbrechts-Tyteca. The New Rhetoric. Notre Dame: University of Notre Dame Press, 1991.

Pratt, Orson. A Series of Pamphlets. Liverpool: R. James, 1851.

Rafinesque, C.S. American Nations; or Outlines of their General History, Ancient and Modern. Philadelphia, 1836.

---.Ancient History or Annals of Kentucky. Frankfort, 1824.

---. Ancient Monuments of North and South America. Philadelphia, 1838. 
---. Atlantic Journal and Friend of Knowledge. Philadelphia, 1832-33.

---. Celestial Wonders and Philosophy. Philadelphia: Central University of Illinois, 1938.

---.Constantine Samuel Rafinesque Schmalz on Classification: A Translation of Early Works by Rafinesque with Introduction and Notes. Trans. A. J. Cain. Philadelphia: Academy of Natural Sciences, 1990.

---. C.S. Rafinesque Anthology. Ed. Charles Boewe. Jefferson: McFarland \& Co, 2005.

---.Genius and Spirit of the Hebrew Bible. Philadelphia: Eleutherium of Knowledge, 1838.

---. Good Book and Amenities of Nature. Philadelphia: Eleutherium of Knowledge, 1840.

---. Life of Travels and Researches in North American and South Europe. Philadelphia, 1836.

---. The World; or Instability. Philadelphia: J. Dobson, 1836.

---. Safe Banking including The Pleasures and Duties of Wealth. Philadelphia: Eleutherium of Knowledge, 1840.

---. Walam Olum, or Red Score: The Migration Legend of the Lenni Lenape or Delaware Indians. Indianapolis: Indiana Historical Society, 1954.

---. Western Minerva or American Annals of Knowledge and Literature. Lexington, 1821.

Ranciere, Jacques. The Ignorant Schoolmaster: Five Lessons in Intellectual Emancipation. Trans. Kristin Ross. Stanford: Stanford UP, 1991.

Readings, Bill. The University in Ruins. Cambridge: Harvard UP, 1996.

Reeve, C.D.C. Socrates in the Apology: An Essay on Plato's Apology of Socrates. Indianapolis: Hackett, 1989.

Ritvo, Harriet. Platypus and the Mermaid: And Other Figments of the Classifying Imagination. Cambridge: Harvard UP, 1997.

Rudwick, Martin J.S. Georges Cuvier: Fossil Bones and Geological Catastrophes. Chicago: University of Chicago Press, 1998.

Sartre, Jean-Paul. Nausea. Trans. Lloyd Alexander. New York: New Directions, 1964.

Serres, Michel. Parasite. Trans. Lawrence R. Schehr. Minneapolis: University of Minnesota Press, 2007. 
Shapin, Steven. Never Pure: Historical Studies of Science as if it Was Produced by People with Bodies, Situated in Time, Space, Culture, and Society, and Struggling for Credibility and Authority. Baltimore: Johns Hopkins Press, 2010.

Shapin, Steven and Simon Schaffer. Leviathan and the Air-Pump: Hobbes, Boyle, And the Experimental Life. Princeton: Princeton UP, 1985.

Sloterdijk, Peter. "Rules for the Human Zoo." Environment and Planning D: Society and Space Vol. 27, (2009): 12-28.

Spamer, Earle E. and Richard M. McCourt. "Lewis and Clark Herbarium of the Natural Sciences: Part 1, History." Notulae Naturae: The Academy of Natural Sciences of Philadelphia. Number 475 (December 2002).

Trevor-Roper, Hugh. The Invention of Scotland: Myth and History. New Haven: Yale UP, 2009.

Warren, Leonard. Constantine Samuel Rafinesque: A Voice in the American Wilderness. Lexington: University Press of Kentucky, 2004.

Whaler, James. Green River: A Poem for Rafinesque. New York: Harcourt, Brace and Co., 1931.

Williams, Stephen. Fantastic Archeology: The Wild Side of North American Prehistory. Philadelphia: University of Pennsylvania Press, 1991.

Yasusada, Araki. Doubled Flowering. New York: Roof Books, 1997.

Yoon, Carol. Naming Nature: The Clash between Instinct and Science. New York: W.W. Norton and Co., 2009.

Zielinski, Siegfried. Deep Time of the Media: Toward and Archaeology of Seeing and Hearing by Technical Means. Trans. Gloria Custance. Cambridge: MIT Press, 2006. 
CURRICULUM VITAE

\section{Elijah Pritchett}

190 N Bellaire

Louisville, KY 40292 US

Home tel: 502/896-6212
Cell: 502/500-6860

locusarcis@yahoo.com

epprit01@louisville.edu

\section{Education}

Ph.D. University of Louisville, Humanities Program, 2013

Dissertation: The Autodidact: Constantine Samuel Rafinesque and the Limits of the Posthumanities.

Committee: Aaron Jaffe (chair), Annette Allen, John Gibson, Stephen

Schneider

MA University of Louisville, Humanities Program, 2005

Thesis: "Implied in the Idea of Progress": Ducasse's Plagiats as a Token of Cultural Subversion

Committee: Nancy Potter (Chair), Annette Allen, Osborne Wiggins

BA University of Louisville, Humanities Program (with honors), 2003

\section{Awards}

2006-2010 University of Louisville Graduate Fellowship

2005 F Zorn Scholarship (fall)

2005 F Zorn Scholarship (summer)

2003 Morris Bein Endowed Humanities Award

2003 Outstanding Latin Student of the Year

2001 Travel Grant as University of Louisville Student Ambassador to American University in Athens, Greece 
Outstanding Latin Student of the Year

2000

Philomena Farley Grant for Studies in the Humanities

2000

Eta Sigma Phi Classics Honors Society

1999-2003 University of Louisville Dean's List

\section{Presentations}

"The Miseducation of Max Cady: Autodidactic Perversions in Popular Media" (Critical Theory/Literature)

Pop/American Culture Association, Nashville TN, 2012

"Have Eye, Will Travel: Journey, Rhetoric and Theoria in the Scholarship of Constantine Rafinesque"

(Critical Theory/Philosophy/History of Science), Kentucky State University, 2011

"And the Word Was Made Flesh: The Schizophrenic Body of Antonin Artuad"

(Critical Theory/Literature)

Conference on Literature and Culture since 1900, University of Louisville, 2011

"Bataille's Canard: Disquiet, Deformity, Ducks and Other Strategies against Architecture"

(Critical Theory/Cultural Studies)

Association of Humanities Academics, University of Louisville, 2010

"Toward a Theory of the Self-Taught Man: the Unlikely University and Its Impossible

Protagonist"

(Critical Theory/Cultural Studies)

American Comparative Literature Association, Harvard University, 2009

"Frontiers of Knowledge: Constantine Rafinesque the Autodidact"

(Critical Theory/Cultural Studies)

Kentucky Philological Society, Kentucky Wesleyan College, 2009

"Resemblances, Correspondences, and Perverse Attractions: The Modernist Poetics of Baudelaire"

(Critical Theory/Literature)

Humanities Graduate Colloquium, University of Louisville, 2008

"The Unauthorized Copy: Abjection and Fears of Paternal Absence in The Ring"

(Cultural Studies/Film)

Southeast Indiana Humanities Conference, Indiana University Southeast, 2008 
"Phantom in the Text: Some Literary Implications Revealed by the Yasusada Notebooks" (Critical Theory/Literature)

Humanities Graduate Colloquium, University of Louisville, 2004

"Hittite, Indo-European, and the Ancient Near East"

(Historical Linguistics)

Eta Sigma Phi Annual Honors Society Conference, Monmouth College, 2000

\section{Teaching}

Cultures of America, Humanities 152. 1/2009-4/2009; 5/2009-7/2009; 1/2012-5/2012; $1 / 2013-$

present.

University of Louisville introductory undergraduate course focusing on interdisciplinary humanities approaches to identity and expression of culture within the arts and college composition.

Greek Mythology, Humanities 338. 1/2011-5/2011; 6/2011-7/2011; 1/2012-5/2012; $1 / 2012$ -

present.

University of Louisville intermediate undergraduate course focusing on the mythological legacy of ancient Greece and its persistence in the contemporary arts.

Introduction to the Modern Humanities, Huma U102. 1/2011-5/2011; 1/2012-5/2012; $1 / 2013-$

present.

Indiana University Southeast introductory undergraduate course surveying interdisciplinary approaches to the Western humanities in the modern era.

Introduction to the Ancient Humanities, Huma U101. 8/2010-12/2010; 8/2011-12/2011. Indiana University Southeast introductory undergraduate course surveying interdisciplinary approaches to the Western humanities in the ancient era.

Creativity and the Arts, Humanities 151 (Honors Section). 8/2009-12/2009; 8/201012/2010; 8/2011-12/2011.

University of Louisville introductory undergraduate course focusing on interdisciplinary study and appreciation of the arts and college composition.

World Literature to 1700, Humanities 101 (Honors Section). 8/2011-12/2011. University of Louisville introductory undergraduate course surveying the literary legacies of the ancient, medieval, and renaissance worlds and college composition. 
Modern Fiction: the Twentieth Century, Humanities 322. 7/2009-8/2009; 1/2010-5/2010;

6/2010-8/2010; 8/2010-12/2010; 1/2011-5/2011; 6/2011-7/2011.

University of Louisville intermediate undergraduate course focusing on fiction and theories of fiction of the past century.

Masterpieces of Ancient Greece: Writing Course, Humanities 354. 8/2008-12/2008; $8 / 2009$

$12 / 2009$.

University of Louisville intermediate undergraduate course focusing on the literary legacy of ancient Greece from the Homeric to the classical era, with an intensive focus on composition.

World Literature to 1700, Humanities 101. 8/2008-12/2008; 1/2009-4/2009.

University of Louisville introductory undergraduate course surveying the literary legacies of the ancient, medieval, and renaissance worlds.

World Literature: 1700 to the Present, Humanities 102. 8/2005-12/2005; 1/2006-4/2006. University of Louisville introductory undergraduate course surveying the literary legacy of the modern period.

Intermediate Greek, Greek 102. 1/2004-4/2004; 1/2012-4/2012

University of Louisville undergraduate course on ancient Greek.

Intermediate Latin, Latin 202. 1/2004-4/2004; 1/2012-4/2012.

University of Louisville undergraduate course on Latin.

Intermediate Latin, Latin 102. 1/2012-4/2012.

University of Louisville undergraduate course on Latin.

\section{Additional Invited Class Lectures}

“The Ethics of Anarchy,” Ethics, Philosophy 321. University of Louisville, 2004.

\section{Teaching Assistant}

Greek Mythology, Humanities 338, University of Louisville, 8/2003-12/2003.

\section{Service/Academic Affiliations}

Vice President, Association for Humanities Academics. 12/2009-1/2011.

Conference panel co-organizer, "Collecting, Travelling, and Administering Modernity." Kentucky Philological Association, Kentucky State University, 2011.

Co-coordinator, “Anti: Revisions, Reconstructions, Refutations," University of Louisville Graduate Conference in Humanities. 1/2010-3/2010. 
In cooperation with Commonwealth Center for Humanities and Society, Chief Coordinator for the "Humanities, Culture(s), Controversies" series, a public forum hosting guest lectures by liberal arts scholars from around the world. 8/2008-4/2009.

Research Assistant to John Hale for his book, Lords of the Sea: The Epic Story of the Athenian Navy and the Birth of Democracy. 6/2003-9/2003.

\section{Language Competencies}

Basic reading competency in French and German.

Advanced reading competency in Attic Greek and Classical Latin. 